\author{
ZENTRUM \\ FÜR BIODIVERSITÄT UND NACHHALTIGE LANDNUTZUNG \\ SEKTION \\ BIODIVERSITÄT, ÖKOLOGIE UND NATURSCHUTZ \\ - Centre of Biodiversity ANd Sustainable LAND USE - \\ SECTION: BIOdIVERsity, Ecology and Nature Conservation
}

\title{
PLANT - INVERTEBRATE INTERACTIONS IN AGRICULTURALLY MANAGEd GRASSLANDS UNDER FUnCTIONAL GROUP MANIPULATION
}

\author{
Dissertation zur Erlangung des Doktorgrades der \\ Mathematisch-Naturwissenschaftlichen Fakultäten der \\ Georg-August-Universität Göttingen
}

\author{
vorgelegt von \\ Diplom - Biologe \\ Georg Everwand
}

Geboren in

Münster

Göttingen, September, 2013 
Referent:

Korreferent:

Tag der mündlichen Prüfung: 14. Oktober 2013
Professor Dr. Teja Tscharntke

Professor Dr. Johannes Isselstein 
"Nothing in the history of life is more constant than change." (Charles Darwin, English Natural Scientist, 1809-1882) 


\section{TABLE OF CONTENTS}

Chapter 1: General Introduction: Plant - InVERTEBrate InTERActions in Agriculturally Managed Grasslands under Functional Group $\begin{array}{ll}\text { MANIPULATION } & 7\end{array}$

INTRODUCTION

STUDY DESIGN \& SITE

STUDY ORGANISMS 19

RESEARCH OBJECTIVES \& CHAPTER OUTLINE

REFERENCES

Chapter 2: Bringing Biodiversity EXPERIMENTS to the REAL WoRLD:

Diversity Versus Management In A Semi-Natural Grassland 30

$\begin{array}{lr}\text { ABSTRACT } & 31\end{array}$

$\begin{array}{ll}\text { INTRODUCTION } & 32\end{array}$

$\begin{array}{ll}\text { Material AND MethOdS } & 35\end{array}$

$\begin{array}{lr}\text { RESULTS } & 38\end{array}$

$\begin{array}{lr}\text { DISCUSSION } & 47\end{array}$

$\begin{array}{lr}\text { REFERENCES } & 52\end{array}$ 
Chapter 3: Slug Responses to Grassland Cutting and Fertilizer Application Under Plant Functional Group Removal 57

$\begin{array}{lr}\text { ABSTRACT } & 58 \\ \text { INTRODUCTION } & 59 \\ \text { MATERIAL AND METHODS } & 61 \\ \text { RESULTS } & 67 \\ \text { DISCUSSION } & 73 \\ \text { ACKNOWLEDGEMENTS } & 76 \\ \text { REFERENCES } & 77\end{array}$

CHAPTER 4: DISENTANGLING DIRECT AND INDIRECT EFFECTS OF EXPERIMENTAL GRASSLAND MANAGEMENT AND PLANT FUNCTIONAL-GROUP MANIPULATION ON PLANT AND LEAFHOPPER BIODIVERSITY

$\begin{array}{lr}\text { INTRODUCTION } & 84\end{array}$

MAterial AND Methods $\quad 86$

$\begin{array}{ll}\text { RESULTS } & 91\end{array}$

$\begin{array}{ll}\text { DISCUSSION } & 97\end{array}$

$\begin{array}{ll}\text { OVERALL CONCLUSION } & 102\end{array}$

$\begin{array}{ll}\text { ACKNOWLEDGEMENTS } & 102\end{array}$

$\begin{array}{ll}\text { REFERENCES } & 103\end{array}$

$\begin{array}{lr}\text { SUPPLEMENTARY MATERIAL } & 109\end{array}$ 
CHAPTER 5: INVERTEBRATE HERBIVORY-DRIVEN NUTRIENT CYCLING IN A Grassland MANAGEMENT EXPERIMENT

ABSTRACT

INTRODUCTION

Material AND Methods 120

RESULTS

DISCUSSION 139

Overall Conclusions 146

ACKNOWLEDGEMENTS 146

REFERENCES 147

SUPPLEMENTARY MATERIAL 154

CHAPTER 6: SYNTHESIS

General Discussion 156

GENERAL CONCLUSIONS 166

REFERENCES

SUMMARY

ZUSAMMENFASSUNG

ACKNOWLEDGEMENTS

Publications

CONFERENCE CONTRIBUTIONS 


\section{ChAPTER 1}

GENERAL INTRODUCTION:

PLANT - INVERTEBRATE INTERACTIONS IN AGRICULTURALLY MANAGEd GrassLands Under Functional Group MANIPULATION 


\section{Introduction}

Over the past centuries human impact has led to environmental changes at global scale, and especially within the last few decades the world has been changing at an increasing rate (Sala et al. 2000, Susan 2007). Most of these megatrends, such as rising $\mathrm{CO}_{2}$ concentrations and temperatures in the atmosphere and oceans as well as rising sea level and increasing climatic variability are linked to and further amplified by increasing human populations (Susan 2007), which is expected to hit the nine billion benchmark before the 2050s (Lee 2011, Barnosky et al. 2012). Also the demand of increasing economic wealth and increasing use of energy from fossil and non-fossil fuels (Tilman et al. 2009), especially of developing countries contributes to steeply rising greenhouse gas emissions (Ehrlich et al. 2012). Biodiversity is known to be sensitive to these megatrends, including atmospheric $\mathrm{CO}_{2}$, climate, vegetation, nitrogen deposition, biotic exchange and land use change, therefore this will lead to further declines and change in biodiversity (Sala et al. 2000).

To cope with increasing food demands for a growing world population, agriculturally used areas are being expanded and agricultural utilization on existing areas is intensified to maximize crop production (Tscharntke et al. 2012). In order to improve yields, increasing amounts of fertilizer are applied and where possible the utilization frequency is increased (Vickery et al. 2001). Grasslands cover over two thirds of the agriculturally used area in the world, and over one third of the agriculturally used area in Europe (FAOSTAT 2013). Consequently, grasslands are of great economical importance for fodder production, livestock breeding and in recent years for bioenergy (Gelfand et al. 2013). However, since grasslands can harbour up to 70 plant species per $20 \mathrm{~m}^{2}$ (Herben and Huber-Sannwald 2002), these highly diverse biomes are also of great importance for conserving biodiversity, maintaining ecosystem functioning as well as providing space for recreation (Schmid 2010).

Agricultural intensification is a threat to biodiversity. Fertilizer application was shown to decrease plant diversity and to shift plant community composition towards highly productive and competitive grasses (Smart et al. 2006, Wesche et al. 2012). Nitrogen fertilizer can also affect nutrient cycling in grasslands, such as $\mathrm{N}$ mineralization and nitrification, as well as increasing soil nitrate and ammonium concentrations (Mueller et al. 2013). 
Studies have linked emissions of greenhouse gases, such as $\mathrm{N}_{2} \mathrm{O}$ (nitrous oxide), to grassland management ( $\mathrm{Li}$ et al. 2013) or animal production systems (Clough et al. 2013). Lower cutting frequencies of one or two cuts per year may maintain high species diversity by preventing succession (Balmer and Erhardt 2000), when no fertilizers are applied. In contrast, higher cutting frequencies have been shown to lead to a decline in species richness (Zechmeister et al. 2003). The application of pesticides in order to reduce herbivorous invertebrates, plant disease or unwanted plant species was also shown to affect plant diversity and higher tropic guilds (Wilson et al. 1999, Blake et al. 2011).

Many higher trophic levels, such as herbivorous invertebrates, are highly specialized in their feeding and habitat requirements. Diverse plant communities are therefore of great importance host plants to maintain species diversity at higher trophic levels. Decreasing diversity in intensively agriculturally managed areas is shown to lead to cascading effects on invertebrate species (Tylianakis et al. 2008, Kleijn et al. 2009), where only generalists can maintain stable populations (McKinney and Lockwood 1999). Ecosystem functions are also influenced by agricultural management. Fertilizer application can decrease recharge of groundwater (Rose et al. 2012a), increase nitrous oxide emissions (Clayton et al. 1997) and even lead to declines in ecosystem productivity on longer time scales (Isbell et al. 2013). High plant biodiversity has been shown to play an important role to sustain multiple ecosystem services in grasslands, such as productivity, invasion resistance or stress tolerance (Zavaleta et al. 2010).

Herbivorous invertebrates can strongly affect plant biomass production and species composition in grasslands (Curry 1994, Scherber et al. 2003, del-Val and Crawley 2004, Scheidel and Bruelheide 2005, Scherber et al. 2006). Invertebrates, such as grasshoppers and snails, are often the dominant invertebrate herbivores in temperate agricultural grassland ecosystems (Stein et al. 2010) and have been shown to affect several components within an ecosystem (Belovsky and Slade 2000). Herbivores can enhance plant diversity through feeding directly on competitively dominant plant species and therefore indirectly affecting plant competition (Olff and Ritchie 1998). Herbivores can be expected to influence nutrient cycling and plant species composition under diverse management regimes and plant functional group combinations (Belovsky and Slade 2000, Allan and Crawley 2011). 
However, combined with nutrient enrichment, herbivory may even further accelerate nutrient cycling. This results in an increase of components of the nitrogen flux, since nitrogen cycling in the soil is related to many important ecosystem functions, such as biodiversity, productivity (Oelmann et al. 2011) or water balance (Rose et al. 2012a).

Plant functional group removal experiments using herbicides (e.g. to promote forbs versus graminoids for conservation) have demonstrated a positive effect of forb species enhancement on invertebrates (Blake et al. 2011). We expect that a removal experiment better reflects the effects of herbivory and varying regimes of grassland management on nitrogen flux, than a sown diversity gradient (Diaz et al. 2003).

But still the interactions between land use change, agricultural intensification, declines in biodiversity and changes in species composition represent one of the largest uncertainties in projections of future biodiversity change (Sala et al. 2000).

Most experiments to date have relied on artificially sown gradients in plant diversity (e.g. "Jena-Experiment" (Roscher et al. 2004), "Cedar Creek" (Tilman et al. 2012). Other long-term grassland experiments (e.g. "Rengen Grassland Experiment") have studied the effects of fertilizer application and cutting frequency (Pavlů et al. 2011), but have not experimentally manipulated the composition of established grasslands. In particular, the effects of functional group manipulation in combination with experimentally increased herbivore pressure in mature grassland and its consequences for ecosystem processes are largely unexplored. There is still too little knowledge about the direct and indirect impacts of agricultural intensification, further loss of species diversity and shifts in plant functional group composition on trophic interactions and ecosystem processes in grasslands. It is also important to better understand how nitrogen cycling and $\mathrm{N}_{2} \mathrm{O}$ emissions respond to invertebrate herbivores in combination with agricultural management and shifts in plant functional group composition and plant diversity.

With this thesis, I aimed to further investigate the direct and indirect effects and interactions between cutting, fertilizing, herbivory, nutrient cycling, productivity and shifts in plant composition and diversity. Twelve treatment combinations were therefore created by independently combining two cutting frequencies, two fertilizer application levels and three different sward types via manipulation of functional groups, also installing mesocosms on the experimental plots. 


\section{Study Design \& Site}

This studies for this thesis were performed between 2010 and 2013 as part of the "GrassMan"-Experiment (Petersen et al. 2012) near the towns of Neuhaus (Solling) and Silberborn in the Solling Mountains, which are situated in Northern Germany $\left(51^{\circ} 440 \mathrm{~N}, 9^{\circ} 320 \mathrm{E}, 490 \mathrm{~m}\right.$ a.s.l.). The study site was documented by the experimental farm of the University at Relliehausen as extensively managed permanent grassland.

The vegetation prior to the start of the experiment was a nutrient poor, moderately wet Lolio-Cynosuretum grassland with high abundances of Agrostis capillaris (L.), Festuca rubra (L.) and Rumex acetosa (L.), Veronica chamaedrys (L.) and Ranunculus repens (L.) (Petersen et al. 2012). Mean annual precipitation is $1028 \mathrm{~mm}$ and mean annual temperature is $6.9^{\circ} \mathrm{C}$ (Deutscher Wetterdienst, 1961-1990, station Holzminden-Silberborn, $440 \mathrm{~m}$ above sea level). In 2010, the year in which data for this study were collected, mean annual temperature was $8.0{ }^{\circ} \mathrm{C}$ and annual precipitation was $1110 \mathrm{~mm}$. The dominant soil type in experimental area is a shallow (40-60 cm), stony Haplic Cambisol, developed on sediments of loess on the Middle Bunter (Triassic sandstone) formation with a loamy silt texture (Keuter et al. 2012).

The experiment was established in 2008 on permanent, formerly extensively cattle-grazed grassland and laid out as a three-factorial latin rectangle (Clewer and Scarisbrick 2001) with the following factors (Fig. 1.1): (i) plant functional group removal (3 levels) using herbicides, (ii) fertilizer application (2 levels) and (iii) cutting frequency (2 levels), resulting in 12 treatment combinations. To study the direct and indirect interactions within the system, in 2010 we additionally installed two in-field lysimeter mesocosms per plot. In 2011, both lysimeters were covered with a cage and one lysimeter populated with herbivores, whereas the other was the control.

To manipulate plant functional group presence, we applied (i) a combination of the forb-specific herbicides Fluroxypyr (Starane; Dow AgroSciences, Munich, Germany; $3 \mathrm{~L} \mathrm{ha}^{-1}$ ) and Mecoprop-P (Duplosan; KV, Du Pont de Nemours, Neu-Isenburg, Germany; $3 L_{\text {ha }}^{-1}$ ) or (ii) the graminoid-specific herbicide Select 240 EC (Stähler Int., Stade, Germany; $0.5 \mathrm{~L} \mathrm{ha}^{-1}$ ), resulting in three levels of plant diversity: i) forb reduced (=graminoid rich), ii) graminoid reduced (=forb rich) and iii) control. 
Herbicides were applied once in June 2008 ("pulse" experiment sensu Bender et al. (1984)). In 2009 and 2010, plots were treated with $\mathrm{N}$-fertilizer (Calcium ammonium nitrate $\left.\mathrm{N} 27: 13.5 \% \mathrm{NH}_{4}{ }^{-} \mathrm{N}, 13.5 \% \mathrm{NO}_{3}{ }^{-} \mathrm{N}, 4 \% \mathrm{MgO}, 6 \% \mathrm{Ca}\right)$ at two equal doses $(2 \mathrm{x}$ $90 \mathrm{~kg} \mathrm{~N} \mathrm{ha}^{-1}$ ) in April and May/June; in addition, NPK-fertilized plots received $30 \mathrm{~kg} \mathrm{P}$ per ha and $100 \mathrm{~kg} \mathrm{~K}$ per ha in early June (Thomaskali®, 8\% $\mathrm{P}_{2} \mathrm{O}_{5}, 15 \% \mathrm{~K}_{2} \mathrm{O}, 20 \%$ $\mathrm{CaO}$ ). On control plots we did not apply NPK-fertilizer. Figure 1.1 depicts the study design.

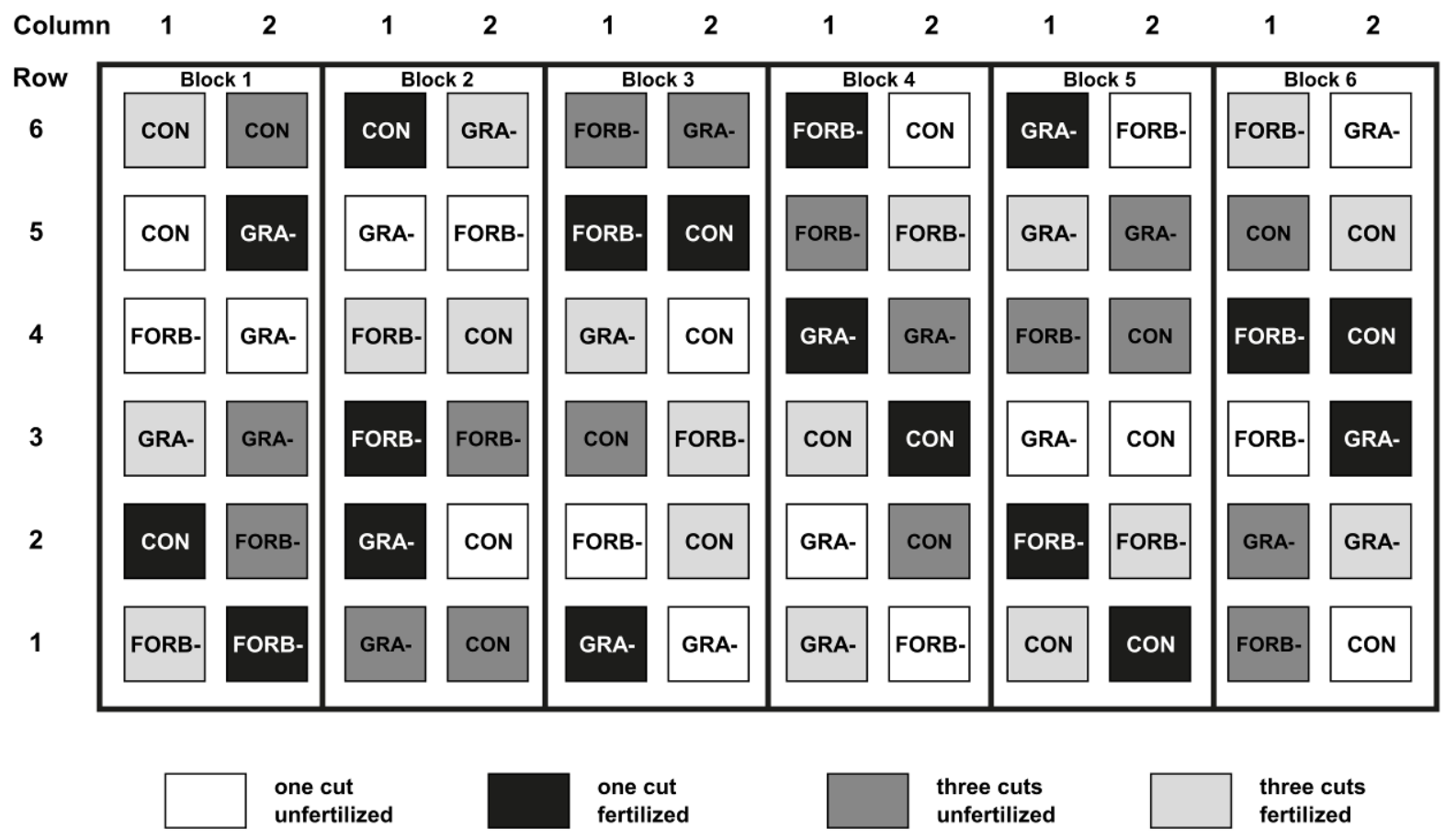

Figure 1.1: Experimental design of the Grassman Experiment, showing the Latin rectangle with 12 treatments in 6 replications. GRA- = graminoid reduced plots (=forb enhanced); FORB- =forb reduced (=graminoid enhanced); $\mathrm{CON}=$ Control (no herbicide application). The grey area around and between the plots is mown monthly. Plot size $15 \mathrm{~m} \times 15 \mathrm{~m}$, space between plots $3 \mathrm{~m}$, between blocks $5 \mathrm{~m}$.

Plots were mown either once (in July) or three times a year (May, July, September) using a Haldrup ${ }^{\circledR}$ forage combine harvester (Inotec Engineering $\mathrm{GmbH}$, Ilshofen, Germany) at a cutting height of $7 \mathrm{~cm}$. The resulting 12 treatment combinations (equalling one block of the latin rectangle; Fig. 1.1) were arranged at random and replicated six times, resulting in 72 plots. Each plot was a square of $15 \mathrm{~m}$ side length and surrounded by at least $3 \mathrm{~m}$ of regularly mown area between the plots of a block and $5 \mathrm{~m}$ between two blocks. 
This mowing was done every two to three weeks during the growing season using a rotor mowing machine (Fig. 1.2), to avoid input of large amounts of plant seeds into the plots in late summer and to impede invertebrate to move easily between plots.

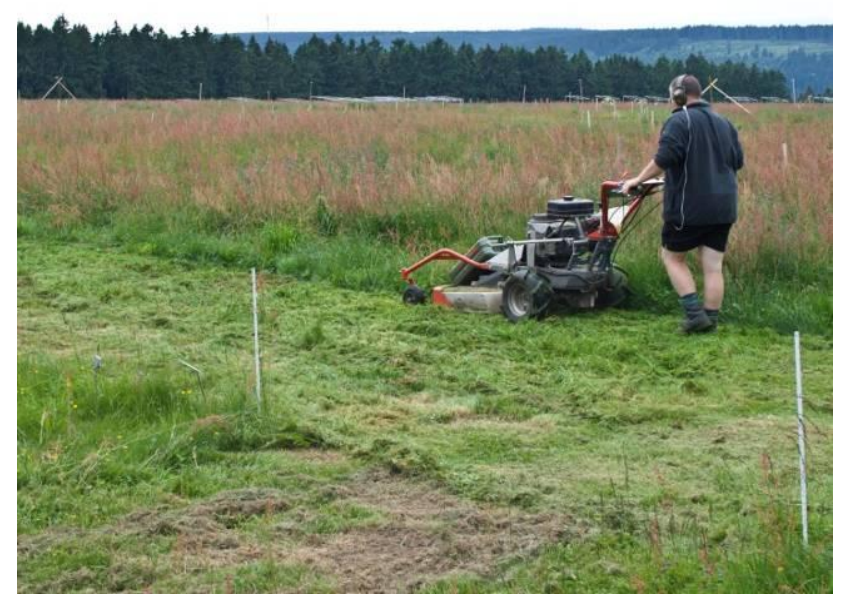

Figure 1.2: Mowing of the space between plots and blocks.

Note that plant functional groups were not entirely removed but strongly reduced in abundance, with slow recovery after herbicide application. However, even three years after herbicide application, all herbicide treatments significantly affected several vegetation parameters, such as compressed sward height, biomass, functional group composition and plant species richness (Table 1.1). For more details on the experimental design, setup and treatment effects on vegetation see Petersen et al. (2012) and Rose et al. (2012a, 2012b).



Figure 1.3: The GrassMan Experiment from above in 2010 (@ L. Rose). 
To investigate the effects of our treatments on plant diversity, productivity and the relationship between diversity and productivity, which is the focus of chapter 2 , we conducted vegetation surveys (Fig. 1.4) twice a year (beginning of May and end of August). We recorded species number and identity for each plot and estimating yield shares of each species, as well as functional groups' shares (grasses, herbs and legumes) according to Klapp \& Stählin (1936) in two 3 $\mathrm{m} \times 3 \mathrm{~m}$ quadrats per plot. The total species pool consisted of 73 species that were found over the whole growing season at the site. The mean overall species richness per plot was 25.3 species across all

Figure 1.4: Performing vegetation surveys in the GrassMan Experiment (Tatiana From). study years, disregarding the differences in


management system or sward type (for more detailed Information see chapter 2).

\section{Slug sampling}

To assess the treatment effects on diversity and abundance of slugs, we used a cover board technique (Oggier et al. 1998, Severns 2005) by placing a $50 \mathrm{~cm} \mathrm{x}$

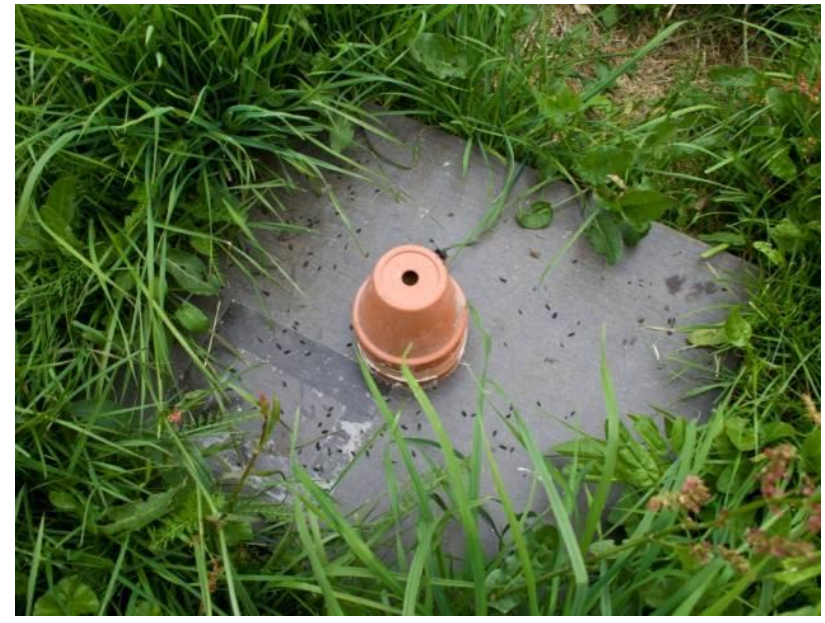

Figure 1.5: Wooden board for slug sampling in the field, covered with a plant pot as weight.
$41.5 \mathrm{~cm}$ wooden board (Masonite with a thickness of $0.4 \mathrm{~cm}$ ) in the middle of each plot (Fig. 1.5). While this sampling method excludes the subterranean component of slug populations (Hawkins et al. 1998) or small species (McCoy and Nudds 1997), it has been proven to be a reliable measure of slug activity, abundance and species richness on the soil surface (Suominen et al. 2003). 
Since slugs prefer rather humid soil conditions (Ondina et al. 2004, Willis et al. 2008), sampling was performed in two cool and wet periods in early May and late September 2010. In each sampling period, wooden boards were left undisturbed for four weeks, allowing slugs to seek shelter over an extensive time period. At the end of both sampling periods, we collected all slugs found within five minutes of intensive search in the dead vegetation and the upper soil (first 2-3 cm topsoil) and transferred them into ethanol $(70 \% \mathrm{w} / \mathrm{v})$ for later enumeration and identification (for more information see chapter 3 ).

\section{Leafhopper sampling}

To sample leafhoppers, in order to assess their responses to our experimental treatments, we used two methods.

i) Sweep netting: We used a sweep net (Fig. 1.6; Heavy Duty Sweep Net, 7215HS, BioQuip, diameter: $38 \mathrm{~cm}$ ), walking a circular transect with a diameter of $8 \mathrm{~m}$ around the centre of each plot (30 sweeps each) in dry weather on two occasions (at the

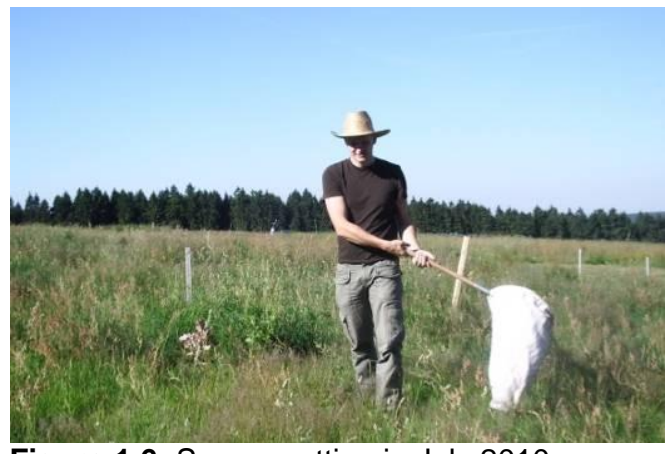

Figure 1.6: Sweep netting in July 2010. beginning of July and at the end of August 2010). Transects were approximately $20 \mathrm{~m}$ long, and there was a distance of at least $4 \mathrm{~m}$ to the edge of each plot.

ii) Pan Traps: We sampled leafhoppers by placing two transparent pan traps (Fig. 1.7), containing an ethylene glycol / water mixture (1:3) with $1 \mathrm{~m}$ distance to one another close to the centre of each plot. Pan traps were about $5 \mathrm{~cm}$ above vegetation height and were active for

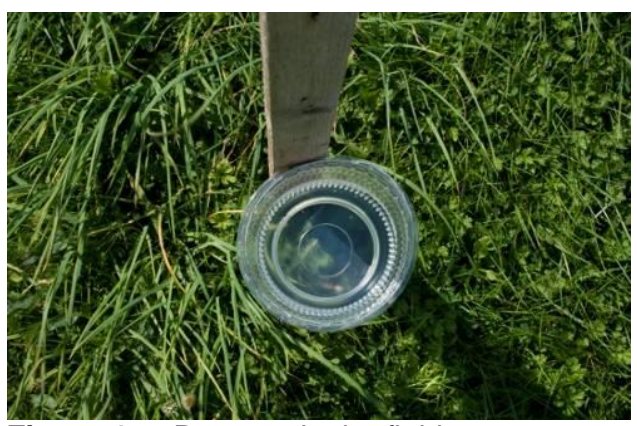

Figure 1.7: Pan trap in the field. one week in five time intervals in 2010 (end of June, mid-July, early August, mid-August, end of August). 
The specimens caught with both methods were transferred individually into ethanol (70 \% vol.) and identified to species level in the laboratory using Biedermann and Niedringhaus (2004) and Kunz et al. (2011). One species with woody host plants was excluded, as we assumed that it had been swept off its host tree by wind and was not a true member of the grassland fauna. Species whose larvae used herbs or grasses as host plants and only the imagines fed on trees were included in the analysis.

For female specimens of several genera identification to species level is not possible (e.g. Psammotettix) (Biedermann and Niedringhaus 2004, Kunz et al. 2011). Thus, if male specimens were present, female specimens were assumed to belong to the same species. If not, they were only identified to genus level. If males of more than one species of a genus were present, the number of females was assumed to mirror that of males (for more information see chapter 4).

\section{Lysimeters}

Lysimeters (Fig. 1.8) were made from transparent Plexiglas cylinders (height $30 \mathrm{~cm}$, inside diameter $14.6 \mathrm{~cm}$, wall thickness $0.3 \mathrm{~cm}$ ). A transparent material was selected in order to control if the soil core was free from cracks, holes or large stones.



Figure 1.8: Lysimeter as installed in the field. Left picture shows a lysimeter with a cage for the herbivores; middle picture shows lysimeter bottom; right picture shows lysimeter with the wide neck bottle to collect leak water. 
To install lysimeters, a sharpened, tightly fitting metal ring was fixed to the bottom and a metal cap on the head end of the plastic cylinder to avoid damage of the Plexiglas whilst driving it into the soil using a hammer.

After extracting the cylinder and the intact soil core, a baseplate with a culvert (diameter $1.6 \mathrm{~cm}$ ) was fixed to the bottom of the lysimeter using a light curing adhesive (@ Acrifix 192) (Fig. 1.9). To collect the drainage water, a Plexiglas tube (length $10 \mathrm{~cm}$ ) was connected to the culvert in the baseplate (Fig. $1.8 \& 1.9$ ). To ensure effective drainage of drainage water the baseplate was covered with 100 fiberglass wicks (diameter $0.1 \mathrm{~cm}$ ) (Fig. 1.8, middle), which channeled the water from the lysimeter through the culvert into a PE-bottle placed underneath (Fig. 1.8, right). The hole where the lysimeter was extracted from was stabilized using a PVC-cylinder (height $50 \mathrm{~cm}$, inside diameter $15.5 \mathrm{~cm}$ ) as permanent cladding, also to protect the lysimeter and allow frequent weighing and sampling of the soil water (PVC pipe shown in Fig. 1.9, left). To give the soil core time to regenerate after the disturbance, the lysimeters were installed one year prior to the start of the herbivory experiment in August and September 2010.



Figure 1.9: Installation of lysimeters, Right: The plexiglas cylinder of the lysimeter is stabilized using a PVC pipe whilst driving it into the ground. Left: fixing of the base plate to the lysimeter after the soil core is extracted from the ground. 
Cages on top of the aboveground part of each lysimeter were made of gauze of $1.5 \mathrm{~mm}$ mesh size, which were sewn to fit tightly to the lysimeter and additionally fixed using a zip tie (Fig. 1.8, left). The whole gauze cage was stabilized using a bamboo stick with a length of $45 \mathrm{~cm}$, which was pushed $5 \mathrm{~cm}$ into the ground for to prevent the structure from moving in heavy wind and rain.

At the end of the experiment $\left(02^{\text {nd }}\right.$ September 2011), we determined several parameters, such as above-ground biomass, plant composition and yield proportions, impact of herbivory, N-cycle measurements and $\mathrm{N}_{2} \mathrm{O}$ gas fluxes (for more information see chapter 5 ).

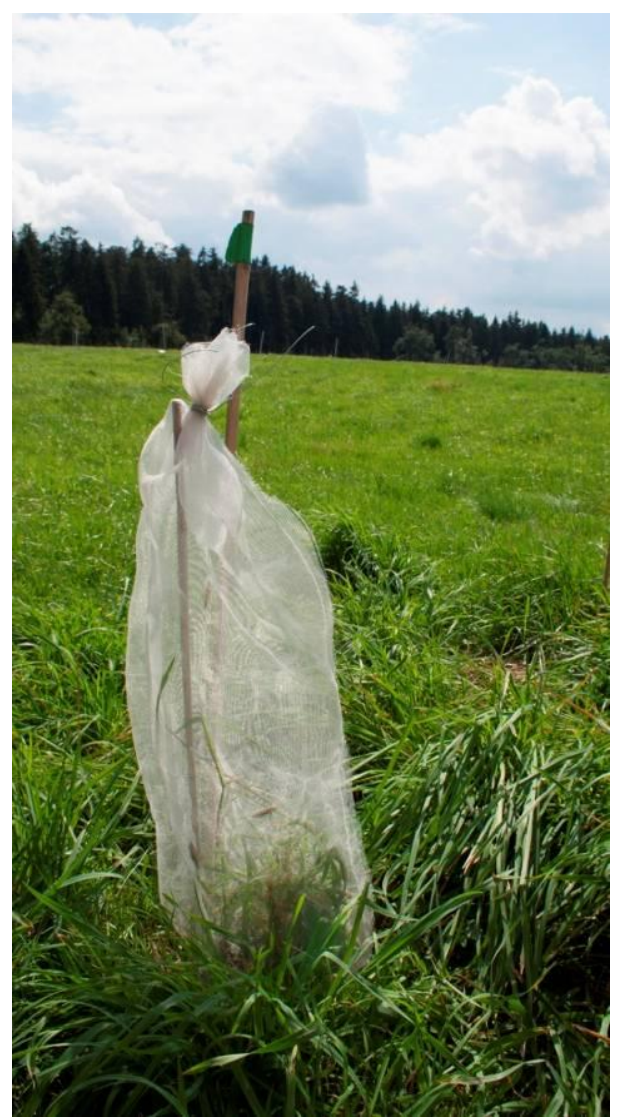

Figure 1.10: Lysimeter in the field, covered with a gauze cage. 


\section{Study Organisms}

Slugs

In chapter 3 we focus on the effects of our treatments on slugs (Mollusca: Gastropoda), which are a major component of the invertebrate community. With our approach, we found slugs of three species, Arion distinctus (MABILLE, 1868), Deroceras reticulatum (O. F. MÜLLER, 1774) and Arion lusitanicus (MOQUINTANDON, 1855). Slugs, such as $D$. reticulatum are considered important crop pests in agriculture, causing severe damage, e.g. in oilseed rape fields (Frank 1998). Slugs prefer humid and high-biomass habitats (Rathcke 1985, Ondina et al. 2004). D. reticulatum was also shown to shift community composition towards graminoids, due to its preference for forbs (Allan and Crawley 2011) and nitrogen-rich plants such as Trifolium spp., whereas graminoids such as Dactylis glomerata (L.) are mostly avoided (Cottam 1986). Additionally exclusion experiments (Curry 1994, Scherber et al. 2003, del-Val and Crawley 2004, Scheidel and Bruelheide 2005, Scherber et al. 2006) have shown that slugs can strongly affect plant biomass production and species composition in grasslands. Compared to other grassland invertebrates, slugs have low mobility, which makes them a good study organism on the rather small experimental plots of $225 \mathrm{~m}^{2}$.

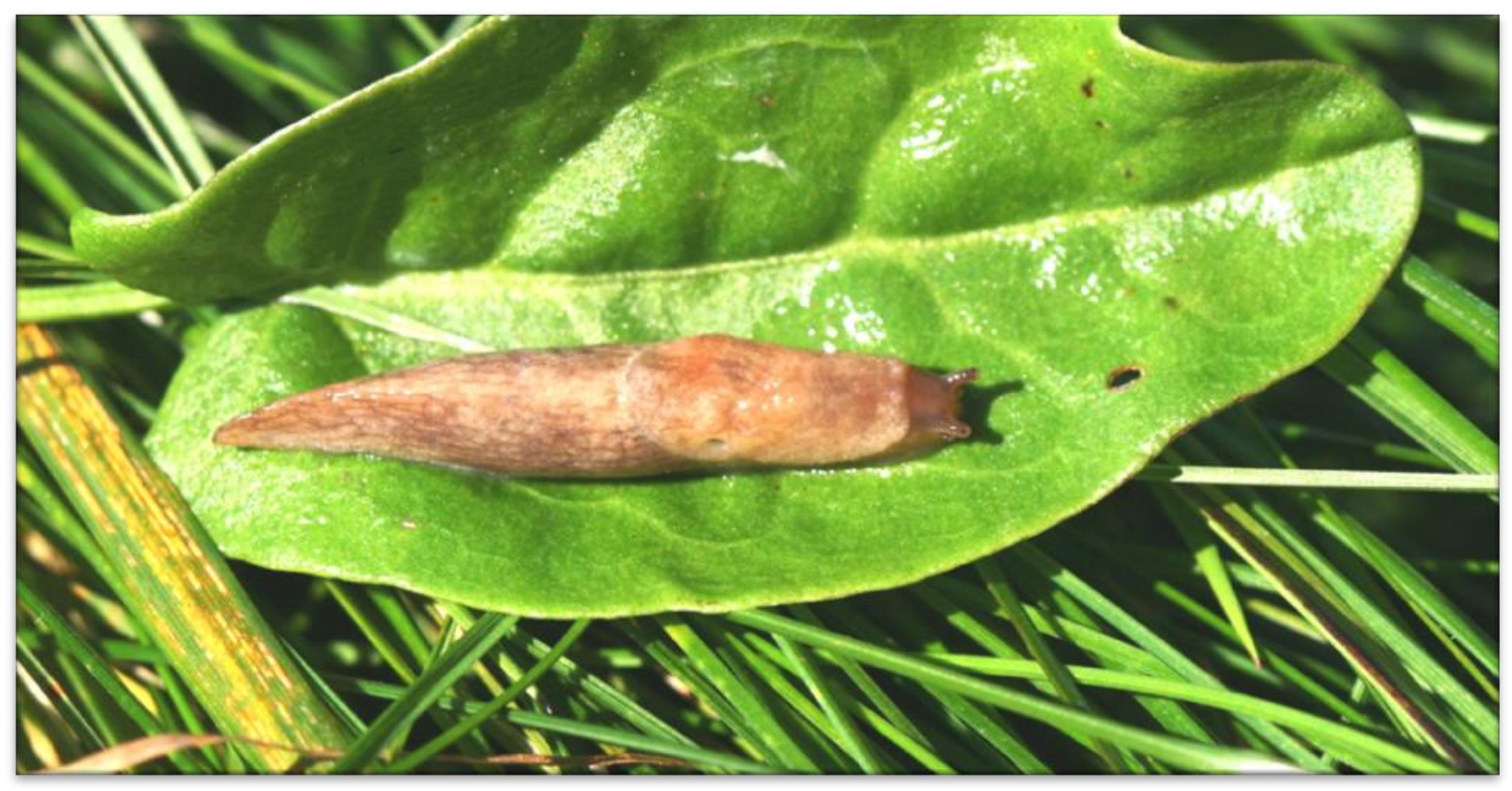

Figure 1.11: Slug (D. reticulatum) on a leaf of Rumex acetosa within the GrassMan experiment. 


\section{Leafhoppers}

In chapter 4 we study the treatment effects on leafhoppers, planthoppers and froghoppers (Auchenorrhyncha), a highly species-rich plant-sucking insect group that has been shown to be strongly influenced by management regime, vegetation structure and plant species composition (Nickel 2003, Biedermann et al. 2005). Leafhoppers play an important role both as herbivores and as prey for higher trophic levels. Their rapid reaction to changes in management regime makes leafhoppers very appropriate for ecological studies, despite most species being highly mobile (Waloff 1973, Nickel 2003).

Many leafhopper species are shown to have highly specialized feeding preferences (Nickel and Hildebrandt 2003) and most of the species found within our study site preferably feed on graminoids (see Table 1.1).

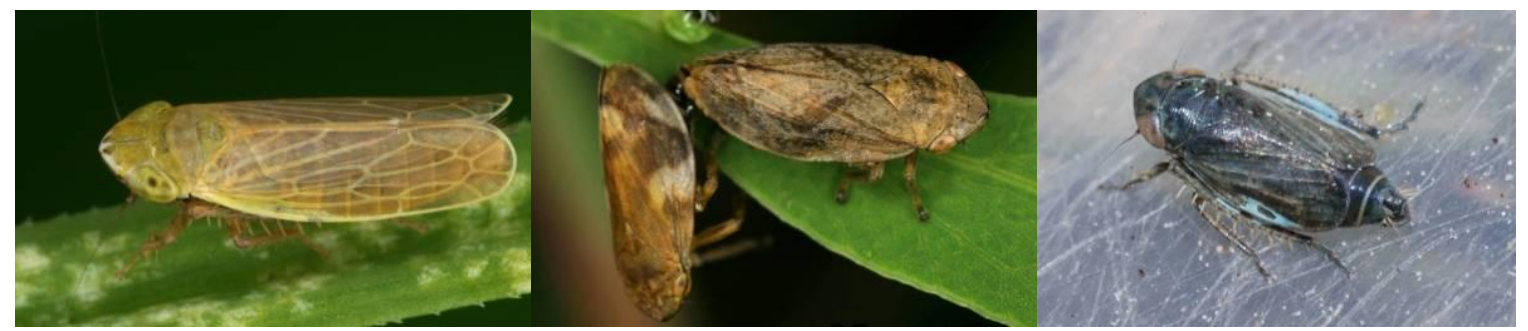

Figure 1.12: The three most abundant leafhopper species within the GrassMan experiment. Left: Arthaldeus pascuellus; middle: Philaenus spumarius; right: Streptanus sordidus (@ pictures by Gernot Kunz). 
Table 1.1: Species list of the Auchenorrhyncha within the GrassMan experiment with food preferences according to Nickel and Remane (2002) and their abundance.

\section{species}

Acanthodelphax spinosa

Anoscopus flavostriata

Anoscopus serratulae

Anoscopus spec.

Aphrodes makarovi

Aphrophora alni

Arthaldeus pascuellus

Balclutha punctata

Cicadella viridis

Cicadula persimilis

Colobotettix morbillosus

Conomelus anceps

Cosmotetix costalis

Criomorphus albomarginatus

Deltocephalus pulicaris

Elymana sulphurella

Errastunus ocellaris

Eupteryx aurata

Eupteryx vittata

Evacanthus interruptus

Javesella dubia

Javesella pellucida

Kosswigianella exigua

Macrosteles viridigriseus

Macustus grisescens

Megadelphax sordidula

Megophtalamus scanicus

Mirabella albifrons

Neophilaenus lineatus

Philaenus spumarius

Psammotettix confinis

Stenocranus minutus

Stiroma bicarinata

Streptanus sordidus

Xanthodelphax stramineus

Zyginidia scutellaris

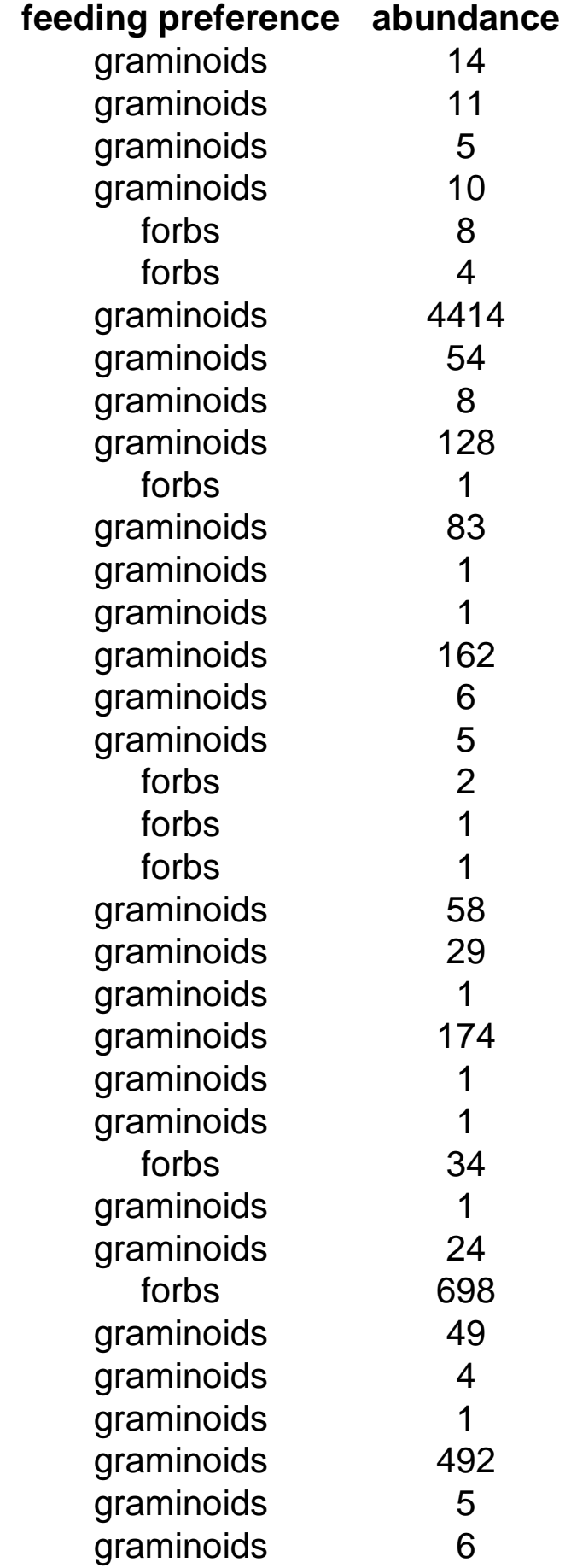




\section{Research objectives \& chapter outline}

In the studies presented in this thesis, I show the effects of different combinations of two cutting frequencies, two levels of fertilizer application, and three levels herbicide induced changes in functional group composition (grass reduced, forb reduced; no herbicides) on plants and herbivorous invertebrates.

The effects of these treatments on plant composition, diversity, productivity and the relationship between diversity and productivity is the focus of chapter 2 . Further we investigate how these treatment effects on the vegetation influences the diversity and abundance of the next trophic guild, namely herbivorous invertebrates such as slugs (chapter 3) and leafhoppers (chapter 4).

Also I examine how ecosystem processes, such as nutrient cycling (chapter 5) are influenced by experimentally increased herbivore activity, which is especially interesting in the context of agricultural intensification and deterministic plant species loss.

The main hypotheses were:

I. Reduction of graminoids due to functional group manipulation enhances species richness, whereas reduction of forbs will decrease plant diversity (chapter $2-5$ ).

II. Plant species diversity is correlated with productivity (chapter 2).

III. Productivity will increase with higher cutting frequency and fertilizer application, whereas plant diversity will decrease with fertilizer application (chapter $2-5$ ).

IV. Feeding damage on leave of Rumex acetosa is affected by abundance of invertebrate herbivores and management regime (chapter 3 ). 
V. Diversity and abundance of herbivorous invertebrates are positively affected by plant species diversity (chapter $3 \& 4$ ).

VI. Due to feeding preferences, diversity and abundance of herbivorous invertebrates, such as slugs or leafhoppers, are affected by changes in plant functional group composition (chapter $3 \& 4$ ).

VII. Higher cutting frequency has negative effects on diversity and abundance of herbivorous invertebrates (chapter $3 \& 4$ ).

VIII. Fertilizer application has positive effects on abundance of herbivorous invertebrates but negative effects on their diversity (chapter $3 \& 4$ ).

IX. Feeding intensities and preferences of different herbivore species may affect plant competition and therefore result in differences in plant species richness and composition (chapter 5).

X. Herbivory and fertilizer application accelerate nutrient cycling (chapter 5). 


\section{References}

Allan, E., and M. J. Crawley. 2011. Contrasting effects of insect and molluscan herbivores on plant diversity in a long-term field experiment. Ecology Letters 14:1246.

Balmer, O., and A. Erhardt. 2000. Consequences of succession on extensively grazed grasslands for central European butterfly communities: rethinking conservation practices. Conservation Biology 14:746-757.

Barnosky, A. D., E. A. Hadly, J. Bascompte, E. L. Berlow, J. H. Brown, M. Fortelius, W. M. Getz, J. Harte, A. Hastings, and P. A. Marquet. 2012. Approaching a state shift in Earth/'s biosphere. Nature 486:52-58.

Belovsky, G. E., and J. B. Slade. 2000. Insect herbivory accelerates nutrient cycling and increases plant production. PNAS 97:14412-14417.

Bender, E. A., T. J. Case, and M. E. Gilpin. 1984. Perturbation Experiments in Community Ecology: Theory and Practice. Ecology 65:1-13.

Biedermann, R., R. Achtziger, H. Nickel, and A. Stewart. 2005. Conservation of Grassland Leafhoppers: A Brief Review. Journal of Insect Conservation 9:229243.

Biedermann, R., and R. Niedringhaus. 2004. Die Zikaden Deutschlands : Bestimmungstafeln für alle Arten. WABV Fründ, Scheeßel.

Blake, R., B. Woodcock, D. Westbury, P. Sutton, and S. Potts. 2011. New tools to boost butterfly habitat quality in existing grass buffer strips. Journal of Insect Conservation 15:221-232.

Clayton, H., I. P. McTaggart, J. Parker, L. Swan, and K. A. Smith. 1997. Nitrous oxide emissions from fertilised grassland: A 2-year study of the effects of $\mathrm{N}$ fertiliser form and environmental conditions. Biology and Fertility of Soils 25:252-260.

Clewer, A. G., and D. H. Scarisbrick. 2001. Practical statistics and experimental design for plant and crop science. John Wiley \& Sons Ltd, Chichester.

Clough, T. J., C. Müller, and R. J. Laughlin. 2013. Using stable isotopes to follow excreta $\mathrm{N}$ dynamics and $\mathrm{N} 2 \mathrm{O}$ emissions in animal production systems. animal 7:418-426.

Cottam, D. A. 1986. The effects of slug-grazing on Trifolium repens and Dactylis glomerata in monoculture and mixed sward. Oikos 47:275-279.

Curry, J. P. 1994. Grassland Invertebrates. Chapman \& Hall, London. 
del-Val, E., and M. J. Crawley. 2004. Importance of tolerance to herbivory for plant survival in a British grassland. Journal of Vegetation Science 15:357-364.

Diaz, S., A. J. Symstad, F. S. Chapin, D. A. Wardle, and L. F. Huenneke. 2003. Functional diversity revealed by removal experiments. Trends in Ecology \& Evolution 18:140-146.

Ehrlich, P. R., P. M. Kareiva, and G. C. Daily. 2012. Securing natural capital and expanding equity to rescale civilization. Nature 486:68-73.

FAOSTAT. 2013. Food and Agricultural Organization Statistics Database. Food and Agricultural Organization of the United Nations., Rome, Italy. http://www.fao.org.

Frank, T. 1998. Slug damage and numbers of slugs in oilseed rape bordering on grass strips. Journal of Molluscan Studies 64:461-466.

Gelfand, I., R. Sahajpal, X. Zhang, R. C. Izaurralde, K. L. Gross, and G. P. Robertson. 2013. Sustainable bioenergy production from marginal lands in the US Midwest. Nature 493:514-517.

Hawkins, J. W., M. W. Lankester, and R. R. A. Nelson. 1998. Sampling terrestrial gastropods using cardboard sheets. Malacologia 39:1-9.

Herben, T., and E. Huber-Sannwald. 2002. Effect of management on species richness of grasslands: sward-scale processes lead to large-scale patterns. Pages 635-643 Grassland Science in Europe Volume 7. Organizing Committee of the European Grassland Federation, Versailles cedex.

Isbell, F., P. B. Reich, D. Tilman, S. E. Hobbie, S. Polasky, and S. Binder. 2013. Nutrient enrichment, biodiversity loss, and consequent declines in ecosystem productivity. Proceedings of the National Academy of Sciences 110:1191111916.

Keuter, A., I. Hoeft, E. Veldkamp, and M. Corre. 2012. Nitrogen response efficiency of a managed and phytodiverse temperate grassland. Plant and Soil:1-14.

Klapp, E., and A. Stählin. 1936. Standorte, Pflanzengesellschaften und Leistung des Grünlandes. Stuttgart: Ulmer.

Kleijn, D., F. Kohler, A. Baldi, P. Batary, E. D. Concepcion, Y. Clough, M. Diaz, D. Gabriel, A. Holzschuh, E. Knop, A. Kovacs, E. J. P. Marshall, T. Tscharntke, and J. Verhulst. 2009. On the relationship between farmland biodiversity and land-use intensity in Europe. Proceedings of the Royal Society B-Biological Sciences 276:903-909. 
Kunz, G., H. Nickel, and R. Niedringhaus. 2011. Fotoatlas der Zikaden Deutschlands - Photographic Atlas of the Planthoppers and Leafhoppers of Germany. WABV-Fründ, Scheeßel.

Lee, R. 2011. The outlook for population growth. Science 333:569-573.

Li, D., C. J. Watson, M. J. Yan, S. Lalor, R. Rafique, B. Hyde, G. Lanigan, K. G. Richards, N. M. Holden, and J. Humphreys. 2013. A review of nitrous oxide mitigation by farm nitrogen management in temperate grassland-based agriculture. Journal of Environmental Management 128:893-903.

McCoy, K. D., and T. D. Nudds. 1997. Interspecific variation in climbing by gastropods: Implications for transmission of Parelaphostrongylus tenuis. American Midland Naturalist 137:320-328.

McKinney, M. L., and J. L. Lockwood. 1999. Biotic homogenization: a few winners replacing many losers in the next mass extinction. Trends in Ecology \& Evolution 14:450-453.

Mueller, K. E., S. E. Hobbie, D. Tilman, and P. B. Reich. 2013. Effects of plant diversity, $\mathrm{N}$ fertilization, and elevated carbon dioxide on grassland soil $\mathrm{N}$ cycling in a long-term experiment. Global Change Biology 19:1249-1261.

Nickel, H. 2003. The leafhoppers and planthoppers of Germany (Hemiptera, Auchenorrhyncha): Patterns and strategies in a highly diverse group of phytophagous insects. Goecke \& Evers, Keltern.

Nickel, H., and J. Hildebrandt. 2003. Auchenorrhyncha communities as indicators of disturbance in grasslands ( Insecta, Hemiptera ) - a case study from the Elbe flood plains ( northern Germany ). Environment 98:183-199.

Nickel, H., and R. Remane. 2002. Artenliste der Zikaden Deutschlands, mit Angabe von Nährpflanzen , Nahrungsbreite , Lebenszyklus , Areal und Gefährdung (Hemiptera, Fulgoromorpha et Cicadomorpha). Beiträge zur Zikadenkunde 5:27-64.

Oelmann, Y., N. Buchmann, G. Gleixner, M. Habekost, C. Roscher, S. Rosenkranz, E.-D. Schulze, S. Steinbeiss, V. M. Temperton, A. Weigelt, W. W. Weisser, and W. Wilcke. 2011. Plant diversity effects on aboveground and belowground $\mathrm{N}$ pools in temperate grassland ecosystems: Development in the first 5 years after establishment. Global Biogeochemical Cycles 25:GB2014.

Oggier, P., S. Zschokke, and B. Baur. 1998. A comparison of three methods for assessing the gastropod community in dry grasslands. Pedobiologia 42:348-357. 
Olff, H., and M. E. Ritchie. 1998. Effects of herbivores on grassland plant diversity. Trends in Ecology \& Evolution 13:261-265.

Ondina, P., J. Hermida, A. Outeiro, and S. Mato. 2004. Relationships between terrestrial gastropod distribution and soil properties in Galicia (NW Spain). Applied Soil Ecology 26:1-9.

Pavlů, V., J. Schellberg, and M. Hejcman. 2011. Cutting frequency vs. $\mathrm{N}$ application: effect of a 20-year management in Lolio-Cynosuretum grassland. Grass and Forage Science 66:501-515.

Petersen, U., N. Wrage, L. Köhler, C. Leuschner, and J. Isselstein. 2012. Manipulating the species composition of permanent grasslands-A new approach to biodiversity experiments. Basic and Applied Ecology 13:1-9.

Rathcke, B. 1985. Slugs as generalist herbivores - Tests of 3 Hypotheses on plant choices. Ecology 66:828-836.

Rösch, V., T. Tscharntke, C. Scherber, and P. Batáry. 2013. Landscape composition, connectivity and fragment size drive effects of grassland fragmentation on insect communities. Journal of Applied Ecology 50:387-394.

Roscher, C., J. Schumacher, J. Baade, W. Wilcke, G. Gleixner, W. W. Weisser, B. Schmid, and E. D. Schulze. 2004. The role of biodiversity for element cycling and trophic interactions: an experimental approach in a grassland community. Basic and Applied Ecology 5:107-121.

Rose, L., H. Coners, and C. Leuschner. 2012a. Effects of fertilization and cutting frequency on the water balance of a temperate grassland. Ecohydrology 5:64-72.

Rose, L., M. C. Rubarth, D. Hertel, and C. Leuschner. 2012b. Management alters interspecific leaf trait relationships and trait-based species rankings in permanent meadows. Journal of Vegetation Science:DOI:10.1111/j.16541103.2012.01455.x.

Sala, O. E., F. S. Chapin, J. J. Armesto, E. Berlow, J. Bloomfield, R. Dirzo, E. HuberSanwald, L. F. Huenneke, R. B. Jackson, A. Kinzig, R. Leemans, D. M. Lodge, H. A. Mooney, M. Oesterheld, N. L. Poff, M. T. Sykes, B. H. Walker, M. Walker, and D. H. Wall. 2000. Biodiversity - Global biodiversity scenarios for the year 2100. Science 287:1770-1774.

Scheidel, U., and H. Bruelheide. 2005. Effects of slug herbivory on the seedling establishment of two montane Asteraceae species. Flora 200:309-320. 
Scherber, C., M. J. Crawley, and S. Porembski. 2003. The effects of herbivory and competition on the invasive alien plant Senecio inaequidens (Asteraceae). Diversity and Distributions 9:415-426.

Scherber, C., P. N. Mwangi, V. M. Temperton, C. Roscher, J. Schumacher, B. Schmid, and W. W. Weisser. 2006. Effects of plant diversity on invertebrate herbivory in experimental grassland. Oecologia 147:489-500.

Schmid, B. 2010. Biodiversity, Ecosystem Functioning \& Human Wellbeing. Pages 14-29. Nature Publishing Group, a division of Macmillan Publishers Limited. All Rights Reserved.

Severns, P. M. 2005. Response of a terrestrial mollusc community to an autumn prescribed burn in a rare wetland prairie of western Oregon, USA. Journal of Molluscan Studies 71:181-187.

Smart, S. M., K. Thompson, R. H. Marrs, M. G. Le Duc, L. C. Maskell, and L. G. Firbank. 2006. Biotic homogenization and changes in species diversity across human-modified ecosystems. Proceedings of the Royal Society B: Biological Sciences 273:2659-2665.

Stein, C., S. B. Unsicker, A. Kahmen, M. Wagner, V. Audorff, H. Auge, D. Prati, and W. W. Weisser. 2010. Impact of invertebrate herbivory in grasslands depends on plant species diversity. Ecology 91:1639-1650.

Suominen, O., L. Edenius, G. Ericsson, and V. Resco de Dios. 2003. Gastropod diversity in aspen stands in coastal northern Sweden. Forest Ecology and Management 175:403-412.

Susan, S. 2007. Climate change 2007-the physical science basis: Working group I contribution to the fourth assessment report of the IPCC. Cambridge University Press.

Tilman, D., P. B. Reich, and F. Isbell. 2012. Biodiversity impacts ecosystem productivity as much as resources, disturbance, or herbivory. Proceedings of the National Academy of Sciences 109:10394-10397.

Tilman, D., R. Socolow, J. A. Foley, J. Hill, E. Larson, L. Lynd, S. Pacala, J. Reilly, T. Searchinger, and C. Somerville. 2009. Beneficial biofuels-the food, energy, and environment trilemma. Science 325:270. 
Tscharntke, T., Y. Clough, T. C. Wanger, L. Jackson, I. Motzke, I. Perfecto, J. Vandermeer, and A. Whitbread. 2012. Global food security, biodiversity conservation and the future of agricultural intensification. Biological Conservation 151:53-59.

Tylianakis, J. M., R. K. Didham, J. Bascompte, and D. A. Wardle. 2008. Global change and species interactions in terrestrial ecosystems. Ecology Letters 11:1351-1363.

Vickery, J. A., J. R. Tallowin, R. E. Feber, E. J. Asteraki, P. W. Atkinson, R. J. Fuller, and V. K. Brown. 2001. The management of lowland neutral grasslands in Britain: effects of agricultural practices on birds and their food resources. J. Appl. Ecol 38:647-664.

Waloff, N. 1973. Dispersal by flight of leafhoppers (Auchenorrhyncha: Homoptera). Journal of Applied Ecology:705-730.

Wesche, K., B. Krause, H. Culmsee, and C. Leuschner. 2012. Fifty years of change in Central European grassland vegetation: Large losses in species richness and animal-pollinated plants. Biological Conservation 150:76-85.

Willis, J. C., D. A. Bohan, S. J. Powers, Y. H. Choi, J. Park, and E. Gussin. 2008. The importance of temperature and moisture to the egg-laying behaviour of a pest slug, Deroceras reticulatum. Annals of Applied Biology 153:105-115.

Wilson, J. D., A. J. Morris, B. E. Arroyo, S. C. Clark, and R. B. Bradbury. 1999. A review of the abundance and diversity of invertebrate and plant foods of granivorous birds in northern Europe in relation to agricultural change. Agriculture, ecosystems \& environment 75:13-30.

Zavaleta, E. S., J. R. Pasari, K. B. Hulvey, and G. D. Tilman. 2010. Sustaining multiple ecosystem functions in grassland communities requires higher biodiversity. Proceedings of the National Academy of Sciences 107:1443-1446.

Zechmeister, H. G., I. Schmitzberger, B. Steurer, J. Peterseil, and T. Wrbka. 2003. The influence of land-use practices and economics on plant species richness in meadows. Biological Conservation 114:165-177. 


\section{CHAPTER 2}

\section{BRINGING BIODIVERSITY EXPERIMENTS TO THE}

Real World: Diversity Versus Management

in A SEMI-NATURAL GRASSLAND

Tatiana From, Georg Everwand, Nicole Wrage, Christoph Scherber, Christoph Leuschner, Teja Tscharntke, Johannes Isselstein 


\section{Abstract}

Recent studies in the field of biodiversity and ecosystem functioning in temperate grassland systems reported a variety of results regarding the nature of the relationship between diversity and productivity. Findings supporting the positive effects of species diversity on productivity came mostly from experimental communities. Studies in natural and semi-natural grassland communities, on the contrary, often reported weak or even no relationship between the two variables. These studies were, however, criticized for not including productive sites, confounded site and diversity effects, as well as low control of external factors. We present the results of a 5-year biodiversity experiment in a semi- natural grassland with a more than one-hundred-year-old history of extensive agricultural use. We managed to create three different sward types via removal of functional groups and a gradient of management intensity resulting from a combination of two cutting frequencies and nutrient input. In our study, overall species richness had no significant effect on the above-ground biomass production across the five study years. Sward type diversity had significant effects on the above-ground biomass production only in the experimental year with extremely dry weather conditions in the summer months before the peak standing crop, when control plots had larger yields than dicot- and monocotreduced. While management intensification caused an increase in above-ground biomass production, changes in species numbers were not dramatic over the whole investigation period with increasing cutting frequency promoting establishing of more species. In our study existing species composition of the semi-natural grassland was highly resilient and four years after the removal of functional groups it regained a composition of grasses, herbs and legumes showing almost no differences among the sward types with larger shares of grasses being typical of fertilized plots and larger shares of herbs typical of frequent cutting. Shares of legumes were suppressed by fertilization, but were found in almost all plots by the end of the experimental period. We suggest that under appropriate agricultural management a semi-natural grassland might have a high potential for forage production without significant species losses and the need of being converted to arable land or reseeding it with diverse species mixtures. 


\section{Introduction}

A lot of grassland communities in Central Europe are nowadays characterized by a species-poor composition of mowing-tolerant, $\mathrm{N}$-demanding competitive grasses and a decline of early-flowering species, especially insect-pollinated herbs (Wesche et al. 2012). Multifunctionality of grasslands, however, depends on the plant species diversity (Hector and Bagchi 2007, Zavaleta et al. 2010) and promotes stability across levels of ecosystem organization (Isbell et al. 2009, Proulx et al. 2010, Yang et al. 2011). But farmers and ecologists often have different views on the role of biodiversity for grassland production (Wrage et al. 2011) leading to a controversy concerning research priorities between the two groups. The need for agricultural production in Europe is still high, be it the primary source of forage for livestock or for bioenergy purposes. Species-rich grasslands are not perceived as an attractive source for agricultural production by farmers, but they are of focal interest for nature conservation and there have been attempts to restore diverse grasslands all over Europe, however, not all attempts were successful (Critchley et al. 2004, Hodgson et al. 2005).

Due to this increasing interest in grassland biodiversity and the scarcity of land resources for agricultural production, two main strategies emerged: intensification of the use of diverse grassland or diversification of the existing species composition. The former may comprise grassland diversity, while the latter requires knowledge about the relationship between diversity and biomass production. Correspondingly, many studies addressed the problem of species losses and ecosystem functioning, as well as the nature of the relationship between diversity and biomass production (Chapin et al. 2000, Sala et al. 2000).

A large number of studies was conducted in order to examine the ecosystem functioning and the impacts of species losses on it. Biodiversity studies have often concentrated on the relationship between species diversity and productivity (Hector et al. 1999, Tilman et al. 2001, Roscher et al. 2005), but most of these studies took place in experimental grasslands sown with diverse species mixtures (Sanderson et al. 2004).

Such studies (Tilman et al. 2001, Roscher et al. 2005, Reich et al. 2012) found mostly strong positive effects of species diversity on biomass production, which in long- running studies were also reported over time (Cardinale et al. 2007, Tilman et 
al. 2012). These results, however, were criticized for unnatural species abundances and artificial conditions, leading to the difficulty of scaling up or generalizing those findings (among others Loreau et al. (2001) Wilsey and Polley (2004)).

Observational studies, conducted in natural and semi-natural grasslands, often reported weak or no relationship between species diversity and productivity (Huston et al. 2000, Adler et al. 2011, Assaf et al. 2011), but were considered to have a number of weaknesses, such as no defined biodiversity levels, confounded sites and diversity effects (Kahmen et al. 2005, Jiang et al. 2009) or low control of external factors (Diaz et al. 2003). Therefore, later generations of biodiversity studies, known as removal experiments, simulated the losses of certain species and functional groups and examined induced ecosystem responses emphasizing that these responses differ between natural and semi- natural grassland communities on the one hand and synthetic communities on the other (Wardle et al. 1999, Symstad and Tilman 2001, McLaren and Turkington 2010, Petersen et al. 2012).

Inconsistency of the findings from experimental and observational studies, as well as the challenges of transferring the results from synthetic communities to natural ecosystems and the need for long- term and large-scale studies have been on the agenda of many research projects as diversity loss was considered by many authors to be underestimated in synthetic communities compared to natural and semi-natural grassland systems (Diaz et al. 2003, Tylianakis et al. 2008). Thus, many scientists considered that research should focus on how biodiversity changes and biodiversity loss affect functioning of „real-world“ ecosystems (among others Schmid \& Hector (2004), Zavaleta \& Hulvey (2004), Naeem et al.(2012)).

We present the results of a biodiversity experiment in an old semi-natural grassland in central Germany. By establishing a management gradient and creating three different sward types via removal of functional groups, we induced a change likely to affect ecosystem processes and functions.

Thus, we could investigate not only the effect of the removal itself, but the functioning of the native species composition of this grassland ecosystem under disturbance resembling common levels of moderate intensification of grassland management and associated changes in yield production.

Along with the herbicide treatment, we created a management gradient resulting in four management systems presented by a combination of fertilization and cutting 
frequency. The total of twelve established experimental treatments thus represented the combination of the three main experimental factors and matched common agricultural practices in Europe. We investigated the relationship between species diversity and productivity, as well as the changes in above-ground biomass production and vegetation diversity under management intensification. 


\section{Material and Methods}

\section{a. Study site}

The study site is situated at the experimental farm of the University of

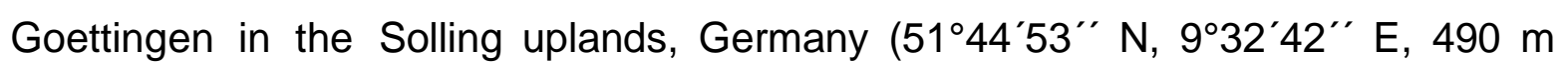
a.s.I.). Before establishing of the experiment, the site was used in common farm management as pasture or for hay cutting. The mean annual temperature is $6.9^{\circ} \mathrm{C}$, mean annual precipitation 1100 mm (German Weather Service: DWD 1960-1990). The vegetation composition is characteristic of a nutrient-poor montane mesic-moist Lolio- Cynosuretum community with high shares of Festuca rubra and Agrostis capillaris. The soil is a haplic Cambisol with $\mathrm{pH} \mathrm{H}_{2} \mathrm{O}$ values of 5.2 - 5.6.

\section{b. Experimental design}

In total, 72 plots, $15 \times 15 \mathrm{~m}$ each, arranged in a Latin rectangle design consisting of six blocks and six rows, were set up in 2008 and resulted from the combination of the three experimental factors and their 6-times replication. The main experimental factors were sward type, fertilization, and cutting frequency. A change in sward diversity was achieved by the application of herbicides on July $31^{\text {st }} 2008$ to reduce the shares of grasses in the monocot-reduced (-Mon) sward (active component Clethodim (0.5 I ha ${ }^{-1}$ ): Select 240 EC, Stähler Int., Stade, Germany; 0.5 I ha-1) and the share of herbs in the dicot-reduced (-Dic) sward (active components were Fluoroxypyr + Triclopyr and Mecoprop-P $\left.\left(3 \mathrm{I} \mathrm{ha}^{-1}\right)\right)$. One third of the plots were left untreated (control sward). Fertilization (180-100-30 kg NPK ha-1 year $^{-1}$ (NPK)) and cutting frequency (plots cut once a year $(1 \mathrm{x})$ and 3 times a year $(3 \mathrm{x})$ were two further management factors. As $\mathrm{N}$ fertilizer, we used calcium ammonium nitrate N27 (half of it applied in the beginning of April and half in the beginning of June), as P\&K fertilizer Thomaskali® (8\% P2O5, 15\% K2O, 20\% CaO) in 2008-2009 and „PK fertilizer" (12\% P2O5, 24\% K2O, 6\% S, 21\% CaO) in 2010-2012. Plots cut three times a year were harvested in the middle of May, middle of July, and late September.

Plots cut once a year were harvested at July harvest. Harvesting of the plots was done using a Haldrup® forage harvester by cutting of two stripes, each $1.5 \mathrm{~m}$ wide 
and $15 \mathrm{~m}$ long, on each plot, which was found to be a representative measurement technique for the plot size of $225 \mathrm{~m}^{2}$ and established as the standard measure of above-ground biomass production at the set-up of the experiment.

\section{c. Vegetation surveys}

Before the start of the experiment, the vegetation community was characterized and the minimum species area determined for defining the optimal vegetation survey size. Vegetation surveys were subsequently conducted twice a year in the beginning of May and in the end of August by recording species number and identity for each plot and estimating yield shares of each species, as well as functional groups' shares (grasses, herbs and legumes) according to Klapp \& Stählin (1936) in two $3 \mathrm{~m} \times 3 \mathrm{~m}$ vegetation survey areas and $1 \mathrm{~m} \times 1 \mathrm{~m}$ quadrates per plot. The total species pool consisted of 73 species that were found over the whole vegetation period at the site. The mean overall species richness per plot was 25.3 species across all study years disregarding the differences in management system or sward type. Shannon evenness was calculated as $\mathrm{J}^{\prime}=\mathrm{H}^{\prime} / \log \mathrm{e}(\mathrm{n})$ and is hereafter referred to as evenness (where $\mathrm{H}^{\prime}$ is the Shannon diversity index (log e) and $\mathrm{n}$ is the number of species found on the corresponding plot).

\section{d. Data analyses}

Turboveg for Windows 2.91d (Alterra, Wageningen) was used for processing vegetation data and calculating diversity indices (Shannon diversity, Shannon evenness, Simpson diversity). Statistical analysis of the data was performed using the $R$ software, Version 2.14 .0 (2012) with a significance level of $\alpha \leq 0.05$. The climate data was implemented in the models as year effects. We used linear and linear mixed effect models (Pinheiro et al. 2010) to explore the effects of the three main treatment factors on the relationship between species richness and productivity, as well as further diversity indices.

The best fitting adequate minimum models including the significant predictive variables were selected by comparison of the Akaike Information Criteria (AIC) following the principle of marginality implying not deleting non-significant effects in presence of higher-order interactions of the corresponding factors. We used the maximum likelihood method to update the models and recalculated the final models with REML as we had spatial factors included as random effects. Residuals of the 
models were inspected for normality of distribution and homogeneity of variance in groups of according factors. Adjustments for non-linearity were performed if needed. If the models' residuals were heterogeneous, the variance was adjusted with the varldent structure for the corresponding factor. We used the autocorrelation function in the models for the dataset from the whole investigation period to account for temporal variation of the data. Models were simplified using an updated AICC procedure for small data-sets (Scherber 2011). Means (for grasses and herbs) and medians (for legumes) in the dicot-reduced and monocot-reduced swards were compared to the shares of corresponding functional groups in the control sward based on the linear models with block and row included as spatial factors using linear contrasts with the sward type as explanatory variable. 


\section{Results}

Overall species richness increased by the end of the experimental study period (from 23 species on average up to 25.7 species on average per plot) (Fig. 2.1). We successfully achieved the expected change in sward composition by the year following the herbicide treatment (Petersen et al. 2012). Compared to the set-up year, there were slightly higher numbers of species (on average 1.4 species more) in monocot-reduced plots than in the control sward and 1.6 species less in dicotreduced plots than in control plots in 2009.

\begin{tabular}{|c|c|c|c|c|}
\hline .. Mon-1xNPK & -0 & Dic-1xNPK & $\Delta$ & Con1xNPK \\
\hline Mon-1x & -0 & Dic-1x & $\triangle$ & Con $1 x$ \\
\hline . & -0 & Dic-3x & $\Delta$ & Con3x \\
\hline Mon-3xNPK & -0 & Dic-3xNPK & $\Delta$ & Con3xNP \\
\hline
\end{tabular}

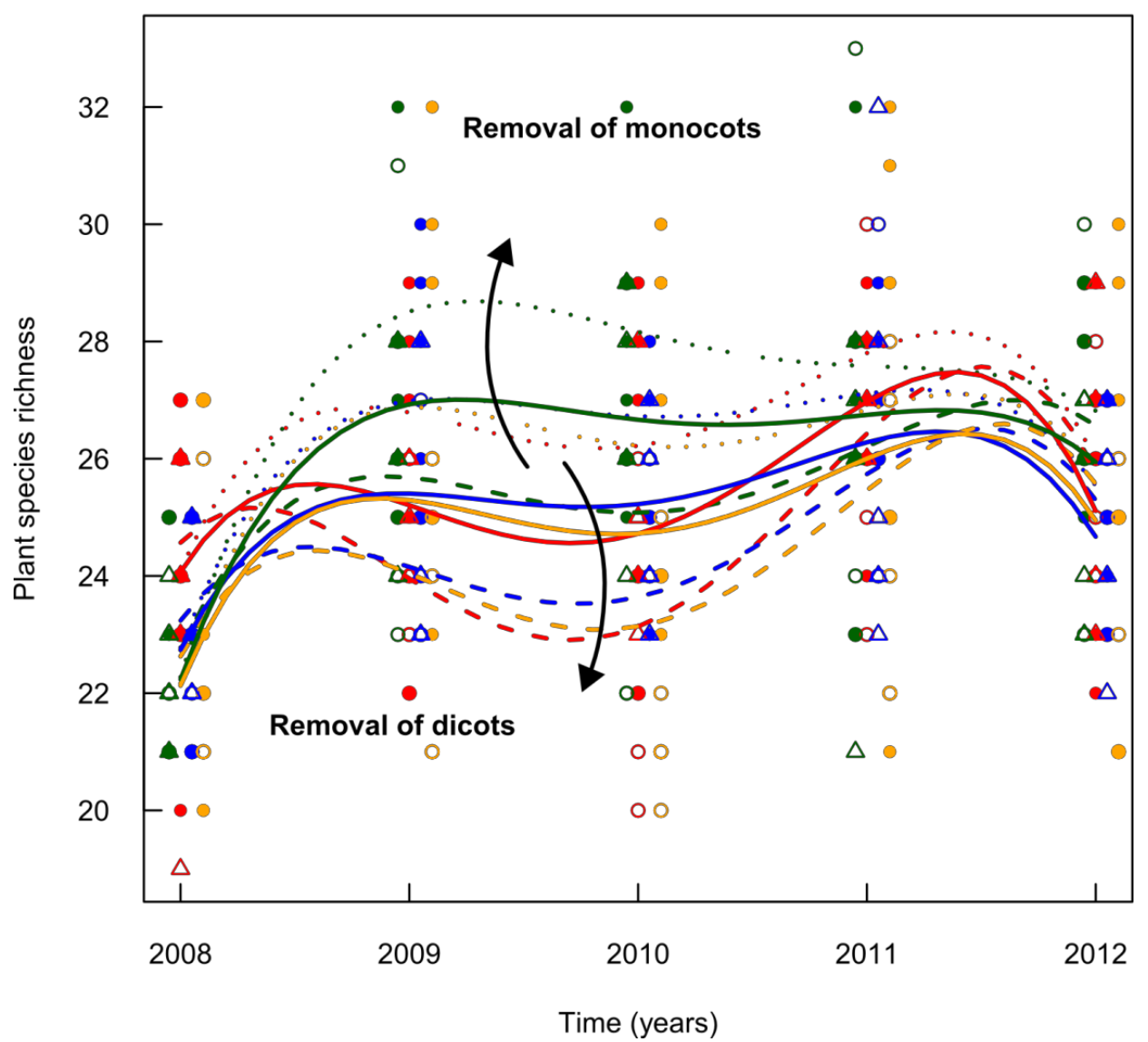

Figure 2.13: Change in overall species numbers over time in 100-year-old grassland. Lines show predicted values from minimal adequate mixed effects models corrected for temporal autocorrelation and variance heterogeneity. Abbreviations of treatments are combinations of the following factors: Mon- = monocot- reduced sward, Dic- $=$ dicot-reduced sward, Con $=$ control sward. $1 \mathrm{x}=$ plots cut once a year, $3 \mathrm{x}=$ plots cut three times a year; NPK = fertilized plots. 
In the last vegetation period (2012), recorded maximum species loss compared to the initial year was 3 species while the maximum number of species gained was 10 species per plot. Changes in species numbers were affected by the experimental year $(p<0.0001)$ and cutting frequency $(p<0.05)$ and the interactions of year and the following factors: sward type $(p<0.0001)$, cutting frequency $(p<0.001)$, as well as fertilization $(p<0.01)$.

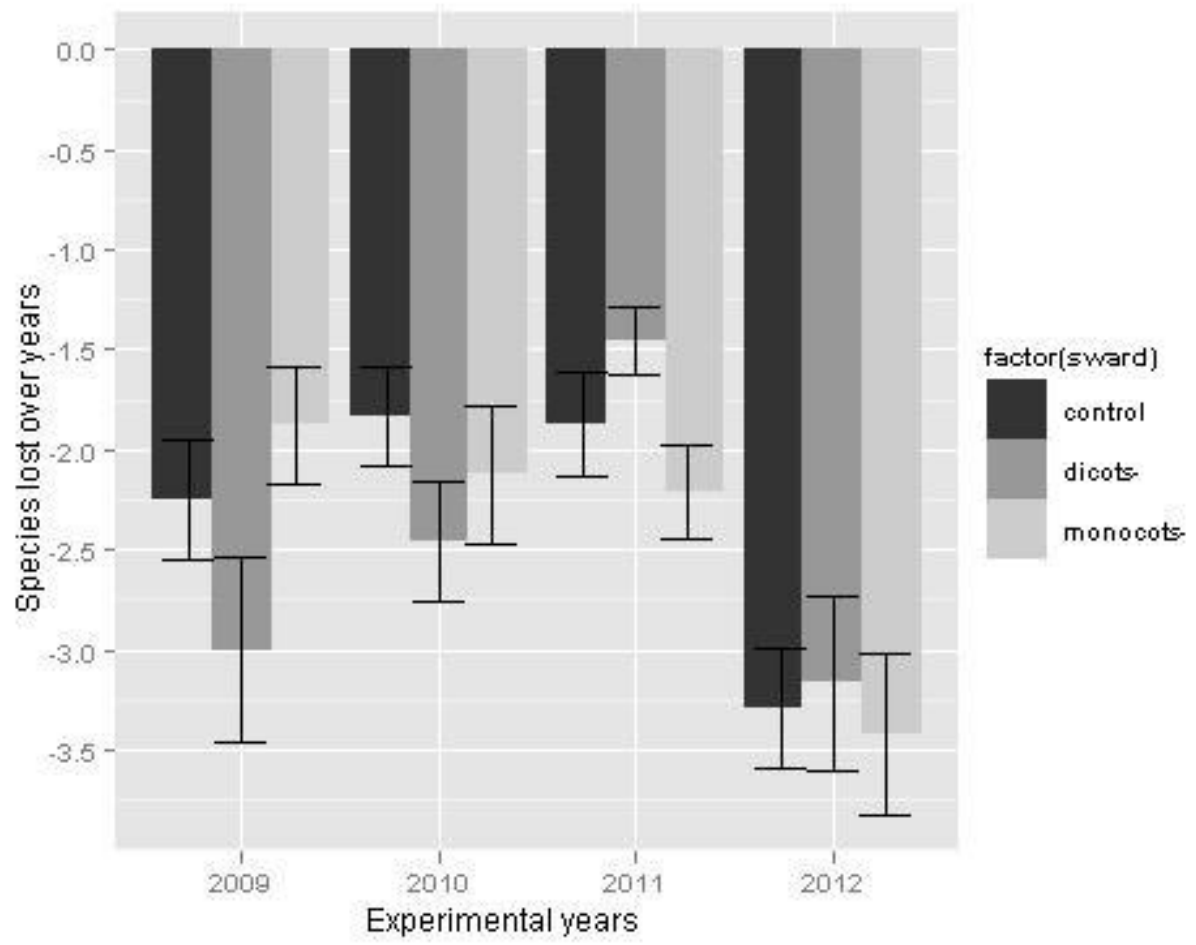

Figure 2.2: Consecutive species losses of overall species richness in the three sward types (based on differences in species presence-absence data for consecutive years).

Species losses in all of the three sward types did not exceed 4 species per plot (Fig. 2.2). Along with the losses of species in swards that were treated with herbicides to manipulate the functional groups abundances, there was a natural dynamic of species present and absent in the control sward as well (Fig. $2.2 \& 2.3$ ). In the year 2011, there was a significant effect of sward type on the number of species gained with higher number of species found in dicot-reduced plots (3.7 on average) while the effects of herbicide application were weakening (Fig. 2.3).

Regarding the effects of management intensification on species richness, in some of the years the change in species number and number of species gained compared to the previous year was found to be positively affected by cutting 
frequency $(p<0.05)$, whereas fertilization was not significant unless in combination with the experimental year $(p<0.01)$ with a trend in decreasing species numbers in fertilized compared to non-fertilized plots.

In the year 2010, the change in species number, compared to the year 2009 was not affected by any of the main experimental factors, except for the combination of fertilization and cutting frequency $(p<0.02)$, with on average less than one species change over all management systems. In the fourth year after the set-up of the experiment, plots cut three times and not fertilized had on average 2.8 species more than control plots cut once a year and not fertilized $(p<0.01)$.



Figure 2.3: Consecutive species gains of overall species richness in the three sward types (based on differences in species presence-absence data for corresponding years).

Species evenness was found to be significantly affected by all experimental factors and their influence varied across the years $(p<0.0001)$ (Figure 2.4), sward types $(p<0.0001)$, cutting frequencies $(p<0.0001)$ and fertilization levels $(p<0.05)$. In the year following the herbicide application species evenness across all treatments was smaller compared to that of the initial species composition $(p<0.001)$. 
In the two years following the herbicide application, species evenness was significantly different among the three sward types $(p<0.0001$ in 2009; $p<0.001$ in 2010): in the control sward, species evenness was $10 \%$ higher than in the dicotreduced sward while the highest evenness was found in the monocot-reduced sward $\left(\mathrm{J}^{\prime}=0.78\right)$ in 2009. When the removal treatment effects were weakening in the year 2011 (Table 2.1), there were no significant differences found in the species evenness among the three swards ( $p=0.45)$ (Fig. 2.4, a).

Fertilization tended to have a slightly significant effect on species evenness in the year 2009 ( $p=0.07$ ) (Fig. 2.4, b) and was found to affected species evenness in the year 2011 when the average species evenness in fertilized plots was $5 \%$ lower compared to non-fertilized plots $(p<0.001)$.

Cutting frequency had significant effects on species evenness in all of the experimental years following the set-up year: in plots cut three times a year it was $3 \%(2009, p<0.05)$ to $7 \%(p<0.0001$ in 2010 and $p<0.0001$ in 2011) and $8 \%(2012$, $p<0.0001$ ) higher compared to the plots cut once a year (Figure 2.4, b). 




\section{a)}

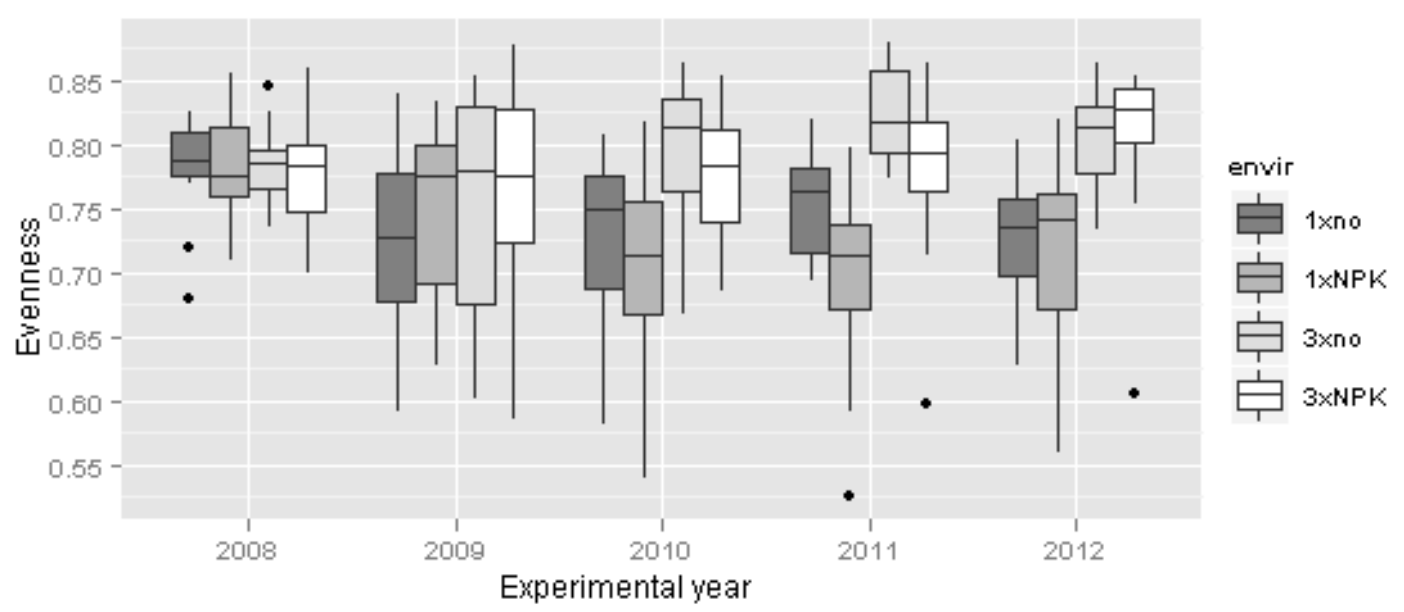

b)

Figure 2.4: Change in species evenness in three sward types (a) $(n=18$, average of vegetation surveys from May and September) and management systems (b) ( $n=24$, average of vegetation surveys from May and September) in corresponding experimental years. Sward types are abbreviated here as following: Con stands for control sward, Dic- for dicot-reduced sward, Mon- for monocot-reduced swards.

The herbicide effects on sward composition lasted up to three years after the removal treatment (Table 2.1 \& Fig. 2.5) whereas in the last two experimental years we found that the functional group composition did not differ significantly between the sward types and came close to the initial composition of the set-up year (73\% grasses, $25 \%$ herbs and $1-2 \%$ legumes in 2012 versus $75.5 \%$ grasses, $21.7 \%$ herbs and $2.8 \%$ legumes, mean overall shares across all plots for corresponding year, for each group respectively). 
Table 2.1: Means (medians for legumes) and standard deviations (median deviations) for biomass shares (\%) of grasses, herbs and legumes in corresponding sward types. Asterisks indicate significant differences from the control sward with the following significance values: . $p<0.05,{ }^{*} p<0.01,{ }^{* *} p<0.001,{ }^{* * *} p<0.0001$.

\begin{tabular}{lllll}
\hline & Functional & Control & -Dic sward & -Mon sward \\
\hline 2008 & Grasses & $74.8 \pm 4.8$ & $75.6 \pm 6.6$ & $76.2 \pm 4.5$ \\
& Herbs & $22.4 \pm .6$ & $21.6 \pm 4.5$ & $21.2 \pm 4.2$ \\
\multirow{2}{*}{2009} & Grasses & $69.9 \pm 7.1$ & $90.6 \pm 4.1$ & $43.6 \pm 7.7^{* * *}$ \\
& Herbs & $26.3 \pm 6.9$ & $9.3 \pm 4.0^{* * *}$ & $49.6 \pm 6.4^{* * *}$ \\
& Legumes & $3.8 \pm 2.7$ & $0.1 \pm 0.1^{* * *}$ & $6.8 \pm 3.6^{* * *}$ \\
& Herbs & $32.8 \pm 7.0$ & $21.8 \pm 7.7$ & $48.7 \pm 7.9^{* * *}$ \\
& Legumes & $1.5 \pm 1.9$ & $0.2 \pm 0.77^{* * *}$ & $2.0 \pm 3.1{ }^{* * *}$ \\
& Herbs & $26.9 \pm 9.0$ & $25.3 \pm 9.7$ & $29.9 \pm 10.1$. \\
& Legumes & $1.4 \pm 1.6$ & $0.5 \pm 1.0 * *$ & $2 \pm 2.4$ \\
& Grasses & $73.1 \pm 8.8$ & $71.8 \pm 10.4$ & $72.2 \pm 9.7$ \\
& & & & \\
& Legumes & $1.6 \pm 1.2$ & $0.6 \pm 0.9 * *$ & $1.9 \pm 1.9$ \\
\hline
\end{tabular}

While in the first year after the removal treatment the shares of grasses, herbs and legumes were significantly different from those of the initial composition (Table 2.1), in the second year after herbicide application (2010) in the dicot-reduced sward type herbs gained about $12 \%$ compared to the shares in 2009 at the expense of the average shares of grasses, which were reduced by $12 \%$ compared to the year 2009 as well (Fig. 2.5, a, b and c). Fertilization and cutting frequency had significant effects on the shares of grasses, herbs and legumes regarding the whole experimental period. Fertilization generally increased shares of grasses by $4.9 \%$ compared to unfertilized plots $(p<0.0001)$ and reduced the shares of herbs by $3.8 \%$ on average compared to unfertilized plots $(p<0.0001)$. Increasing cutting frequency promoted larger shares of herbs compared to the plots cut once a year by $2 \%$ on average $(p<0.0001)$ and decreased shares of grasses by $3.7 \%(p<0.001)$. There were on average $1 \%$ less legumes in the fertilized than unfertilized plots $(p<0.0001)$ and $1.6 \%$ more legumes on plots cut three times a year compared to the plots cut once a year $(p<0.0001)$. 


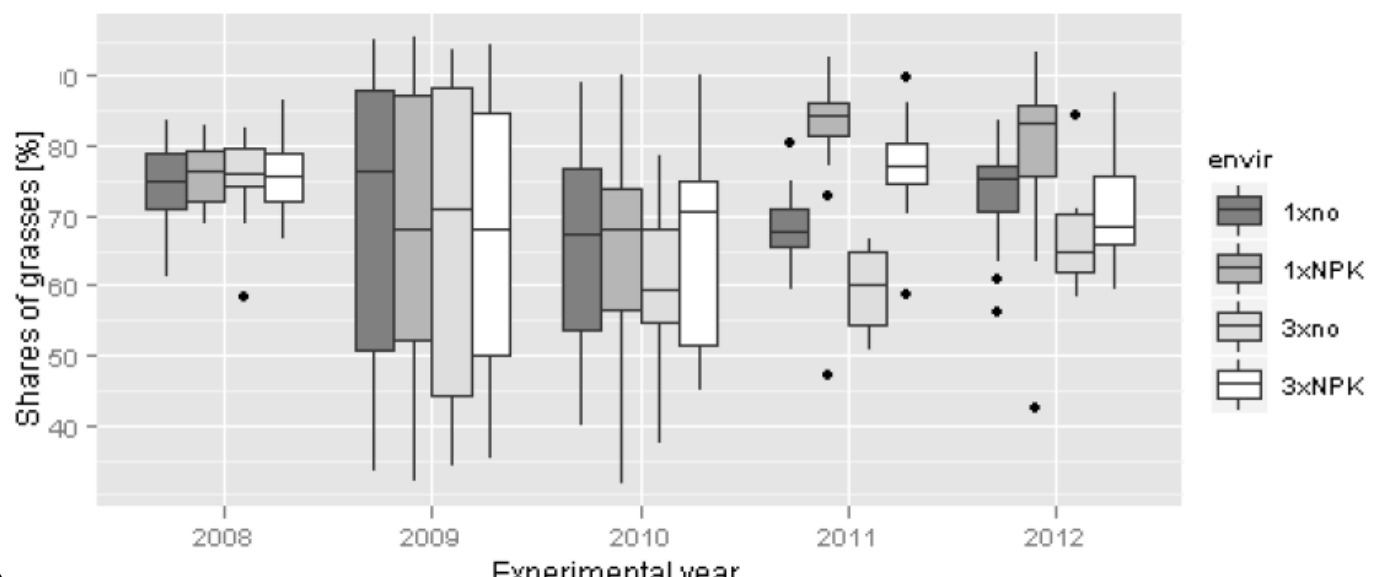

a)

Experimental year

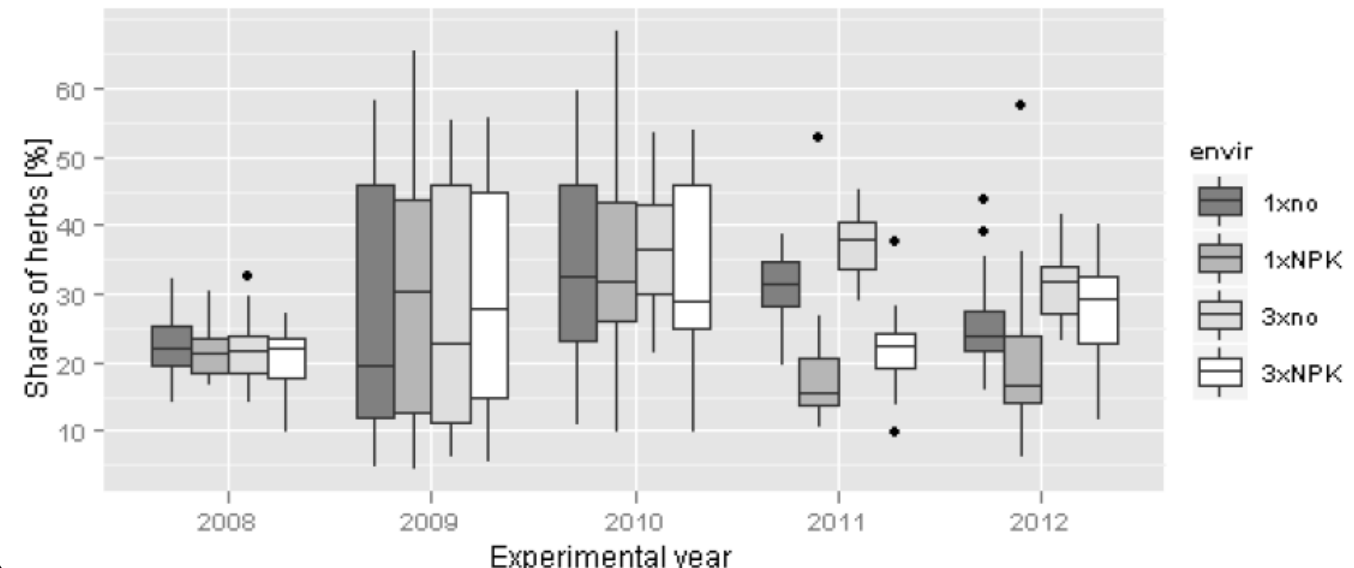

b)

Experimental year

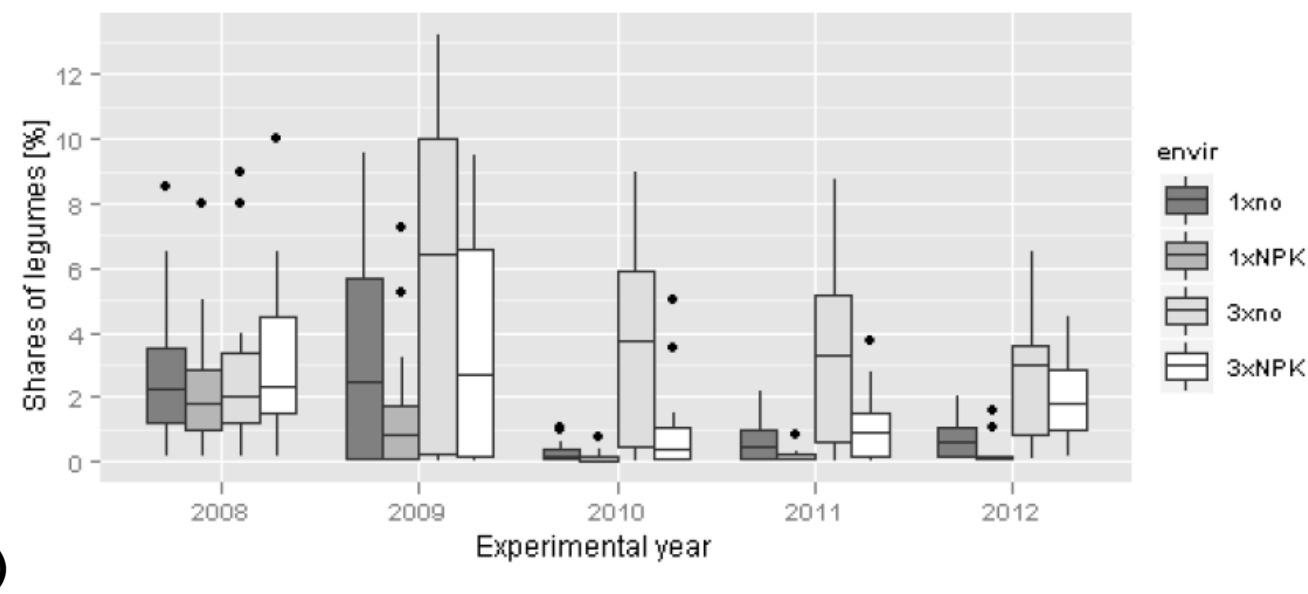

Figure 2.5: Change in shares of functional groups (grasses (a), herbs (b) and legumes (c)) in corresponding management systems over the five experimental years.

Biomass production over the whole investigation period was not affected by overall species richness, except for a marginal effect of the interaction between species richness and sward type $(p<0.1)$. There was only a trend of a significant correlation found between the above-ground biomass production and the Shannon diversity 
index $(p=0.05)$. Species evenness was slightly positively correlated with productivity $(p<0.001)$, except for the year 2011 when the relationship between species evenness and productivity was significantly negative $(p<0.05)$. In presence of other experimental factors, however, species evenness was only marginally related to above-ground biomass production $(p=0.1)$.

The main factors determining the above-ground biomass production were fertilization and cutting frequency, as well as the combination of both factors. Increasing the fertilizer input and cutting frequency, we found an increase in biomass production (Table 2.2) irrespective of the sward types. Sward type was only a significant determinant of above-ground biomass production in the year 2010, when the summer conditions before the cutting event in July were characterized by particularly warm temperatures and scarce amounts of precipitation.

Table 2.2: Percent variance in above-ground biomass production explained for the experimental years 2009-2012 based on linear models with block and row as spatial factors. Asterisks indicated significant levels as following: ${ }^{*} p<0.01,{ }^{* *} p<0.001,{ }^{* * *} p<0.0001$.

\begin{tabular}{|c|c|c|c|c|}
\hline Experimental factors & 2009 & 2010 & 2011 & 2012 \\
\hline Block & 1.67 & 3.96 ** & 1.36 & $1.45^{\star}$ \\
\hline Row & 2.73 & $5.0 * *$ & 1.9 & $1.9^{*}$ \\
\hline Sward type & 0.19 & 2.34 ** & 0.16 & 0.19 \\
\hline Fertilization & $58.47^{\star \star *}$ & 34.92 *** & $81.26^{\star \star \star}$ & $41.89^{\star \star \star}$ \\
\hline Cutting frequency & $10.35^{\star \star \star}$ & 24.71 *** & $1.34^{\star}$ & $26.35^{\star \star \star}$ \\
\hline Fertilization:Cutting frequency & $8.62 * \star \star$ & $16.96 * * \star$ & $4.09 * * \star$ & $22.02^{\star \star \star}$ \\
\hline Residuals & 17.96 & 12.11 & 11.24 & 6.2 \\
\hline
\end{tabular}

Intensification of management had significant effects on the biomass production with the plots cut three times a year and fertilized having the highest dry matter yields in all of the experimental years following the set-up of the experiment (Fig. 2.6). In 2009 and 2011, we also found that the biomass yields of plots cut once a year and fertilized were significantly higher than in 2010 and 2012. 




Figure 2.6: Overall dry-matter yields (average of 24 plots) in four management systems (1xno, 1xNPK, 3xno, $3 \times$ NPK) over the whole experimental period. 


\section{Discussion}

In the present study, we investigated the effects of diversity and management on above-ground biomass production in a semi-natural temperate grassland. We found that changes in sward composition associated with functional groups removal lasted for three years and affected the shares of grasses, herbs and legumes, as well as species evenness, while dynamics of species richness varied across the sward types and years. Overall species richness was not directly associated with an increase or loss of productivity regarding the whole experimental period while species evenness had a slight correlation with above-ground biomass production, direction and degree of which varied across the years. The primary determinants of an increase in biomass production were fertilization and cutting frequency with the highest dry matter yields characteristic for intensively managed plots. Sward type had a significant effect on above-ground biomass production only in the year with extremely dry summer conditions. After five years of establishing the experiment, the change in species numbers across the management systems of this grassland was not dramatic, with even a slightly higher number of species in most of the plots compared to the initial investigation year.

\section{a. Changes in plant species richness}

Given the site characteristics, the experimental design represented the most typical management strategies in common temperate agriculturally-used grasslands. It was previously found that the major agricultural changes have occurred in the second half of the twentieth century and were diminishing after the 1990 (de Snoo et al. 2012, Wesche et al. 2012). We assume that the species composition of this seminatural grassland was highly adapted to the local environmental factors at the setup of the experiment and the changes mediated by the removal of functional groups, fertilization and cutting frequency could successfully reflect the dynamic of species changes in temperate grasslands under corresponding management intensification.

While the dynamics of species gains and losses varied across all experimental years, the average species numbers recorded in the fifth year were higher than at the set-up of the experiment. 
Depending on the state of the plant community and levels of nutrient input, it was found by some authors that fertilization can reduce the species number (Lepš 2004), but it may also have no significant effect on the species number and composition (Pavlů et al. 2012). While the overall species number fluctuated across the experimental years, some of the species that disappeared initially after the removal treatment were found again in the year 2011 as the herbicide effects were weakening. We also found the number of species to fluctuate slightly across the years in the control plots as well. In the study by Marini et al. (2007) both field management and soil fertility were along with topography the main determinants of vascular species richness. We suggest that the long history of use of this grassland for hay cutting and pasture was the primary determinant of the present species composition and the site conditions apparently allowed for the higher levels of above-ground biomass production than at the set-up year of the experiment (about $420 \mathrm{~g} / \mathrm{m}^{2}$ on average across all plots at the harvest in the end of June) without significant changes in species numbers. While in short-term synthetic communities biomass production may be affected by initial species abundances (Jiang et al. 2009) it seems that in real-world grasslands the natural variation of species dynamics is also important for above-ground biomass production. We conclude that at our study site changes in overall species numbers were not dramatic after five experimental years and fluctuations in species composition seem normal.

b. Changes in sward composition: functional groups shares and species evenness

Along with the changes in species numbers, the removal treatment proved to be successful regarding the shares of the three functional groups (for detailed description of the results see Petersen et al. 2012). While the immediate effects of removal of dicot- and monocot- species on the shares of grasses and herbs were significant, three years after herbicide application the changes in sward composition were weakening and disappeared by the fourth year.

Nevertheless, we found significantly larger shares of grasses in fertilized plots and significantly larger shares of herbs in plots cut three times even in the last observation period, suggesting that along with high natural resilience of this grassland's species composition, management matters for the sward diversity. 
It was previously found that the productivity of plots within natural vegetation was related more to the relative composition of species (evenness) than to the number of species, with predominantly negative relationships between the two variables (Laird et al. 2003, Mulder et al. 2004). In our study, there was a significantly positive correlation between species evenness and productivity found, but the degree and the direction of this correlation varied across the years while the effects of the main experimental factors (fertilization, cutting frequency and sward type) had various effects on species evenness as well. We suggest that when a positive relationship was found between species evenness and productivity (e.g. in the years 2010 and 2012), the sward composition at our site became more even, productive species took advantage of an increased nutrient input, but not at the expense of limiting growth of the less-dominant species. It seems that in this grassland coexistence of the characteristic matrix of large productive grasses (Dactylis glomerata, Lolium perenne) and shorter sub-dominant grasses (Agrostis capillaris, Festuca rubra) and herbs (Veronica chamaedrys, Ranunculus repens) was possible also under increased fertilization levels. It was previously shown that species composition might be highly variable and changes according to the environmental conditions while species richness stays within narrow limits (Brown et al. 2001). Interestingly, in our study the species composition of most plots did not differ significantly after five years compared to the initial composition suggesting that this grassland remained rather stable concerning the species richness reaction on mid-term (multivariate analysis of the vegetation composition performed with Canoco (ter Braak and Smilauer 2002) revealed a short gradient of the variation of vegetation relevés in the dataset for the whole investigation period, data not shown).

c. Diversity-productivity relationship in a real-world grassland Our results suggest that the absence of a direct effect of species richness on aboveground biomass production regarding the whole investigation time-period is the result of multiple direct and indirect effects of fertilization, sward composition and cutting frequency. In the year 2010, however, the sward diversity had an effect on the biomass production, and it might be due to combination of still pronounced differences in the sward diversity and better nitrogen use efficiency in the control sward (as shown by Keuter et al. 2012). Laird et al. (2003) considered that the absence of a relationship between diversity and productivity in an old field might have been due to competitive dominance causing deterministic structuring of the 
vegetation composition. Jiang et al. (2009) compared the findings from synthetic and natural communities and suggested that reduction in diversity in a natural community does not necessarily result in the reduced presence of productive species, thus a negative effect of reduced diversity on productivity may not apply. We could not find any consistent effects of diversity on productivity across the experimental years. While dominant species are the most important factors in determining ecosystem processes and properties (Grime 1998, Mokany et al. 2008), it seems that their contribution to the above-ground biomass production did not cause a reduction of the numbers of less-dominant species in this grassland and the effects of species richness on productivity were therefore not significant.

In line with the results reported by Assaf et al. (2011) who found that species richness poorly explained productivity in managed grasslands, we found that species number had no direct effects on the above-ground biomass production only and that sward diversity had a positive effect on biomass production in the year 2010 when the control swards had higher dry-matter yields compared to the further two sward types. Keuter et al. (2012) found in the year 2010 a better $\mathrm{N}$-use efficiency in the control sward plots which may have improved biomass production under the exceptionally dry summer months. Bernhardt-Römermann et al. (2011) investigated the effects of climate, species and functional diversity on the biomass yields in temperate environments and found that the importance of each factor depended on the nutrient status and management frequency of the system.

In our study, fertilization and cutting frequency were the determining factors of productivity. We suppose that in the dry summer period 2010 the not disturbed shares of grasses, herbs and legumes in the control sward composition might have compensated in terms of yield production for the reduced effects of fertilizer under drought conditions.

d. Need for more biodiversity experiments in real-world grasslands?

On the one hand, the needs for agricultural production in Europe are still growing and large areas of temperate grasslands are needed as the primary source of forage for cattle and other grazing animals, which drives the attention to maximizing their production potential. Such grasslands, however, are mostly represented by relatively species-poor mixtures sown on highly fertilized arable land. On the other hand, species-rich grasslands often receive a special status of high biodiversity value and are not used for agricultural practices anymore. 
Changes in species diversity do not only directly influence the ecosystem processes but have also direct links to ecosystem services, resilience of the ecosystem and resistance to disturbance (Chapin et al. 2000).

Managing for improved biodiversity and for conservation is particularly challenging in agriculturally used areas (Hopkins and Holz 2006). And while experimental grasslands can on the one hand sometimes offer more insights into the functioning of the ecosystems (e.g. Spehn et al. (Spehn et al. 2000) who reported that in experimental grassland communities mixtures perform better than monocultures suggesting complementary resources use), effects of realistic species losses can be studies better in removal experiments (Diaz et al. 2003, Jiang et al. 2009).

Therefore, it is particularly important to study the patterns of diversity effects on ecosystem functioning in the real-world ecosystems.

\section{e. Implications for agricultural land use}

Our results suggest that with proper management strategies, providing sufficient resources for the least-productive species, it is possible to maintain high productivity without losing plant species. Increasing cutting frequency, for instance, promoted species gains over the years compared to the plots cut only once a year in our study. Previous work has indicated that extensification might not be an adequate measure to increase grassland diversity (Schmid 2002).

The studied grassland ecosystem was quite resilient and after disturbance bounced back to the original state of its long- term well-tried functional group composition while an increase of above-ground biomass production was mainly achieved by an appropriate management without a trade-off of losing diversity. Weigelt et al. (2009), as well as Tilman et al. (2012) found recently that the use of diverse mixtures might be more effective in increasing grassland productivity of some crops than fertilization and may provide better ecosystem services. We found that at least on a mid-term basis it was possible to improve productivity of an old grassland and even gain new species through management adapted to the site conditions without the need of reseeding it with diverse species mixtures. The high nature value of this really long-term grassland system might thus be even higher, especially regarding its capacity for carbon storage, for example, provided the soil is not disturbed by plowing activities. 


\section{References}

Adler, P. B., E. W. Seabloom, E. T. Borer, H. Hillebrand, Y. Hautier, A. Hector, W. S. Harpole, L. R. O’Halloran, J. B. Grace, and T. M. Anderson. 2011. Productivity is a poor predictor of plant species richness. Science 333:1750-1753.

Assaf, T., W. Beyschlag, and J. Isselstein. 2011. The relationship between plant diversity and productivity in natural and in managed grasslands.

Bernhardt-Römermann, M., C. Römermann, S. Sperlich, and W. Schmidt. 2011. Explaining grassland biomass-the contribution of climate, species and functional diversity depends on fertilization and mowing frequency. Journal of Applied Ecology 48:1088-1097.

Brown, J. H., S. M. Ernest, J. M. Parody, and J. P. Haskell. 2001. Regulation of diversity: maintenance of species richness in changing environments. Oecologia 126:321-332.

Cardinale, B. J., J. P. Wright, M. W. Cadotte, I. T. Carroll, A. Hector, D. S. Srivastava, M. Loreau, and J. J. Weis. 2007. Impacts of plant diversity on biomass production increase through time because of species complementarity. Proceedings of the National Academy of Sciences of the United States of America 104:18123-18128.

Chapin, F. S., E. S. Zavaleta, V. T. Eviner, R. L. Naylor, P. M. Vitousek, H. L. Reynolds, D. U. Hooper, S. Lavorel, O. E. Sala, S. E. Hobbie, M. C. Mack, and S. Diaz. 2000. Consequences of changing biodiversity. Nature 405:234-242.

Critchley, C., M. Burke, and D. Stevens. 2004. Conservation of lowland semi-natural grasslands in the UK: a review of botanical monitoring results from agrienvironment schemes. Biological Conservation 115:263-278.

de Snoo, G. R., N. Naus, J. Verhulst, J. Ruijven, and A. P. Schaffers. 2012. Long-term changes in plant diversity of grasslands under agricultural and conservation management. Applied Vegetation Science 15:299-306.

Diaz, S., A. J. Symstad, F. S. Chapin, D. A. Wardle, and L. F. Huenneke. 2003. Functional diversity revealed by removal experiments. Trends in Ecology \& Evolution 18:140-146.

Grime, J. P. 1998. Benefits of plant diversity to ecosystems: immediate, filter and founder effects. Journal of Ecology 86:902-910. 
Hector, A., and R. Bagchi. 2007. Biodiversity and ecosystem multifunctionality. Nature 448:188-190.

Hector, A., B. Schmid, C. Beierkuhnlein, M. C. Caldeira, M. Diemer, P. G. Dimitrakopoulos, J. A. Finn, H. Freitas, P. S. Giller, J. Good, R. Harris, P. Högberg, K. Huss-Danell, J. Joshi, A. Jumpponen, C. Körner, P. W. Leadley, M. Loreau, A. Minns, C. P. H. Mulder, G. O'Donovan, S. J. Otway, J. S. Pereira, A. Prinz, D. J. Read, M. Scherer-Lorenzen, E.-D. Schulze, A.-S. D. Siamantziouras, E. M. Spehn, A. C. Terry, A. Y. Troumbis, F. I. Woodward, S. Yachi, and J. H. Lawton. 1999. Plant Diversity and Productivity Experiments in European Grasslands. Science 286:1123-1127.

Hodgson, J., G. Montserrat-Martı, J. Tallowin, K. Thompson, S. Diaz, M. Cabido, J. Grime, P. Wilson, S. Band, and A. Bogard. 2005. How much will it cost to save grassland diversity? Biological Conservation 122:263-273.

Hopkins, A., and B. Holz. 2006. Grassland for agriculture and nature conservation: production, quality and multi-functionality. Agronomy Research 4:3-20.

Huston, M. A., L. W. Aarssen, M. P. Austin, B. S. Cade, J. D. Fridley, E. Garnier, J. P. Grime, J. Hodgson, W. K. Lauenroth, K. Thompson, J. H. Vandermeer, and D. A. Wardle. 2000. No consistent effect of plant diversity on productivity. Science 289:1255.

Isbell, F. I., H. W. Polley, and B. J. Wilsey. 2009. Biodiversity, productivity and the temporal stability of productivity: patterns and processes. Ecology Letters 12:443-451.

Jiang, L., S. Q. Wan, and L. H. Li. 2009. Species diversity and productivity: why do results of diversity-manipulation experiments differ from natural patterns? Journal of Ecology 97:603-608.

Kahmen, A., J. Perner, and N. Buchmann. 2005. Diversity-dependent productivity in semi-natural grasslands following climate perturbations. Functional Ecology 19:594-601.

Keuter, A., I. Hoeft, E. Veldkamp, and M. Corre. 2012. Nitrogen response efficiency of a managed and phytodiverse temperate grassland. Plant and Soil 364:193206.

Klapp, E., and A. Stählin. 1936. Standorte, Pflanzengesellschaften und Leistung des Grünlandes. Stuttgart: Ulmer. 
Laird, R., J. Pither, and L. Aarssen. 2003. Species evenness, not richness, has a consistent relationship with productivity in old-field vegetation. Community Ecology 4:21-28.

Lepš, J. 2004. What do the biodiversity experiments tell us about consequences of plant species loss in the real world? Basic and Applied Ecology 5:529-534.

Loreau, M., S. Naeem, P. Inchausti, J. Bengtsson, J. P. Grime, A. Hector, D. U. Hooper, M. A. Huston, D. Raffaelli, B. Schmid, D. Tilman, and D. A. Wardle. 2001. Ecology - Biodiversity and ecosystem functioning: Current knowledge and future challenges. Science 294:804-808.

Marini, L., M. Scotton, S. Klimek, J. Isselstein, and A. Pecile. 2007. Effects of local factors on plant species richness and composition of Alpine meadows. Agriculture, ecosystems \& environment 119:281-288.

McLaren, J. R., and R. Turkington. 2010. Ecosystem properties determined by plant functional group identity. Journal of Ecology 98:459-469.

Mokany, K., J. Ash, and S. Roxburgh. 2008. Functional identity is more important than diversity in influencing ecosystem processes in a temperate native grassland. Journal of Ecology 96:884-893.

Mulder, C., E. Bazeley-White, P. Dimitrakopoulos, A. Hector, M. Scherer-Lorenzen, and B. Schmid. 2004. Species evenness and productivity in experimental plant communities. Oikos 107:50-63.

Naeem, S., J. E. Duffy, and E. Zavaleta. 2012. The functions of biological diversity in an age of extinction. Science 336:1401-1406.

Pavlů, V., J. Gaisler, L. Pavlů, M. Hejcman, and V. Ludvíková. 2012. Effect of fertiliser application and abandonment on plant species composition of Festuca rubra grassland. Acta Oecologica 45:42-49.

Petersen, U., N. Wrage, L. Köhler, C. Leuschner, and J. Isselstein. 2012. Manipulating the species composition of permanent grasslands-A new approach to biodiversity experiments. Basic and Applied Ecology 13:1-9.

Pinheiro, J., D. Bates, S. DebRoy, and D. Sarkar. 2010. the R Core team (2009) nlme: Linear and Nonlinear Mixed Effects Models. R package version 3.1-96. R Foundation for Statistical Computing, Vienna.

Proulx, R., C. Wirth, W. Voigt, A. Weigelt, C. Roscher, S. Attinger, J. Baade, R. L. Barnard, N. Buchmann, and F. Buscot. 2010. Diversity promotes temporal 
stability across levels of ecosystem organization in experimental grasslands. Plos One 5:e13382.

R-Development-Core-Team. 2012. R: A language and environment for statistical computing. $\mathrm{R}$ foundation for statistical computing. Vienna, Austria,.

Reich, P. B., D. Tilman, F. Isbell, K. Mueller, S. E. Hobbie, D. F. Flynn, and N. Eisenhauer. 2012. Impacts of biodiversity loss escalate through time as redundancy fades. Science 336:589-592.

Roscher, C., V. M. Temperton, M. Scherer-Lorenzen, M. Schmitz, J. Schumacher, B. Schmid, N. Buchmann, W. W. Weisser, and E. D. Schulze. 2005. Overyielding in experimental grassland communities-irrespective of species pool or spatial scale. Ecology Letters 8:419-429.

Sala, O. E., F. S. Chapin, J. J. Armesto, E. Berlow, J. Bloomfield, R. Dirzo, E. HuberSanwald, L. F. Huenneke, R. B. Jackson, A. Kinzig, R. Leemans, D. M. Lodge, H. A. Mooney, M. Oesterheld, N. L. Poff, M. T. Sykes, B. H. Walker, M. Walker, and D. H. Wall. 2000. Biodiversity - Global biodiversity scenarios for the year 2100. Science 287:1770-1774.

Sanderson, M., R. Skinner, D. Barker, G. Edwards, B. Tracy, and D. Wedin. 2004. Plant species diversity and management of temperate forage and grazing land ecosystems. Crop Science 44:1132-1144.

Scherber, C., Ripley B.D., Venables, W.N. 2011. StepAICc procedure for Ime models. Adjusted to work for Im, glm and Ime models.

Schmid, B. 2002. The species richness-productivity controversy. Trends in Ecology \& Evolution 17:113-114.

Schmid, B., and A. Hector. 2004. The value of biodiversity experiments. Basic and Applied Ecology 5:535-542.

Spehn, E., J. Joshi, B. Schmid, M. Diemer, and C. Korner. 2000. Above-ground resource use increases with plant species richness in experimental grassland ecosystems. Functional Ecology 14:326-337.

Symstad, A. J., and D. Tilman. 2001. Diversity loss, recruitment limitation, and ecosys-tem functioning: lessons learned from a removal experiment. Oikos 3:424-435.

ter Braak, C., and P. Smilauer. 2002. CANOCO reference manual and user's guide to Canoco for Windows: software for canonical community ordination (version 4.5). Microcomputer Power, Ithaca, New York, USA. 
Tilman, D., P. B. Reich, and F. Isbell. 2012. Biodiversity impacts ecosystem productivity as much as resources, disturbance, or herbivory. Proceedings of the National Academy of Sciences 109:10394-10397.

Tilman, D., P. B. Reich, J. Knops, D. Wedin, T. Mielke, and C. Lehman. 2001. Diversity and productivity in a long-term grassland experiment. Science 294:843-845.

Tylianakis, J. M., T. A. Rand, A. Kahmen, A. M. Klein, N. Buchmann, J. Perner, and T. Tscharntke. 2008. Resource heterogeneity moderates the biodiversityfunction relationship in real world ecosystems. Plos Biology 6:947-956.

Wardle, D. A., K. I. Bonner, G. M. Barker, G. W. Yeates, K. S. Nicholson, R. D. Bardgett, R. N. Watson, and A. Ghani. 1999. Plant Removals in Perennial Grassland: Vegetation Dynamics, Decomposers, Soil Biodiversity, and Ecosystem Properties. Ecological Monographs 69:535-568.

Weigelt, A., W. W. Weisser, N. Buchmann, and M. Scherer-Lorenzen. 2009. Biodiversity for multifunctional grasslands: equal productivity in high-diversity low-input and low-diversity high-input systems. Biogeosciences 6:1695-1706.

Wesche, K., B. Krause, H. Culmsee, and C. Leuschner. 2012. Fifty years of change in Central European grassland vegetation: Large losses in species richness and animal-pollinated plants. Biological Conservation 150:76-85.

Wilsey, B. J., and H. W. Polley. 2004. Realistically low species evenness does not alter grassland species-richness-productivity relationships. Ecology 85:26932700.

Wrage, N., J. Strodthoff, H. Cuchillo, J. Isselstein, and M. Kayser. 2011. Phytodiversity of temperate permanent grasslands: ecosystem services for agriculture and livestock management for diversity conservation. Biodiversity and Conservation 20:3317-3339.

Yang, Z., J. van Ruijven, and G. Du. 2011. The effects of long-term fertilization on the temporal stability of alpine meadow communities. Plant and Soil 345:315-324.

Zavaleta, E. S., and K. B. Hulvey. 2004. Realistic species losses disproportionately reduce grassland resistance to biological invaders. Science 306:1175-1177.

Zavaleta, E. S., J. R. Pasari, K. B. Hulvey, and G. D. Tilman. 2010. Sustaining multiple ecosystem functions in grassland communities requires higher biodiversity. Proceedings of the National Academy of Sciences 107:14431446. 


\section{ChAPTER 3}

SLUG RESPONSES to GRASSLAND CUTTING AND

Fertilizer ApPlication Under Plant

Functional Group Removal

Georg Everwand, Christoph Scherber \& Teja Tscharntke



In: Acta Oecologica 2013, Volume 48, Pages 62-68

http://dx.doi.org/10.1016/j.actao.2013.01.015 


\section{Abstract}

Current studies on trophic interactions in biodiversity experiments have largely relied on artificially sown gradients in plant diversity, but removal experiments with their more natural plant community composition are more realistic.

Slugs are a major part of the invertebrate herbivore community, with some species being common pests in agriculture. We therefore investigated how strongly slugs are influenced by grassland management, plant biodiversity and composition.

Here we analysed the effects of cutting frequency, fertilizer application and plant functional group composition on slug densities and their contribution to herbivory on Rumex acetosa in a removal experiment within a $>100$-year old grassland in Northern Germany.

The experiment was laid out as a latin rectangle with full factorial combinations of (i) plant functional group removal (3 levels) using herbicides, (ii) fertilizer application (2 levels) and (iii) cutting frequency (2 levels). The resulting 12 treatment combinations were replicated 6 times, resulting in 72 plots.

We collected a total of 1020 individuals belonging to three species Arion distinctus (60.4\% of individuals), Deroceras reticulatum (34.7\%) and Arion lusitanicus (4.9\%) using a cover board technique and additionally measured herbivore damage to R. acetosa.

We found the highest slug abundance on plots with a low cutting frequency and high food resource availability (increased cover of forbs and taller vegetation).

Fertilizer application had no significant effect on slug abundance, but caused higher herbivore damage to on $R$. acetosa, possibly as a result of increased tissue quality. The negative effect of higher cutting frequency on slug abundance was lowest in control plots with their naturally developed graminoid-forb communities (cutting reduced slug density by $6 \%$ in the control vs. $29 \%$ in herbicide plots). Our experiments therefore support the idea that more natural plant species compositions reduce the impact of disturbances (e.g. through cutting or grazing) on invertebrates.

Keywords: biodiversity experiment, management intensity, mollusc, gastropod, mowing, invertebrate 


\section{Introduction}

In temperate agricultural grassland ecosystems, invertebrates are often the dominant herbivores (Stein et al., 2010) and slugs (Mollusca: Gastropoda) are a major component of this invertebrate community. In addition, many slug species (e.g. Deroceras reticulatum (O. F. MüLlER, 1774) or Arion lusitanicus (MOQUIN-TANDON, 1855)) are considered important crop pests in agriculture, causing severe damage, e.g. in oilseed rape fields (Frank, 1998b). D. reticulatum can shift community composition towards graminoids, due to its preference for forbs (Allan and Crawley, 2011) and nitrogen-rich plants such as Trifolium spp., whereas graminoids such as Dactylis glomerata (L.) are mostly avoided (Cottam, 1986). Exclusion experiments (Curry, 1994; del-Val and Crawley, 2004; Scheidel and Bruelheide, 2005; Scherber et al., 2003; Scherber et al., 2006) have shown that slugs can strongly affect plant biomass production and species composition in grasslands. Plant functional group removal experiments using herbicides (e.g. to promote forbs versus graminoids for conservation) have often demonstrated a positive effect of forb species enhancement on invertebrates (Blake et al., 2011).

However, little is known about the combined effects of plant functional group composition and grassland management on slug densities. In particular, the effects of functional group removal in mature grassland are largely unexplored. Most experiments to date have relied on artificially sown gradients in plant diversity (e.g. "Jena-Experiment" (Roscher et al., 2004), Cedar Creek (Tilman et al., 2012), while other long-term grassland experiments (e.g. Rengen Grassland Experiment) have only studied the effects of fertilizer application and cutting frequency (Pavlů et al., 2011), but have not experimentally manipulated composition.

Here, we present results from a large-scale grassland management and plant functional group removal experiment ("GrassMan" experiment; (Petersen et al., 2012)), where a control was compared to either forb or graminoid reduced plant communities (both induced by application of specific herbicides). In addition, cutting frequency and nutrient availability were experimentally manipulated. 
We hypothesize that:

I. Slug abundance is higher in forb- than graminoid-dominated plant communities, due to the greater availability of preferentially consumed herbaceous plants (Briner and Frank, 1998).

II. Slug abundance is decreased under three-cut in comparison to one-cut management, because cutting reduces standing plant biomass and slugs prefer humid and high-biomass habitats (Ondina et al., 2004; Rathcke, 1985).

III. The negative effects of cutting frequency on slug abundance are lower in more natural plant communities (control plots), because the plant community and slugs are well suited to the local conditions more resilient to disturbance (Tscharntke and Greiler, 1995). 


\section{Material and Methods}

\section{Site description}

This study was performed in 2010 as part of the "GrassMan"-Experiment (Petersen et al., 2012) near the town of Neuhaus (Solling) in the Solling Mountains, which are situated in Northern Germany (51440 N, $9^{\circ} 320$ E, 490 m a.s.I.).

The vegetation prior to the start of the experiment was a nutrient poor, moderately wet Lolio-Cynosuretum grassland with high abundances of Agrostis capillaris (L.), Festuca rubra (L.) and Rumex acetosa (L.), Veronica chamaedrys (L.) and Ranunculus repens (L.) (Petersen et al., 2012). Mean annual precipitation is 1028 $\mathrm{mm}$ and mean annual temperature is $6.9^{\circ} \mathrm{C}$ (Deutscher Wetterdienst, 1961-1990, station Holzminden-Silberborn, $440 \mathrm{~m}$ above sea level). In 2010, the year of the study, mean annual temperature was $8.0^{\circ} \mathrm{C}$ and annual precipitation was $1110 \mathrm{~mm}$. The dominant soil type in experimental area is a shallow $(40-60 \mathrm{~cm})$, stony Haplic Cambisol, developed on sediments of loess on the Middle Bunter (Triassic sandstone) formation with a loamy silt texture (Keuter et al., 2012).

The experiment was established in 2008 on permanent, formerly extensively cattlegrazed grassland and laid out as a three-factorial latin rectangle (Clewer and Scarisbrick, 2001) with the following factors (Fig. 3.1): (i) plant functional group removal (3 levels) using herbicides, (ii) fertilizer application (2 levels) and (iii) cutting frequency (2 levels), resulting in 12 treatment combinations. 


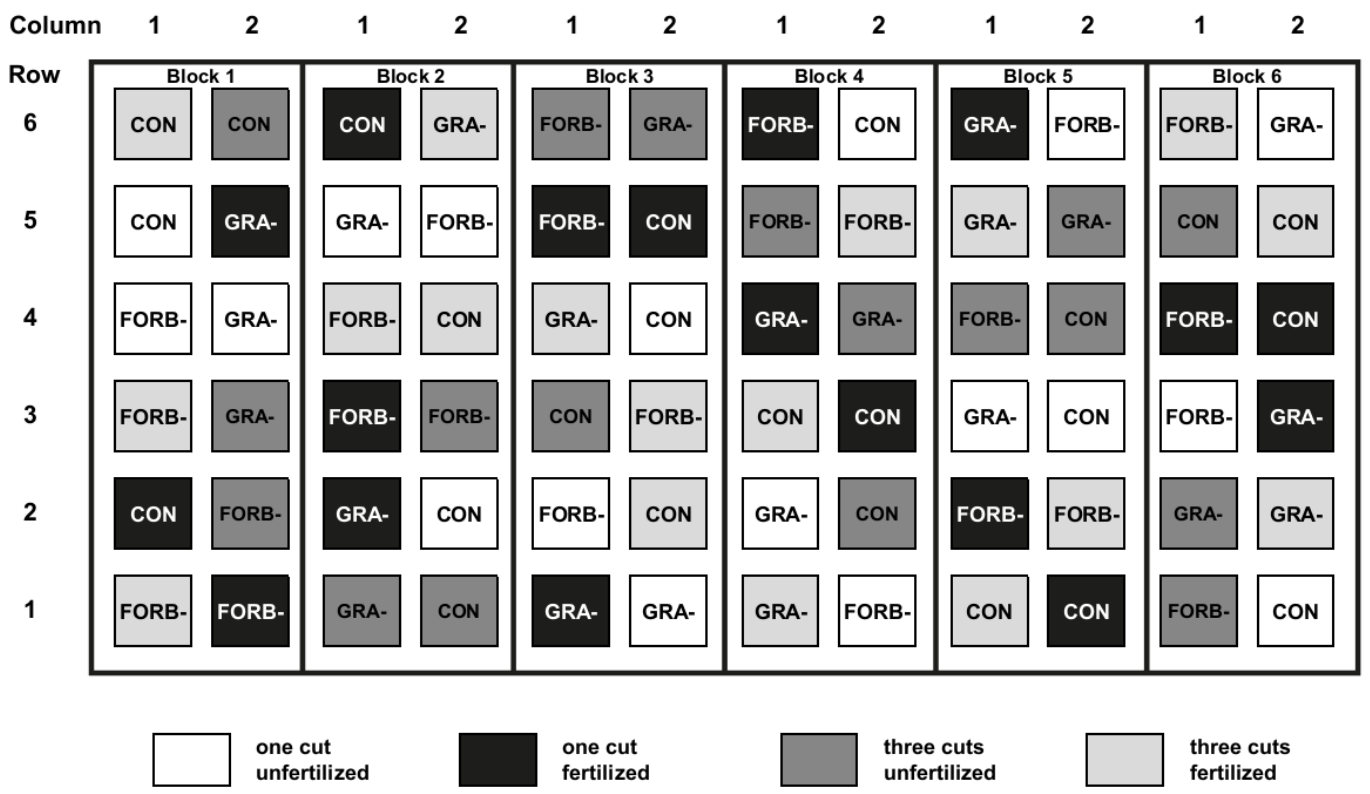

Fig.3.1: Experimental design of the Grassman Experiment, showing the Latin rectangle with 12 treatments in 6 replications. GRA- = graminoid reduced plots (=forb enhanced); FORB- =forb reduced (=graminoid enhanced); $\mathrm{CON}=$ Control (no herbicide application). The grey area around and between the plots is mown monthly. Plot size $15 \mathrm{~m} \times 15 \mathrm{~m}$, space between plots $3 \mathrm{~m}$, between blocks $5 \mathrm{~m}$.

To manipulate plant functional group presence, we applied (i) a combination of the forb-specific herbicides Fluroxypyr (Starane; Dow AgroSciences, Munich, Germany; $3 \mathrm{~L} \mathrm{ha}^{-1}$ ) and Mecoprop-P (Duplosan; KV, Du Pont de Nemours, Neu-Isenburg, Germany; $3 \mathrm{~L} \mathrm{ha}^{-1}$ ) or (ii) the graminoid-specific herbicide Select 240 EC (Stähler Int., Stade, Germany; $0.5 \mathrm{~L} \mathrm{ha}^{-1}$ ), resulting in three levels of plant diversity: i) forb reduced (=graminoid rich), ii) graminoid reduced (=forb rich) and iii) control. Herbicides were applied once in June 2008 ("pulse" experiment sensu Bender et al. (1984)). In 2009 and 2010, plots were treated with $\mathrm{N}$-fertilizer (Calcium ammonium nitrate N27: 13.5\% $\left.\mathrm{NH}_{4}-\mathrm{N}, 13.5 \% \mathrm{NO}_{3}-\mathrm{N}, 4 \% \mathrm{MgO}, 6 \% \mathrm{Ca}\right)$ at two equal doses $\left(2 \times 90 \mathrm{~kg} \mathrm{~N}^{-1}\right)$ in April and May/June; in addition, NPK-fertilized plots received $30 \mathrm{~kg} P$ per ha and 100 $\mathrm{kg} \mathrm{K}$ per ha in early June (Thomaskali®, $8 \% \mathrm{P}_{2} \mathrm{O}_{5}, 15 \% \mathrm{~K}_{2} \mathrm{O}, 20 \% \mathrm{CaO}$ ). On control plots we did not apply NPK-fertilizer. Plots were mown either once (in July) or three times a year (May, July, September) using a Haldrup ${ }^{\circledR}$ forage combine harvester (Inotec Engineering $\mathrm{GmbH}$, Ilshofen, Germany) at a cutting height of $7 \mathrm{~cm}$. The resulting 12 treatment combinations (equalling one block of the latin rectangle; Fig. 3.1) were arranged at random and replicated six times, resulting in 72 plots.

Each plot was a quadrat of $15 \mathrm{~m}$ side length and surrounded by at least $3 \mathrm{~m}$ of regularly mown area between the plots of a block and $5 \mathrm{~m}$ between two blocks. 
Note that plant functional groups were not entirely removed but strongly reduced in abundance, with slow recovery after herbicide application. However, even three years after herbicide application, all herbicide treatments significantly affected several vegetation parameters, such as compressed sward height, biomass, functional group composition and plant species richness (Table 3.1). For more details on the experimental design, setup and treatment effects on vegetation see Petersen et al. (2012) and Rose et al. (2012a; 2012b).

\section{Slug sampling}

Slugs were sampled using a cover board technique (Oggier et al., 1998; Severns, 2005 ) by placing a $50 \mathrm{~cm} \times 41.5 \mathrm{~cm}$ wooden board (Masonite with a thickness of $0.4 \mathrm{~cm}$ ) in the middle of each plot. While this sampling method excludes the subterranean component of slug populations (Hawkins et al., 1998) or small species (McCoy and Nudds, 1997), it has been proven to be a reliable measure of slug activity, abundance and species richness on the soil surface (Suominen et al., 2003). Since slugs prefer rather humid soil conditions (Ondina et al., 2004; Willis et al., 2008), sampling was performed in two cool and wet periods in early May and late September 2010. In each sampling period, wooden boards were left undisturbed for four weeks, allowing molluscs to seek shelter over an extensive time period.

Summer drought prevented us from sampling between May and September. At the end of both sampling periods, we collected all molluscs found within five minutes of intensive search in the dead vegetation and the upper soil (first 2-3 cm topsoil) and transferred them into ethanol $(70 \% \mathrm{w} / \mathrm{v})$ for later enumeration and identification.

We collected slugs only within one vegetation season, since slug abundance shows large inter-annual variation (Choi et al., 2004; Fabian et al., 2012), especially due to the diminishing effect of the sward composition treatment from 2011 to 2012.

Since we assumed slugs to have a large contribution to herbivory, we also measured rates of herbivory on $R$. acetosa, which was the locally most abundant forb species with an average $11.8 \%$ cover, on all 72 plots. We collected 20 leaves within the inner $\sim 150 \mathrm{~m}^{2}$ of the plot, each of a different plant with at least $50 \mathrm{~cm}$ distance to each other. All leaves were placed on an A4 sheet of paper and photographed from $1 \mathrm{~m}$ distance using a Canon PowerShot A620 (Canon Inc., Tokyo, Japan). 
Images were processed using the software LAMINA (Bylesjo et al., 2008) to measure the amount of leaf area damaged by invertebrate herbivores for each leaf.

We measured the average total area of damage, separately for leaf edges and leaf centre, since we expected slugs to have a large contribution to herbivore damage. We also recorded the number of cavities per leaf and calculated the percentage of the total leaf area damaged by herbivores.

\section{Assessment of vegetation parameters}

Because our treatments have the potential to affect vegetation structure (and support different mollusc densities), we additionally measured a series of vegetation parameters:

(i) we conducted vegetation surveys on two quadrats, each of $9 \mathrm{~m}^{2}$ size, to record the percentage cover and proportional yield of each species (Klapp and Stählin, 1936) twice a year (in May before the first harvest and in August) in each plot.

Plant species richness, functional group composition and presence-absence data of the functional groups (graminoids, legumes and other forbs) were derived from these data.

(ii) Plant aboveground biomass (AGB) was estimated as follows: First, fresh weight of two $1.50 \times 15 \mathrm{~m}$ strips per plot was measured using the harvester's built-in scale.

To determine the water content of this sample, we took four subsamples that were homogenized, weighed, dried for $48 \mathrm{~h}$ at $65^{\circ} \mathrm{C}$ and weighed again. We then multiplied fresh weight by water content to arrive at the total aboveground dry biomass ( $\mathrm{tha}^{-1}$ ) for every plot. Proportional biomass of grasses and herbs (\%) was determined by multiplying AGB with proportional yield values (derived as described above).

Harvest was performed on all plots once a year in the end of June and additionally for the 3-cut treatment in mid-May and mid-September (Petersen et al., 2012).

(iii) Compressed sward height $(\mathrm{cm})$ was measured using a rising plate meter constructed by Castle (1976) and the average value of 25 measures per plot was calculated. This was performed every 2-3 weeks, resulting in eleven time points across 2010. 
(iv) We also measured soil moisture content (\%) between early April and late September 2010 every 2-3 weeks, resulting in data for 10 time points. Soil moisture was expressed as gravimetric water content, determined by weight loss due to drying homogenized soil samples from the field at $105^{\circ} \mathrm{C}$ for 24 hours.

\section{Statistical Analysis}

We used the software package "R" (version 2.10.1) (R-Development-Core-Team, 2010) for data analysis. Two types of statistical models were fitted using generalized linear models (GLM); (Crawley, 2007) for both slug abundance and herbivory measures on $R$. acetosa:

(i) To analyze treatment effects, we fitted a model (hereafter referred to as design model) containing only row- and column effects (fitted as factors), sward composition (factor with three levels), cutting frequency and nutrient input.

(ii) To analyze effects of additional covariates (see below), we fitted a model hereafter referred to as the covariate model (Scherber et al., 2010), not containing treatment variables.

The covariate model was fitted using row- and column effects, plant diversity, harvested aboveground biomass (AGB), functional group biomasses, functional group presence-absence data, soil water content, compressed sward height and either herbivory measures or slug abundance, with up to 3-way-interactions. For count data, we used quasipoisson GLMs, for proportion data GLMs with a logit link were used (Warton and Hui, 2010) and continuous variables were log-transformed to account for overdispersion.

For each model a maximum model containing all possible terms was manually simplified into model subsets and we compared model subsets using F-tests, until a minimal adequate model that only contained significant effects was attained.

To allow at least a rough comparison of fit between models (unfortunately, AIC is not defined for quasipoisson models), we provide pseudo- $R^{2}$ (hereafter $p R^{2}$ ) values based on Heinzl (2003). Our comparisons showed that the fit of the minimum adequate slug abundance design model $\left(\mathrm{pR}^{2}=0.22\right)$ was approximately twice as good as the fit of the covariate model $\left(\mathrm{pR}^{2}=0.08\right)$. 
Significance of terms was assessed in two ways:

(i) each parameter estimate from linear models was compared to zero using marginal t tests (e.g. Table 3.2); and

(ii) term in the models were additionally tested by sequential addition to a null model (sequential analysis of deviance tables); the corresponding F- and $\mathrm{P}$ values are given in the main text. 


\section{Results}

Treatment effects on vegetation

Plant species richness (per $18 \mathrm{~m}^{2}$ ) was highest in forb-rich sward treatments with 26.8 ( $\pm 0.51 \mathrm{SE}$ ) species (Table 3.1). On plots that were mown three times a year we found 27.4 ( \pm 0.75 SE) species. Plant species richness was lowest with $23.8( \pm 0.47$ $\mathrm{SE}$ ) species in graminoid-dominated plots, especially when mown three times (see also Table 3.1). Our analyses showed that plant species richness was mainly driven by forbs, because the average number of graminoid species (all between 11.08 ( $\pm 0.29 \mathrm{SE})$ and 11.50 ( $\pm 0.26 \mathrm{SE})$ species) was not measurably affected by the treatments. Fertilizer application reduced plant species richness slightly. Further details on treatment effects on vegetation can be found in Petersen et al. (2012) and Rose et al. (2012a; 2012b). 
Table 3.1: Effects of cutting frequency and sward composition on vegetation and slug abundance ( \pm 1SE). The columns show plant species richness (per $\left.18 m^{2}\right)$, total biomass $\left(\mathrm{t} \mathrm{ha}^{-1}\right)$, grass and forb biomass $(\%)$, compressed sward height $(\mathrm{cm})$ and slug abundance (number per plot). $(\mathrm{SE}=\mathrm{standard}$ error; $1 \mathrm{x}=\mathrm{cut}$ once a year; $3 x=$ three cuts per year)

\begin{tabular}{|c|c|c|c|c|c|c|c|c|}
\hline & $\begin{array}{l}\text { No. Of plant } \\
\text { species } \\
( \pm S E)\end{array}$ & $\begin{array}{c}\text { Total dry } \\
\text { matter } \\
\text { biomass [t } \\
\text { ha-1] ( } \pm S E)\end{array}$ & $\begin{array}{l}\text { No. of Forb } \\
\text { Species } \\
( \pm S E)\end{array}$ & $\begin{array}{c}\text { Forb } \\
\text { biomass [\%] } \\
( \pm \mathrm{SE})\end{array}$ & $\begin{array}{c}\text { No. of grass } \\
\text { species } \\
( \pm S E)\end{array}$ & $\begin{array}{c}\text { Grass } \\
\text { biomass [\%] } \\
( \pm \mathrm{SE})\end{array}$ & $\begin{array}{c}\text { Compressed } \\
\text { sward height } \\
\text { ( } \pm \text { SE) }\end{array}$ & Slugs ( $\pm S E)$ \\
\hline graminoid-rich & $23.75( \pm 0.47)$ & 50) & $1.75( \pm 0.37)$ & $2.83( \pm$ & 28) & $76.98( \pm$ & $10.17( \pm 0.37)$ & $9.67( \pm 1.05)$ \\
\hline gr.-rich - $1 x$ & $23.83( \pm 0.56)$ & .36) & 12.00 & $21.43( \pm 2$ & 38) & $78.64( \pm 2$ & $11.40( \pm 0.40)$ & $11.33( \pm 1.16)$ \\
\hline gr.-rich & 23.67 & 6.60 & 11.50 & $24.23( \pm$ & 11.17 & 75.33 & 8.93 & 8.00 \\
\hline cor & 25.33 & $6.13( \pm 0.54)$ & $13.00( \pm 0.35)$ & $35.07( \pm 1.50)$ & $.13( \pm 0.22)$ & $64.38( \pm 1.49)$ & $10.54( \pm 0.42)$ & $15.17( \pm 1.65)$ \\
\hline control - $1 x$ & $24.75( \pm 0.45)$ & $4.66( \pm 0.29)$ & $12.50( \pm 0.44)$ & $35.18( \pm 2.58)$ & $11.08( \pm 0.29)$ & $64.60( \pm 2.57)$ & $12.13( \pm 0.42)$ & $15.67( \pm 2.71)$ \\
\hline control - $3 x$ & $25.92( \pm 0.66)$ & $7.60( \pm 0.87)$ & $13.50( \pm 0.53)$ & $34.97( \pm 1.67)$ & $11.17( \pm 0.34)$ & $64.16( \pm 1.63)$ & $8.96( \pm 0.35)$ & $14.67( \pm 2.01)$ \\
\hline forb-rich & $26.75( \pm 0.51)$ & $5.46( \pm 0.47)$ & $13.96( \pm 0.44)$ & $55.35( \pm 1.96)$ & $11.38( \pm 0.21)$ & $43.80( \pm 1.97)$ & $10.27( \pm 0.41)$ & $17.67( \pm 1.32)$ \\
\hline forb-rich - $1 x$ & $26.08( \pm 0.67)$ & $3.91( \pm 0.16)$ & $13.67( \pm 0.63)$ & $54.83( \pm 2.54)$ & $11.25( \pm 0.33)$ & $45.07( \pm 2.51)$ & $11.90( \pm 0.31)$ & $20.67( \pm 1.80)$ \\
\hline forb-rich $-3 x$ & $27.42( \pm 0.75)$ & $7.02( \pm 0.69)$ & $14.25( \pm 0.62)$ & $55.87( \pm 3.10)$ & $11.50( \pm 0.26)$ & $42.53( \pm 3.10)$ & $8.65( \pm 0.34)$ & $14.67( \pm 1.56)$ \\
\hline
\end{tabular}


Treatment effects on slug abundance

We found a total slug abundance of 1020 individuals collected over two sampling periods and belonging to three species that were all members of the Arionidae family. The most abundant species was A. distinctus (MABILLE, 1868), making up $60.4 \%$ of the collected individuals, followed by D. reticulatum (O. F. MüLLER, 1774) with $34.7 \%$, while $A$. Iusitanicus (MoQUIN-TANDON, 1855) the lowest abundance $(4.9 \%)$. In spring, we mainly found juvenile individuals. Whereas mollusc species richness or single species abundance were not significantly affected by the experimental treatments, we found strong and significant main effects of treatments on total mollusc abundance.

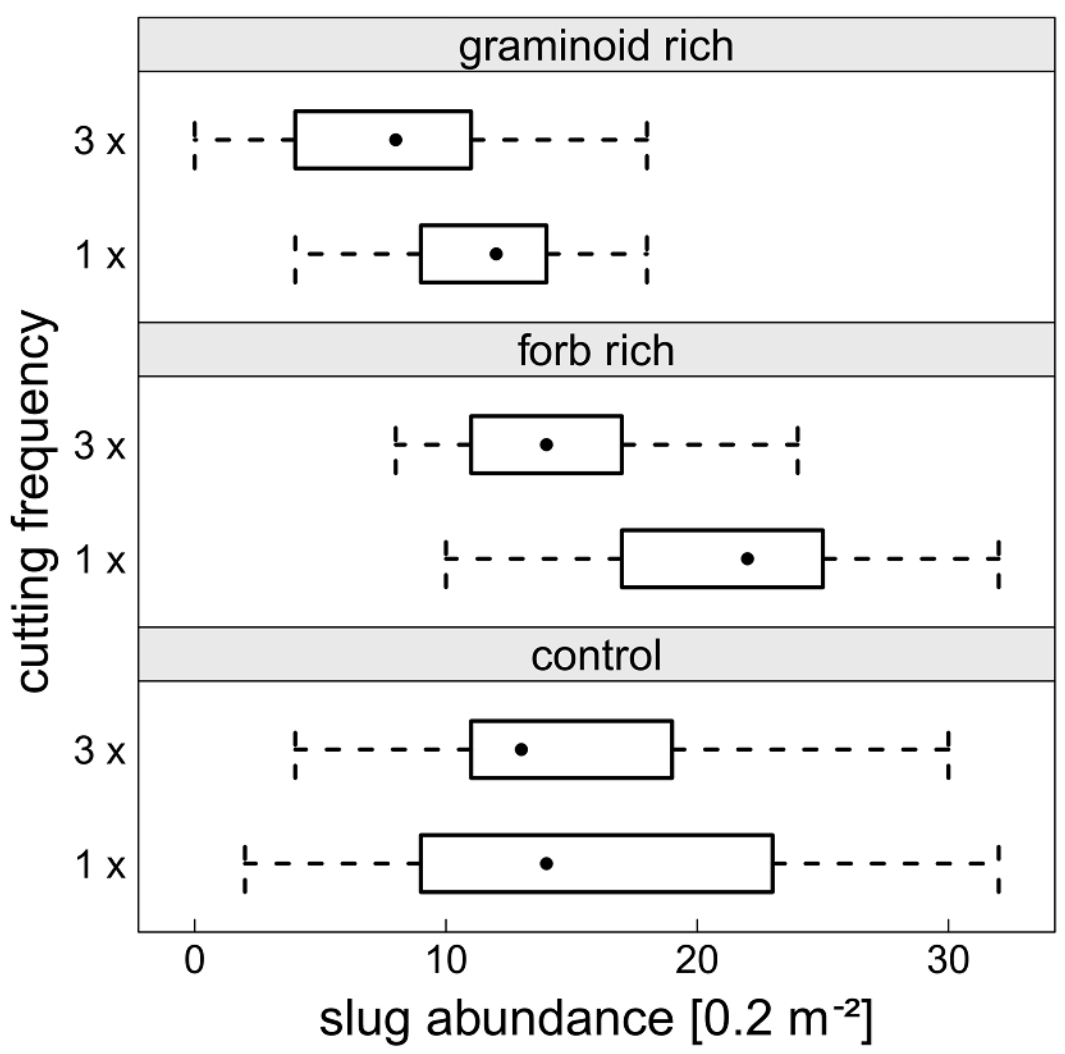

Fig. 3.2: Effect of grassland cutting frequency and plant functional group composition on slug abundance $\left[0.20 \mathrm{~m}^{-2}\right]$. The box plot shows the smallest and largest observations (dashed line), inner quartile range (rectangle) and median (point). Slug abundance showed significant responses of plant composition $(p=0.001)$ and cutting frequency $(p=0.027) . N=72$. 
Table 3.2: Treatment effects on slug abundance. The table shows parameter estimates (log scale) from a minimal adequate quasipoisson GLM fitted using successive difference contrasts. The Intercept is the overall mean. Bold estimates (effect sizes) with 1 SE indicate significant effects at $p<0.05$.

\begin{tabular}{lrccc}
\hline & Estimate & $\pm \mathrm{SE}$ & $t$ & $p$ \\
\hline Intercept & $\mathbf{2 . 6 1 2}$ & $\mathbf{\pm 0 . 0 6}$ & 46.49 & $<0.001$ \\
sward; & & & & \\
$\quad$ forbs vs. control & 0.152 & \pm 0.12 & 1.24 & 0.220 \\
$\quad$ graminoids vs. forbs & $\mathbf{- 0 . 6 0 3}$ & $\mathbf{0 0 . 1 4}$ & -4.28 & $<0.001$ \\
cutting; & & & &
\end{tabular}

$3 x$ vs. $1 x$

$-0.244 \pm 0.11-2.25 \quad 0.028$

Cutting frequency $\left(F_{1,71}=5.08 ; P=0.023\right)$ and plant functional group composition $\left(F_{2,71}=10.00 ; P<0.001\right)$ strongly influenced mollusc abundance in our agricultural grassland (Fig. 3.2; Tab. 3.1; Tab. 3.2). Slug abundance was significantly higher in forb-rich plots (Fig. 3.2) but was negatively influenced by higher cutting frequency; in plots with (altered) higher forb- or graminoid proportion due to herbicide application, frequent cutting reduced slug abundance by $\sim 29 \%$. In the frequently cut control plots we found slug abundance only a little lower $(6.4 \%)$ (Fig. 3.2). When tested individually, biomass (Tab. 1) of forbs was positively and biomass of graminoids was negatively, correlated to slug abundance and these factors explain more than ten percent of the model deviance. 




Fig. 3.3: Effect of compressed sward height [cm] on slug abundance $\left[0.20 \mathrm{~m}^{-2}\right]$. Slug abundance is positively correlated with compressed sward height $\left(R^{2}=0.110 ; p=0.005\right) . N=72$. The fitted line represents the GLM $(y=\exp (1.73 \pm 0.33-0.09 \pm 0.03$ * sward height $(\mathrm{cm}))+\varepsilon)$.

After simplification of the covariate model, only compressed sward height showed a significantly positive relationship with slug abundance (Fig. 3.3).

Treatment effects on herbivory

We found an average herbivory of $0.320 \%( \pm 0.03 \mathrm{SE})$ of the leaf area of $R$. acetosa and an average of 1.131 ( $\pm 0.04 \mathrm{SE}$ ) cavities per leaf.

Our design models showed that there was a significant positive effect of fertilizer application on rates of herbivore damage and the number of cavities. 


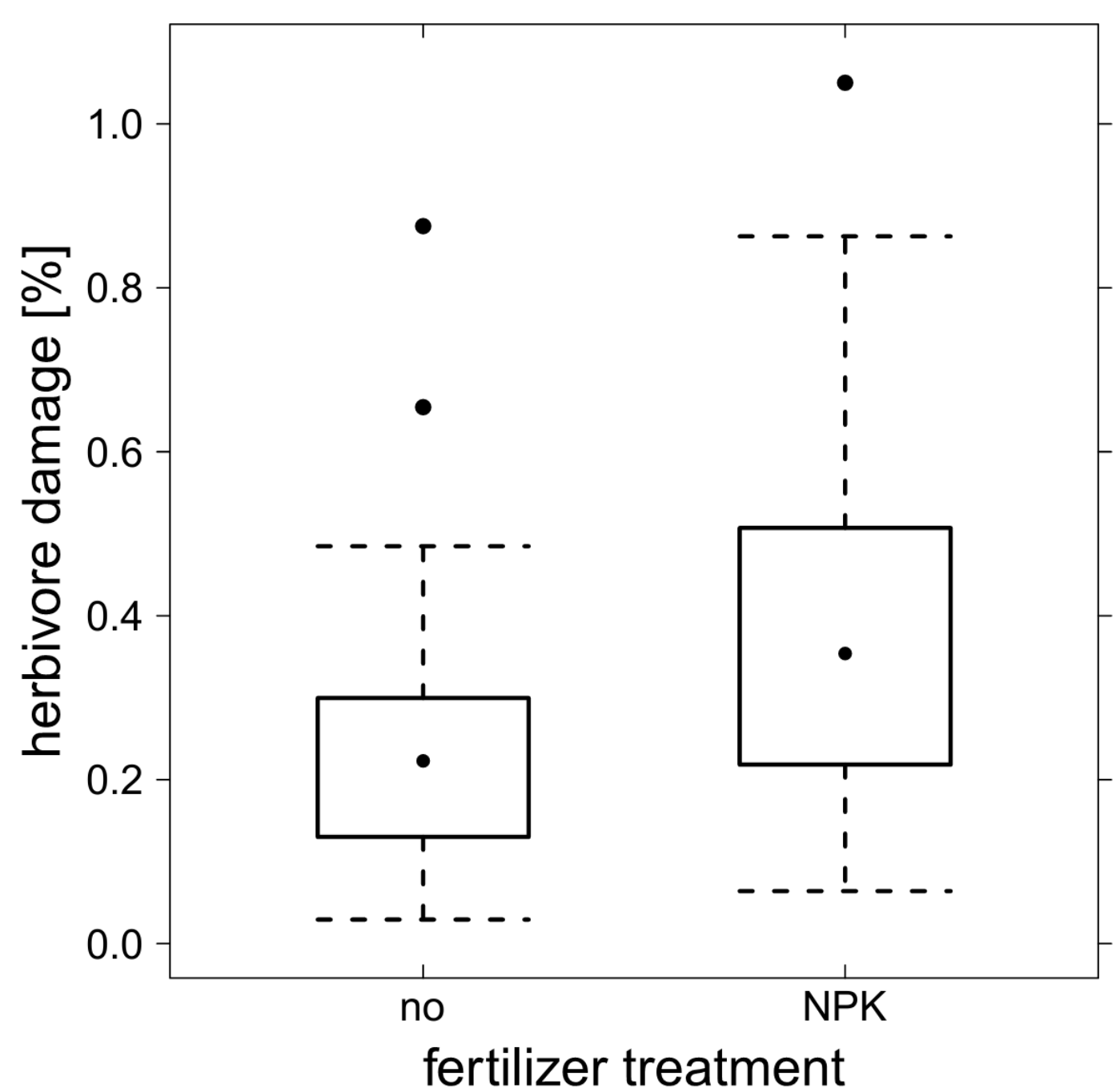

Fig. 3.4: Effect of fertilizer application ( $p=0.005 ; N=72$ ) on herbivore damage [\%] of Rumex acetosa. The box plot shows the inner $75 \%$ of the data (whiskers), inter quartile range (rectangle) and median (point).

On plots without fertilizer application an average herbivore damage of $0.25 \%$ $( \pm 0.03 \mathrm{SE})$ and $0.86( \pm 0.06 \mathrm{SE})$ cavities per leaf was recorded, whereas 1.40 $( \pm 0.11 \mathrm{SE})$ cavities per leaf were according for of $0.39 \%( \pm 0.04 \mathrm{SE})$ herbivore damage on NPK-fertilized plots (Fig. 3.4). All other explanatory variables were not significant and removed during model simplification. The covariate models for herbivory showed no significant effect of slug abundance on herbivory rates on R. acetosa. 


\section{Discussion}

Several studies have examined the effects of slugs on grassland vegetation, e.g. plant composition, germination, seedling survival and biomass production (Allan and Crawley, 2011; del-Val and Crawley, 2004; Hulme, 1996) or the effects of grassland biodiversity, plant functional group composition, management or vegetation structure on invertebrates (Haddad et al., 2001; Woodcock and Pywell, 2010). Our study is the first which investigates the effects of cutting frequency, nutrient availability and plant functional group composition on slug densities.

We found that slug abundance was significantly affected by both plant functional group composition and cutting frequency. Reduced grassland management intensity (e.g. lower cutting frequency) and increased food resource availability (increased cover of forbs and taller vegetation) resulted in a higher abundance of slugs. In addition, the negative effect of cutting on slug abundance was lowest in control plots with their naturally developed graminoid-forb communities.

Increasing proportions of forbs resulted in higher slug abundance, confirming our first hypothesis. It is likely that the slugs were more abundant in forb-dominated plots because of the higher nutritional quality of forb-rich grasslands and the preferential consumption of forbs when given a choice (Briner and Frank, 1998; Pallant, 1969, 1972; Peters et al., 2000; Rathcke, 1985).

The intermediate forb to graminoid ratio in the control plots after cutting may be a suitable habitat for slugs as it could still provide enough shelter due to the higher re-growth capability of graminoids (Tscharntke and Greiler, 1995) whilst also containing high quality and quantity of forbs and annual plants, which are a preferred food source, e.g. for A. lusitanicus (Briner and Frank, 1998).

Higher plant diversity, which was highest in forb-rich plots of our experiment (see also Petersen (2012)), provides a more attractive habitat for slugs, possibly via the higher variety of food sources or a more complex vegetation structure (Dedov et al., 2006). Compared to the lower slug abundance in less plant species rich plots, it gives evidence that decreasing plant biodiversity not only threatens the persistence of generalist insect herbivores (Unsicker et al., 2010), but also of slugs. 
Three cuts had a consistently negative effect on mollusc abundance in comparison to one cut management. This lower abundance has several potential causes:

(i) many slugs are likely to have been killed and removed directly during the process of cutting and/or due to soil compaction by a heavy machine, which has also been shown to decrease invertebrate populations (Ferguson et al., 1988; Hitchmough, 2003; Humbert et al., 2010).

(ii) Sward height is positively correlated with soil moisture (Gross et al., 2008) and due to the obvious effect of cutting on vegetation height and standing biomass, it leads to a lack of food and shelter availability as well as a drier soil surface and altered temperature pattern. All this affects habitat attractiveness for slugs and therefore slug abundance (Willis et al., 2008).

(iii) The removal of biomass and nutrients through harvesting, and the loss of plant species, which are less tolerant to frequent cutting (Valkó et al., 2012), negatively affects slug density. Hence, frequent cutting of field margins or grassland sites close to crop fields could be used as a management strategy to reduce slug herbivory on arable crops. Fertilizer application had no direct effect on slugs in this temperate grassland, but indirect effects of fertilizer application may still occur, e.g. due to the effect of fertilizer application on vegetation density, height and soil moisture (Rose et al., 2012a).

The control plots of our study did not receive any herbicide application and were therefore less disturbed and had a more natural plant composition, which developed over a long time of pasture farming. In this more natural plant composition slug abundance showed either a higher tolerance to disturbance or a higher capacity to re-organize after disturbance. Unfortunately our sampling design did not allow detailed investigation of the mechanisms behind this effect. We found support to our third hypothesis, that slug communities in manipulated ecosystems (e.g. with a disturbed or altered plant community structure) are less tolerant of disturbance (e.g. grazing or mowing) than those in more natural habitats. This is similar to the results of Dedov et al. (2006), who also found slug abundance to be highest in diverse, naturally assembled plant communities.

Such results give rise to the question of whether experiments containing artificially assembled communities, such as the Jena- (Roscher et al., 2004) or 
the Cedar Creek Experiments (Tilman, 1996), might show a lower tolerance and resilience to disturbance, independent of their plant biodiversity.

Thus, data from experiments with sown and artificial plant communities may be more biased than that taken from experiments containing naturally assembled communities (Diaz et al., 2003). We expect that in naturally assembled communities the less disturbed communities should show smaller changes of invertebrate communities in response to further disturbance.

As our study organisms were mobile and allowed to move freely between experimental plots, we caution against interpreting our results as reflecting population changes. Rather, our results may indicate local preferences for microhabitats (shelter, humidity) in a large superpopulation colonizing the whole field.

Since we found no effects of slug abundance on herbivory of $R$. acetosa (L.), despite strong differences in slug abundance between the plots, we assume that other herbivores than slugs may have accounted for most of the herbivory on this plant species. Slugs generally play a minor role as a pest in managed grasslands, which is in line with the finding of Frank (1998a), who found the same for slugs in winter wheat fields adjacent to wild flower strips. Thus, the higher rate of herbivory damage on $R$. acetosa on nutrient-enriched plots may be due to an increase in plant palatability (Tscharntke and Greiler, 1995) and/or a higher abundance and activity of other herbivores not accounted for in this study. Our study is the first to investigate the effects of cutting frequency, nutrient availability and plant functional group composition in a removal experiment and the first to find that there are higher numbers of slugs in less manipulated or more natural plots. This raises the question whether this is also true for other invertebrates, which may have potential implications for pest management practice.

In conclusion, our experimental approach with plant functional group removal revealed positive effects of forb richness on plant diversity and slug density, which is also suggested by other studies on grassland invertebrates (Scherber et al., 2010; Wardle et al., 1999). Our experiment indicates that populations of invertebrates will increase in abundance not only where there is greater plant species richness (Tilman, 1996), but also in more natural plant communities. 


\section{Acknowledgements}

We thank Lena Everwand and Annabelle Rohlfing for their assistance with sampling in the field and Verena Rösch for her advice with identification of slugs. We are also grateful to Tatjana From, Kathleen Lemanski and Andreas Keuter for providing data on vegetation, biomass and soil properties, Lars Köhler and Johannes Isselstein for coordination of the Grassman project, as well as Peter Manning and the reviewers for helpful comments on the manuscript. Furthermore we thank the Ministry of Science and Culture of Lower Saxony and the "Niedersächsisches Vorab" for financial support. 


\section{References}

Allan, E., Crawley, M.J., 2011. Contrasting effects of insect and molluscan herbivores on plant diversity in a long-term field experiment. Ecology Letters 14, 1246.

Bender, E.A., Case, T.J., Gilpin, M.E., 1984. Perturbation Experiments in Community Ecology: Theory and Practice. Ecology 65, 1-13.

Blake, R., Woodcock, B., Westbury, D., Sutton, P., Potts, S., 2011. New tools to boost butterfly habitat quality in existing grass buffer strips. Journal of Insect Conservation 15, 221-232.

Briner, T., Frank, T., 1998. The palatability of 78 wildflower strip plants to the slug Arion lusitanicus. Annals of Applied Biology 133, 123-133.

Bylesjo, M., Segura, V., Soolanayakanahally, R.Y., Rae, A.M., Trygg, J., Gustafsson, P., Jansson, S., Street, N.R., 2008. LAMINA: A Tool for Rapid Quantification of Leaf Size and Shape Parameters. BMC Plant Biol. 8, 9.

Castle, M.E., 1976. Simple disk instrument for estimating herbage yield. Journal of the British Grassland Society 31, 37-40.

Choi, Y.H., Bohan, D.A., Powers, S.J., Wiltshire, C.W., Glen, D.M., Semenov, M.A., 2004. Modelling Deroceras reticulatum (Gastropoda) population dynamics based on daily temperature and rainfall. Agriculture, Ecosystems \& Environment 103, 519-525.

Clewer, A.G., Scarisbrick, D.H., 2001. Practical statistics and experimental design for plant and crop science. John Wiley \& Sons Ltd, Chichester.

Cottam, D.A., 1986. The effects of slug-grazing on Trifolium repens and Dactylis glomerata in monoculture and mixed sward. Oikos 47, 275-279.

Crawley, M.J., 2007. The R Book. John Wiley \& Sons Ltd., Southern Gate, Chichester, West Sussex.

Curry, J.P., 1994. Grassland Invertebrates. Chapman \& Hall, London.

Dedov, I., Stoyanov, I.L., Penev, L., Harvey, J.A., Van der Putten, W.H., Bezemer, T.M., 2006. Long-term effects of sowing high or low diverse seed mixtures on plant and gastropod diversity. Acta Oecologica 30, 173-181.

del-Val, E., Crawley, M.J., 2004. Importance of tolerance to herbivory for plant survival in a British grassland. Journal of Vegetation Science 15, 357-364. 
Diaz, S., Symstad, A.J., Chapin, F.S., Wardle, D.A., Huenneke, L.F., 2003. Functional diversity revealed by removal experiments. Trends in Ecology \& Evolution 18, 140-146.

Fabian, Y., Sandau, N., Bruggisser, O.T., Kehrli, P., Aebi, A., Rohr, R.P., Naisbit, R.E., Bersier, L.-F., 2012. Diversity protects plant communities against generalist molluscan herbivores. Ecology and Evolution 2, 2460-2473.

Ferguson, C.M., Barratt, B., Jones, P.A., 1988. Control of the grey field slug (Deroceras reticulatum (Müller)) by stock management prior to direct-drilled pasture establishment. Journal of Agricultural Science 111, 443-449.

Frank, T., 1998a. Slug damage and number of slugs (Gastropoda : Pulmonata) in winter wheat in fields with sown wildflower strips. Journal of Molluscan Studies 64, 319-328.

Frank, T., 1998b. Slug damage and numbers of slugs in oilseed rape bordering on grass strips. Journal of Molluscan Studies 64, 461-466.

Gross, N., Robson, T.M., Lavorel, S., Albert, C., Le Bagousse-Pinguet, Y., Guillemin, R., 2008. Plant response traits mediate the effects of subalpine grasslands on soil moisture. New Phytologist 180, 652-662.

Haddad, N.M., Tilman, D., Haarstad, J., Ritchie, M., Knops, J.M.N., 2001. Contrasting Effects of Plant Richness and Composition on Insect Communities: A Field Experiment. American Naturalist, The 158, 17-35.

Hawkins, J.W., Lankester, M.W., Nelson, R.R.A., 1998. Sampling terrestrial gastropods using cardboard sheets. Malacologia 39, 1-9.

Heinzl, H., Mittlböck, M., 2003. Pseudo R-squared measures for Poisson regression models with over- or underdispersion. Computational Statistics \&amp; Data Analysis 44, 253-271.

Hitchmough, J.D., 2003. Effects of sward height, gap size, and slug grazing on emergence and establishment of Trollius europaeus (Globeflower). Restoration Ecology 11, 20-28.

Hulme, P.E., 1996. Herbivores and the performance of grassland plants: A comparison of arthropod, mollusc and rodent herbivory. Journal of Ecology 84, 43-51.

Humbert, J.Y., Ghazoul, J., Sauter, G.J., Walter, T., 2010. Impact of different meadow mowing techniques on field invertebrates. Journal of Applied Entomology 134, 592-599. 
Keuter, A., Hoeft, I., Veldkamp, E., Corre, M., 2012. Nitrogen response efficiency of a managed and phytodiverse temperate grassland. Plant and Soil,1-14.

Klapp, E., Stählin, A., 1936. Standorte, Pflanzengesellschaften und Leistung des Grünlandes. Stuttgart: Ulmer.

McCoy, K.D., Nudds, T.D., 1997. Interspecific variation in climbing by gastropods: Implications for transmission of Parelaphostrongylus tenuis. American Midland Naturalist 137, 320-328.

Oggier, P., Zschokke, S., Baur, B., 1998. A comparison of three methods for assessing the gastropod community in dry grasslands. Pedobiologia 42, 348-357.

Ondina, P., Hermida, J., Outeiro, A., Mato, S., 2004. Relationships between terrestrial gastropod distribution and soil properties in Galicia (NW Spain). Applied Soil Ecology 26, 1-9.

Pallant, D., 1969. Food of the grey field slug (Agriolimax reticulatus (MÜLLER)) in woodlands. J. Anim. Ecol. 38, 391-397.

Pallant, D., 1972. Food of the grey field slug (Agriolimax reticulatus (MÜLLER)) on grassland. J. Anim. Ecol. 41, 761-769.

Pavlů, V., Schellberg, J., Hejcman, M., 2011. Cutting frequency vs. $N$ application: effect of a 20-year management in Lolio-Cynosuretum grassland. Grass and Forage Science 66, 501-515.

Peters, H.A., Baur, B., Bazzaz, F., Korner, C., 2000. Consumption rates and food preferences of slugs in a calcareous grassland under current and future CO2 conditions. Oecologia 125, 72-81.

Petersen, U., Wrage, N., Köhler, L., Leuschner, C., Isselstein, J., 2012. Manipulating the species composition of permanent grasslands-A new approach to biodiversity experiments. Basic and Applied Ecology 13, 1-9.

R-Development-Core-Team, 2010. R: A language and environment for statistical computing. $R$ foundation for statistical computing. Vienna, Austria,.

Rathcke, B., 1985. Slugs as generalist herbivores - Tests of 3 Hypotheses on plant choices. Ecology 66, 828-836.

Roscher, C., Schumacher, J., Baade, J., Wilcke, W., Gleixner, G., Weisser, W.W., Schmid, B., Schulze, E.D., 2004. The role of biodiversity for element cycling and trophic interactions: an experimental approach in a grassland community. Basic and Applied Ecology 5, 107-121. 
Rose, L., Coners, H., Leuschner, C., 2012a. Effects of fertilization and cutting frequency on the water balance of a temperate grassland. Ecohydrology 5, 64-72.

Rose, L., Rubarth, M.C., Hertel, D., Leuschner, C., 2012b. Management alters interspecific leaf trait relationships and trait-based species rankings in permanent meadows. Journal of Vegetation Science, DOI:10.1111/j.16541103.2012.01455.x.

Scheidel, U., Bruelheide, H., 2005. Effects of slug herbivory on the seedling establishment of two montane Asteraceae species. Flora 200, 309-320.

Scherber, C., Crawley, M.J., Porembski, S., 2003. The effects of herbivory and competition on the invasive alien plant Senecio inaequidens (Asteraceae). Diversity and Distributions 9, 415-426.

Scherber, C., Mwangi, P.N., Schmitz, M., Scherer-Lorenzen, M., Bessler, H., Engels, C., Eisenhauer, N., Migunova, V.D., Scheu, S., Weisser, W.W., Schulze, E.D., Schmid, B., 2010. Biodiversity and belowground interactions mediate community invasion resistance against a tall herb invader. Journal of Plant Ecology-Uk 3, 99-108.

Scherber, C., Mwangi, P.N., Temperton, V.M., Roscher, C., Schumacher, J., Schmid, B., Weisser, W.W., 2006. Effects of plant diversity on invertebrate herbivory in experimental grassland. Oecologia 147, 489-500.

Severns, P.M., 2005. Response of a terrestrial mollusc community to an autumn prescribed burn in a rare wetland prairie of western Oregon, USA. Journal of Molluscan Studies 71, 181-187.

Stein, C., Unsicker, S.B., Kahmen, A., Wagner, M., Audorff, V., Auge, H., Prati, D., Weisser, W.W., 2010. Impact of invertebrate herbivory in grasslands depends on plant species diversity. Ecology 91, 1639-1650.

Suominen, O., Edenius, L., Ericsson, G., Resco de Dios, V., 2003. Gastropod diversity in aspen stands in coastal northern Sweden. Forest Ecology and Management 175, 403-412.

Tilman, D., 1996. Biodiversity: Population versus ecosystem stability. Ecology 77, 350-363.

Tilman, D., Reich, P.B., Isbell, F., 2012. Biodiversity impacts ecosystem productivity as much as resources, disturbance, or herbivory. Proceedings of the National Academy of Sciences 109, 10394-10397. 
Tscharntke, T., Greiler, H.J., 1995. Insect communities, grasses, and grasslands. Annual Review of Entomology 40, 535-558.

Unsicker, S.B., Franzke, A., Specht, J., Koehler, G., Linz, J., Renker, C., Stein, C., Weisser, W.W., 2010. Plant species richness in montane grasslands affects the fitness of a generalist grasshopper species. Ecology 91, 1083-1091.

Valkó, O., Török, P., Matus, G., Tóthmérész, B., 2012. Is regular mowing the most appropriate and cost-effective management maintaining diversity and biomass of target forbs in mountain hay meadows? Flora Morphology, Distribution, Functional Ecology of Plants 207, 303-309.

Wardle, D.A., Bonner, K.I., Barker, G.M., Yeates, G.W., Nicholson, K.S., Bardgett, R.D., Watson, R.N., Ghani, A., 1999. Plant Removals in Perennial Grassland: Vegetation Dynamics, Decomposers, Soil Biodiversity, and Ecosystem Properties. Ecol. Monogr. 69, 535-568.

Warton, D.I., Hui, F.K.C., 2010. The arcsine is asinine: the analysis of proportions in ecology. Ecology 92, 3-10.

Willis, J.C., Bohan, D.A., Powers, S.J., Choi, Y.H., Park, J., Gussin, E., 2008. The importance of temperature and moisture to the egg-laying behaviour of a pest slug, Deroceras reticulatum. Annals of Applied Biology 153, 105--115.

Woodcock, B., Pywell, R., 2010. Effects of vegetation structure and floristic diversity on detritivore, herbivore and predatory invertebrates within calcareous grasslands. Biodiversity and Conservation 19, 81-95. 


\section{CHAPTER 4}

DISENTANGLING DIRECT AND INDIRECT EFFECTS

OF EXPERIMENTAL GRASSLAND MANAGEMENT AND

PLANT FUNCTIONAL-GROUP MANIPULATION ON

PLANT AND LEAFHOPPER BIODIVERSITY

Georg Everwand, Verena Rösch, Teja Tscharntke \& Christoph Scherber 


\section{Abstract}

Plant biodiversity can affect trophic interactions in many ways, including direct bottom-up effects on insects, but is negatively affected by agricultural intensification. Grassland intensification promotes plant productivity, resulting in changes in plant community composition, and impacts on higher trophic levels. Here, we use a novel grassland management experiment combining variation in cutting and fertilization with a manipulation of plant functional group composition (independent of management effects) to disentangle the direct and indirect effects of agricultural management on insect herbivore diversity and abundance. We used leafhoppers as model organisms as they are a key insect taxon in grasslands and react rapidly to management changes.

Leafhoppers were sampled between May and September 2010 using standardized sweep netting and pan traps.

Our results show that plant diversity, functional group composition and management regime in grasslands affect leafhopper species richness and abundance. Higher cutting frequencies directly led to decreasing leafhopper species richness, presumably due to the higher disturbance frequency and the reduction in foodresource heterogeneity. In contrast, fertilizer application had only a small indirect negative effect via enhanced aboveground plant biomass, reduced plant diversity and changed functional group composition. The manipulated increase in grass cover had contrasting direct and indirect effects on leafhopper species richness: directly increasing leafhopper species richness, but negatively affecting plant diversity, which in turn was positively related to leafhopper species richness. In conclusion, insect diversity is driven in complex direct and indirect ways by grassland management including changes in functional group composition.

We therefore show that besides food resource heterogeneity in the form of plant diversity, the availability of preferred food sources and the frequency of disturbance are also important direct and indirect drivers of leafhopper species richness, but interactions between these are complex. 


\section{Introduction}

Grasslands, such as permanent meadows and pastures, cover about $37 \%$ of the agricultural area in Europe (FAOSTAT 2013) and harbour much of Europe's overall biodiversity (WallisDeVries, Poschlod \& Willems 2002). Many plant and animal species are restricted to this habitat type (Isselstein, Jeangros \& Pavlu 2005). However, agricultural intensification and land-use change have caused major losses in grassland biodiversity (Sala et al. 2000). Large amounts of fertilizer are applied in grassland to increase yield (Galloway et al. 2004), and allow to be earlier and more frequently cuttings in the growing season. Additionally, herbicides are used, from time to time, to suppress unwanted plant species (Isselstein et al. 2005). These management practices greatly affect both plant biomass and composition. Plant species that are adapted to low nutrient levels and low cutting frequencies are replaced by more competitive, faster-growing species (Smart et al. 2006; Wesche et al. 2012), thereby altering the invertebrate communities of the grassland as well (Attwood et al. 2008). Frequent cutting disturbs the vegetation structure, removes food resources and kills many animals (Isselstein, Jeangros \& Pavlu 2005; Humbert, Ghazoul \& Walter 2009; Humbert et al. 2010; Everwand, Scherber \& Tscharntke 2013).

Here, we present results from a novel grassland management and plant functional group manipulation experiment (GrassMan, Plate 4.1) (Petersen et al. 2012), combining experimental variation in cutting frequency (two levels, one cut or three cuts) and fertilizer application (two levels, fertilized or unfertilized) with a plant functional group manipulation treatment (three levels), testing the enhancement of grasses or herbs independent of management changes. We focus on insect responses to plant species composition and management intensity. The resulting 12 treatment combinations were replicated six times, resulting in 72 plots laid out experimentally as a Latin rectangle (Everwand, Scherber \& Tscharntke 2013).

Other studies on trophic interactions in biodiversity experiments have largely relied on artificially sown gradients in plant diversity (Scherber et al. 2006; Scherber et al. 2010a). To achieve more realistic results, we performed this study in an old grassland and only changed the relative importance of grasses and forbs (Diaz et al. 2003). 


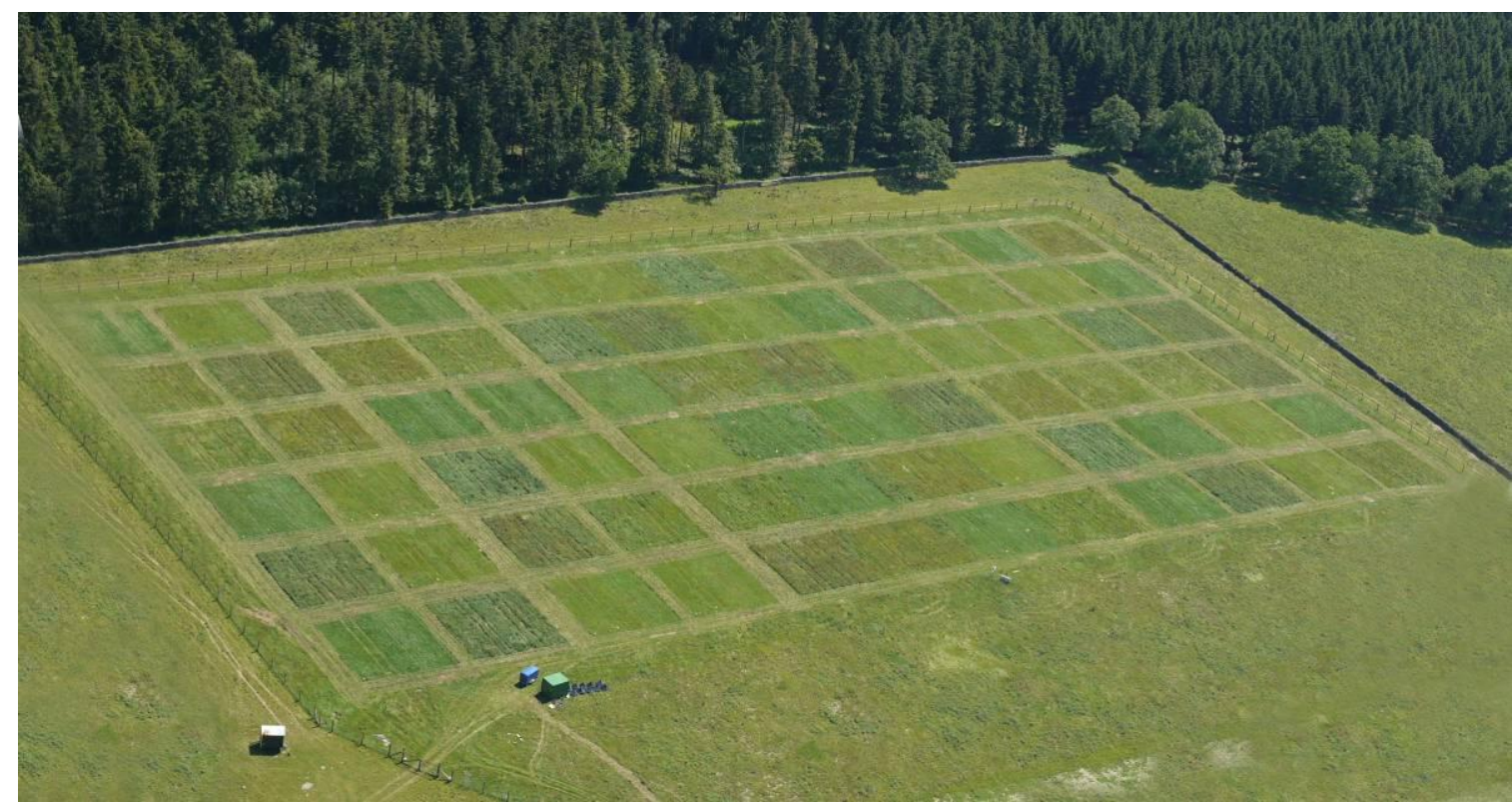

Plate 4.1: Aereial picture of the GrassMan Experiment, taken in 2009 by L. Rose.

We chose leafhoppers, planthoppers and froghoppers (Auchenorrhyncha, hereafter referred to as leafhoppers), as model organisms as they are a highly diverse plantsucking insect group that has been shown to be strongly influenced by management regime, productivity, vegetation structure and plant species composition (Nickel 2003; Biedermann et al. 2005).

Leafhoppers play an important role both as herbivores and as prey for higher trophic levels. Their rapid reaction to changes in management regime makes them highly appropriate for ecological studies such as the one presented here (Biedermann et al. 2005). Nevertheless, they have rarely been studied in this context (but see Hollier et al. 2005).

We hypothesize that

(i) Leafhopper abundance and diversity decrease with cutting frequency, as cutting acts as a mechanical disturbance

(ii) Leafhopper abundance and diversity increase with fertilizer application, as this enhances quantity and nutritional quality of available food resources.

(iii) Leafhopper abundance and diversity increase under experimental enhancement of graminoid cover, because many species feed preferably on graminoids. 


\section{Material and Methods}

Description of study site

This study was performed in 2010 as part of the "GrassMan"-Experiment (Petersen et al. 2012) near Neuhaus (Solling) in the Solling Mountains in Northern Germany ( $51^{\circ} 440 \mathrm{~N}, 9^{\circ} 320 \mathrm{E}, 490 \mathrm{~m}$ a.s.l.).

Prior to the start of the experiment the study site was a nutrient poor, moderately wet Lolio-Cynosuretum grassland with high abundances of Agrostis capillaris (L.), Festuca rubra (L.), Rumex acetosa (L.), Veronica chamaedrys (L.) and Ranunculus repens (L.) (Petersen et al. 2012).

Mean annual precipitation is $1028 \mathrm{~mm}$ and mean annual temperature is $6.9^{\circ} \mathrm{C}$ (Deutscher Wetterdienst, 1961-1990, station Holzminden-Silberborn, 440 m a.s.l.). In 2010 , the year of the study, mean annual temperature was $8.0^{\circ} \mathrm{C}$ and annual precipitation was $1110 \mathrm{~mm}$. The dominant soil type in the experimental area is a shallow (40-60 cm), stony Haplic Cambisol, developed on sediments of loess on the Middle Bunter (Triassic sandstone) formation with a loamy silt texture (Keuter et al. 2012).

Study design

The experiment was established in 2008 in a permanent, formerly extensively used, cattle-grazed grassland. It was laid out as a three-factorial Latin rectangle (Clewer \& Scarisbrick 2001) with the following factors (Fig. 4.S1 Appendix): (i) plant functional group manipulation (three levels) using herbicides, (ii) fertilizer application (two levels) and (iii) cutting frequency (two levels), resulting in twelve treatment combinations.

To manipulate plant functional group presence, we applied (i) a combination of the forb-specific herbicides Fluroxypyr (Starane; Dow AgroSciences, Munich, Germany; $3 \mathrm{~L} \mathrm{ha}^{-1}$ ) and Mecoprop-P (Duplosan; KV, Du Pont de Nemours, Neu-Isenburg, Germany; $3 \mathrm{~L} \mathrm{ha}^{-1}$ ) or (ii) the graminoid-specific herbicide Select 240 EC (Stähler Int., Stade, Germany; $0.5 \mathrm{~L} \mathrm{ha}{ }^{-1}$ ), resulting in three levels of plant diversity: (i) forbreduced (=graminoid-rich), (ii) graminoid-reduced (=forb-rich) and (iii) control. Herbicides were applied once in June 2008 (a "pulse" experiment sensu Bender et al. 1984). 
In 2009 and 2010, plots were fertilized with N (Calcium ammonium nitrate N27: $\left.13.5 \% \mathrm{NH}_{4}-\mathrm{N}, 13.5 \% \mathrm{NO}_{3}-\mathrm{N}, 4 \% \mathrm{MgO}, 6 \% \mathrm{Ca}\right)$ at two equal doses $\left(2 \times 90 \mathrm{~kg} \mathrm{ha}^{-1}\right)$ in April and May/June; in addition, fertilized plots received $30 \mathrm{~kg} \mathrm{P} \mathrm{ha}^{-1}$ and $100 \mathrm{~kg} \mathrm{~K}$ ha $^{-1}$ in early June (Thomaskali®, $8 \% \mathrm{P}_{2} \mathrm{O}_{5}, 15 \% \mathrm{~K}_{2} \mathrm{O}, 20 \% \mathrm{CaO}$ ).

Control plots were not fertilized. Plots were cut either once (in July) or three times a year (May, July, September) using a Haldrup $\AA$ forage combine harvester (INOTEC Engineering $\mathrm{GmbH}$, Ilshofen, Germany) at a cutting height of $7 \mathrm{~cm}$. The resulting twelve treatment combinations (equalling one block of the Latin rectangle; see Everwand et al. 2013, Fig. 4.1) were arranged randomly and replicated six times, resulting in 72 plots. Each plot was a $15 \times 15 \mathrm{~m}$ square surrounded by at least $3 \mathrm{~m}$ of frequently cut grass between plots, and $5 \mathrm{~m}$ between blocks.

Plant functional groups were not entirely removed, but target plant species were strongly reduced in abundance. Plant functional groups slowly recovered following herbicide application, but all FG manipulation treatments significantly affected vegetation parameters, such as compressed vegetation height, harvested biomass, functional group composition and plant species richness. More details on the experimental design, setup and treatment effects on vegetation can be found in Petersen et al. (2012 \& 2013) and Rose et al. (2012a \& 2012b) .

\section{Leafhopper sampling}

Leafhoppers were sampled using two methods: i) by sweep netting (Heavy Duty Sweep Net, 7215HS, BioQuip, diameter: $38 \mathrm{~cm}$ ), while walking a circular transect with a diameter of $8 \mathrm{~m}$ around the centre of each plot (30 sweeps each), in dry weather on two occasions (at the beginning of July and at the end of August 2010). Transects length was approximately $20 \mathrm{~m}$, and there was a distance of at least $4 \mathrm{~m}$ to the edge of each plot. In addition, ii) we sampled leafhoppers by placing two transparent pan traps, containing an ethylene glycol / water mixture (1:3), $1 \mathrm{~m}$ apart, near to the centre of each plot. Pan traps were about $5 \mathrm{~cm}$ above vegetation height and were active for one week in five time intervals in 2010 (end of June, mid-July, early August, mid-August, end of August).

The specimens caught with both methods were transferred into ethanol (70\% vol.) separately and identified to species level in the laboratory using Biedermann \& Niedringhaus (2004) and Kunz et al. (2011). 
One species with woody host plants was excluded, as we assumed that it had been swept off its host tree by wind and was not a true member of the grassland fauna. Species whose larvae used herbs or grasses as host plants and only the imagines fed on trees were included in the analysis.

For female specimens of several genera identification to species level is not possible (e.g. Psammotettix) (Biedermann \& Niedringhaus 2004; Kunz, Nickel \& Niedringhaus 2011). Thus, if male specimens were present, female specimens were assumed to belong to the same species. If not, they were only identified to genus level. If males of more than one species of a genus were present, the proportion of females was assumed to mirror that of males.

We found no interaction effects of the two sampling methods with the management variables (cutting frequency, fertilizer application) on leafhopper species richness (see Fig. 4.S2; Appendix). In addition, vegetation height (a proxy for vegetation density) did not affect the number of leafhoppers caught by sweep netting.

We therefore pooled the data of both methods, which allowed us to cover the growing season of 2010 from early May until late September. For all diversity assessments, we used species richness, Shannon's diversity index ( $\left.H^{\prime}\right)$ or its numbers equivalent $\left(\mathrm{e}^{\mathrm{H}^{\prime}}\right)$ (Jost 2006).

\section{Assessment of vegetation parameters}

Because our treatments are likely to have affected plant productivity and vegetation structure, possibly indirectly affecting leafhopper species richness, we additionally measured a series of vegetation parameters:

(i) We conducted vegetation surveys on two quadrates, each of $1 \mathrm{~m}^{2}$ size, twice (in May before the first harvest and also again in August) on each plot. We recorded the percentage of cover, proportional yield of each species (Klapp \& Stählin 1936), plant species richness, functional group composition and presence-absence data of the functional groups (graminoids and forbs).

(ii) Plant aboveground biomass (AGB) was estimated as follows: First, during harvest, fresh weight of two $1.50 \times 15 \mathrm{~m}$ strips per plot was measured using the harvester's built-in scale.

To determine the water content of this sample, we took four subsamples that were homogenized, weighed, dried for $48 \mathrm{~h}$ at $65^{\circ} \mathrm{C}$ and subsequently weighed again. 
We then multiplied fresh weight by water content to obtain the total aboveground dry biomass $\left(\mathrm{t} \mathrm{ha}^{-1}\right)$ for every plot.

(iii) Proportions of graminoids and forbs (\%) were determined from the vegetation surveys (derived as described above). Harvest was performed on all plots once a year in the end of June and additionally in mid-May and mid-September for the 3-cut treatment (Petersen et al. 2012).

(iv) Compressed sward height $(\mathrm{cm})$ was measured using a rising plate meter according to Castle (1976) and the average value of 25 measures per plot was calculated. This was performed every 2-3 weeks, resulting in eleven time points throughout the growing season of 2010 .

\section{Statistical Analysis}

Data were analysed using the statistical software package $R$ (version 2.15.2) (RDevelopment-Core-Team 2012). In addition, we performed structural equation modelling using AMOS 20.0 (SPSS, Inc.). Treatment effects on vegetation and leafhoppers were assessed using generalized linear models (GLMs; (Crawley 2007)). Models contained row- and column effects (fitted as factors, column was nested within block), sward composition (factor with three levels), cutting frequency and nutrient input (two levels each) with up to two-way-interactions. For abundance data we used quasipoisson GLMs, for proportion data LMs with a logit link (Warton \& Hui 2010; Scherber et al. 2013) and for $\exp ^{\left(H^{\prime}\right)}$ we used GLMs with Gamma errors and an inverse link. Corresponding alternative models (e.g. quasipoisson or Gamma with log link) had higher residual deviance and were therefore not considered.

Continuous response variables (e.g. biomass or vegetation height) were logtransformed and analyzed using GLMs with an identity link. For each response variable in turn, maximal models containing all possible terms were manually simplified into models containing fewer explanatory variables. We compared the resulting nested models using F-tests (and $\mathrm{Chi}^{2}$ for quasipoisson models), until a minimal adequate model that only contained significant effects was obtained.

Significance of terms was assessed in two ways: (i) each parameter estimate from linear models was compared to zero using marginal t-tests (e.g. Table 4.2); and (ii) terms in the models were additionally tested by sequential addition to a null model (sequential analysis of deviance tables). 
In addition to traditional GLM-based analyses, we employed structural equation models (SEMs), allowing us to test more complex hypotheses on indirect effects of treatments, plant productivity and plant diversity on leafhoppers (Bollen 1989; Shipley 2000; Scherber et al. 2010b).

SEMs are particularly well suited for experimental contexts, i.e. where some variables are deliberately manipulated experimentally (Grace 2006). Furthermore, SEMs "can be used to develop accurate and meaningful final multiple regression models when collinearities among explanatory variables are thought to be present" (Graham 2003), which was clearly the case for the vegetation properties measured here.

SEMs contained all three treatment variables, as well as latent variables (Bollen 1989) for plant productivity and plant diversity. For the SEMs we specified our design variables as numeric variables as follows:

Fertilizer treatment:

no fertilizer $=0 ;$ NPK-fertilizer application $=1$

Cutting frequency:

one $\mathrm{cut} /$ year $=0$; three cuts/year $=1$

Functional group manipulation:

$F G$ graminoid-reduced $=-1 ; F G$ control $=0 ; F G$ forb-reduced $=1$

The sorting of FG manipulation was according to its effect on plant diversity and proportion of graminoids (see Fig. 4.1). Plant productivity had two indicator variables: harvested aboveground biomass in July ( $\mathrm{AGB}, \mathrm{t} \mathrm{ha}^{-1}$ ), and average compressed sward height. Plant diversity had the indicator variables "forbs" and "graminoids"; since only four legumes species (Lotus corniculatus, L. pedunculatus, Trifolium repens, Lathyrus pratensis) were present in a very low cover on 61 plots only, and none of the leafhopper species found had been categorized as preferentially feeding on legumes, we did not take legumes into account separately for the SEMs. Leafhopper abundance and species richness were take separately (instead of $\left(\mathrm{e}^{\mathrm{H}^{\mathrm{H}}}\right)$ Shannon diversity) for the SEM to identify effects of design variables and vegetation parameters on leafhoppers. 


\section{Results}

\section{Treatment effects on vegetation}

We found 61 plant species, 22 graminoids and 39 forbs (including four legumes). Plant Shannon diversity was positively affected by higher cutting frequency (three times/year) $\left(F_{1,72}=23.06 ; P<0.001\right)$. In addition, a forb-enriched sward was achieved by monocot specific herbicide application $\left(F_{1,72}=16.34 ; P<0.001\right)$. As shown in Fig. 4.1a and Table 4.1, plant Shannon diversity (numbers equivalent, $\mathrm{e}^{\mathrm{H}^{\prime}}$ ) was highest in unfertilized, forb-rich plots with three cuts $(9.61 \pm 0.35)$ and lowest in fertilized, graminoid-rich plots with one cut $(5.28 \pm 0.45)$.

(a)

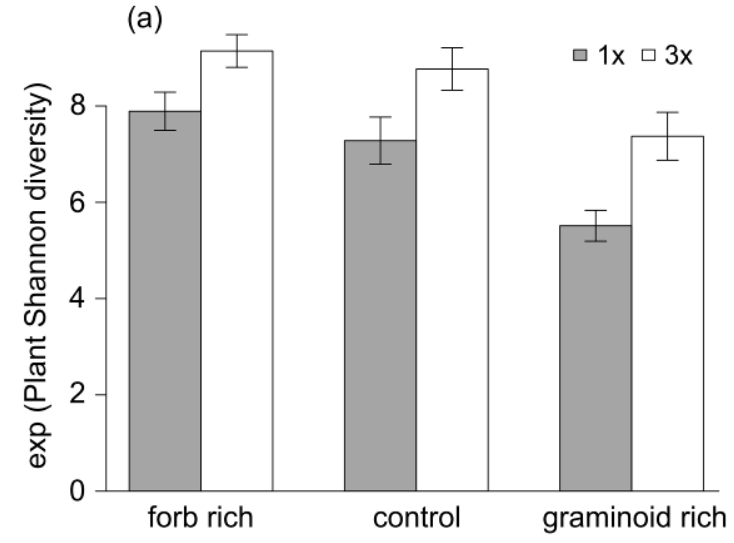

(c)

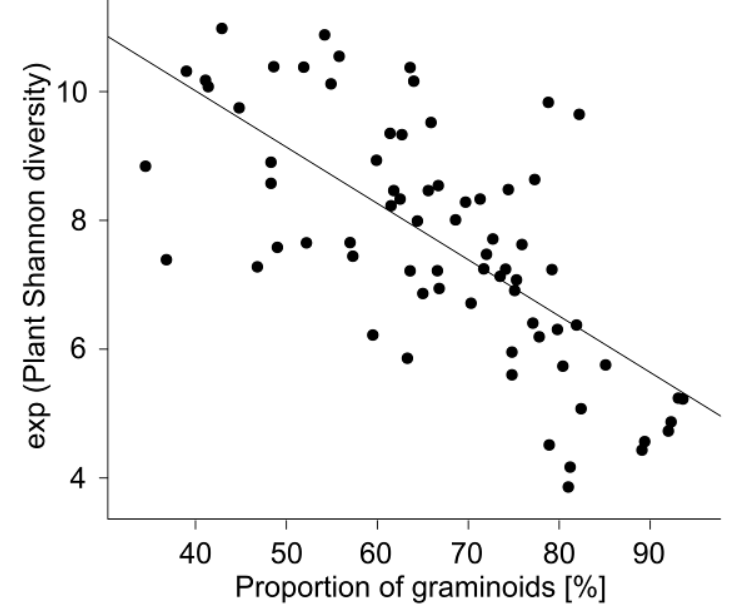

(b)

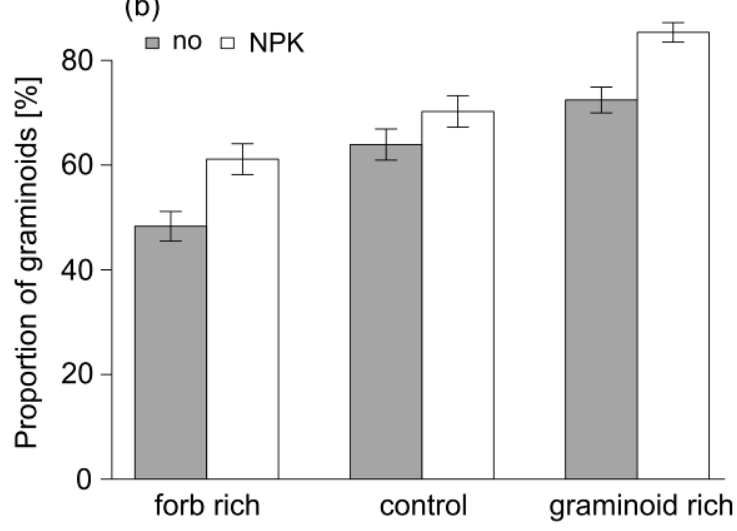

Fig. 4.14: Bar plots showing how (a) FG manipulation treatment and fertilizer application shift the functional group composition and (b) the effects of cutting frequency and FG manipulation on the numbers equivalent of plant Shannon diversity $\left(\mathrm{e}^{\mathrm{H}^{\prime}}\right)$. (c) shows the negative relationship between plant Shannon diversity and the proportion of graminoids (Spearman's rho $=-0.70 ; p<0.001)$. The regression line represents a linear model $\left(\operatorname{Im} ; \mathrm{F}_{1,72}=69.43\right.$; $\mathrm{P}<0.001$ ). 
Fertilizer application had no significant direct effect on plant Shannon diversity. Plant Shannon diversity was strongly negatively correlated with the proportion of graminoids (Spearman's rho $=-0.70 ; p<0.001$, Fig. 4.1b, Tab. 4.1), suggesting that plant diversity was mainly driven by the proportion of forbs.

The effects of proportion of graminoids (\%; equals inverse proportion to forbs) increased with fertilizer application $\left(\mathrm{t}_{1,72}=4.89 ; \mathrm{P}<0.001\right)$ and herbicide induced reduction of forbs (= graminoid-rich: $\mathrm{t}_{1,72}=4.39 ; \mathrm{P}=0.014$ ). Proportion of graminoids decreased with application of graminoid-specific herbicides (= forb-rich: $t_{1,72}=-4.71$; $P=0.071)$.

The proportion of graminoids was highest in fertilized, graminoid-rich plots with one cut $\left(86.67 \pm 2.35 \mathrm{t} \mathrm{ha}^{-1}\right)$ and lowest in unfertilized, forb-rich plots with three cuts $\left(46.33 \pm 5.07 \mathrm{t} \mathrm{ha}^{-1}\right)$. Fig. 4.1c shows how experimental reduction of functional groups and fertilizing alters plant Shannon diversity. The positive effect of fertilization on the proportion of graminoids was even higher under FG reduction of forbs (see also Everwand et al. 2013).

Table 4.3: Effects of experimental treatments on vegetation parameters (mean $\pm 1 \mathrm{SE}$ ).

\begin{tabular}{|c|c|c|c|c|c|c|}
\hline $\begin{array}{l}\text { functional } \\
\text { group }\end{array}$ & $\begin{array}{c}\text { cutting } \\
\text { frequency }\end{array}$ & $\begin{array}{c}\text { fertilizer } \\
\text { application }\end{array}$ & $\begin{array}{l}\text { compr. veg. } \\
\text { height }[\mathrm{cm}] \\
\text { mean }( \pm \mathrm{SE})\end{array}$ & $\begin{array}{c}\text { plant Shannon } \\
\text { diversity } \\
\text { mean ( } \pm \text { SE) }\end{array}$ & $\begin{array}{c}\text { proportion } \\
\text { grass [\%] } \\
\text { mean ( } \pm \text { SE) }\end{array}$ & $\mathbf{N}$ \\
\hline control & $1 \mathrm{x}$ & no & $10.89( \pm 0.29)$ & $6.90( \pm 0.68)$ & $68.52( \pm 2.75)$ & 6 \\
\hline forb-rich & $1 x$ & no & $11.07( \pm 0.23)$ & $7.97( \pm 0.56)$ & $50.28( \pm 2.78)$ & 6 \\
\hline graminoid-rich & $1 x$ & no & $10.27( \pm 0.11)$ & $5.74( \pm 0.48)$ & $75.60( \pm 3.82)$ & 6 \\
\hline control & $3 x$ & no & $7.87( \pm 0.13)$ & $9.44( \pm 0.55)$ & $59.32( \pm 4.79)$ & 6 \\
\hline forb-rich & $3 x$ & no & $7.58( \pm 0.12)$ & $9.61( \pm 0.35)$ & $46.33( \pm 5.07)$ & 6 \\
\hline graminoid-rich & $3 x$ & no & $7.79( \pm 0.13)$ & $7.57( \pm 0.56)$ & $69.27( \pm 2.84)$ & 6 \\
\hline control & $1 x$ & NPK & $13.36( \pm 0.27)$ & $7.65( \pm 0.73)$ & $67.95( \pm 5.07)$ & 6 \\
\hline forb-rich & $1 x$ & NPK & $12.72( \pm 0.32)$ & $7.81( \pm 0.61)$ & $60.72( \pm 5.29)$ & 6 \\
\hline graminoid-rich & $1 x$ & NPK & $12.54( \pm 0.42)$ & $5.28( \pm 0.45)$ & $86.67( \pm 2.35)$ & 6 \\
\hline control & $3 x$ & NPK & $10.05( \pm 0.19)$ & $8.10( \pm 0.61)$ & $72.52( \pm 3.49)$ & 6 \\
\hline forb rich & $3 x$ & NPK & $9.72( \pm 0.15)$ & $8.68( \pm 0.54)$ & $61.55( \pm 3.15)$ & 6 \\
\hline graminoid-rich & $3 x$ & NPK & $10.08( \pm 0.31)$ & $7.17( \pm 0.87)$ & $84.02( \pm 3.01)$ & 6 \\
\hline
\end{tabular}


Treatment effects on leafhoppers

In total, we caught 6497 adult leafhopper specimens from 36 species. Twenty eight species (86.5\% of the total abundance) were graminoid-feeders, and eight species were forb-feeders (Nickel \& Remane 2002). The four most common species were Arthaldeus pascuellus (FALL.) with $67.9 \%$ of total abundance, Philaenus spumarius (10.7\%), Streptanus sordidus (7.6\%) and Macrosteles viridigriseus (2.7\%).

(a)

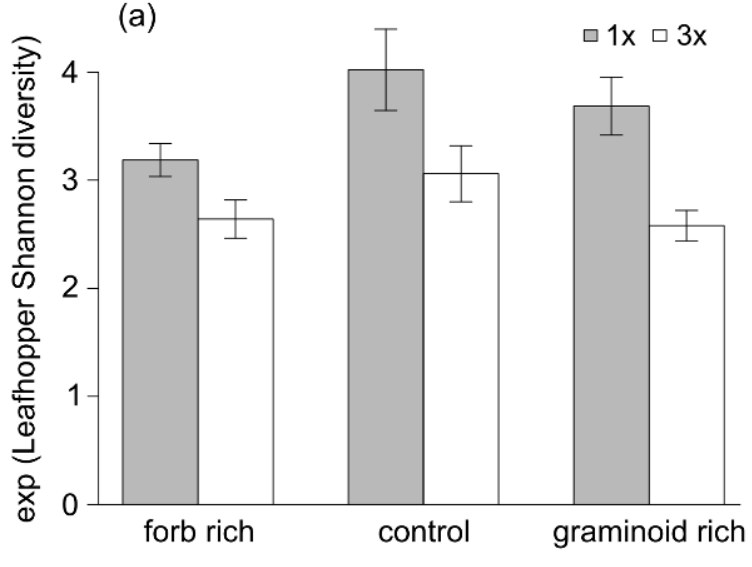

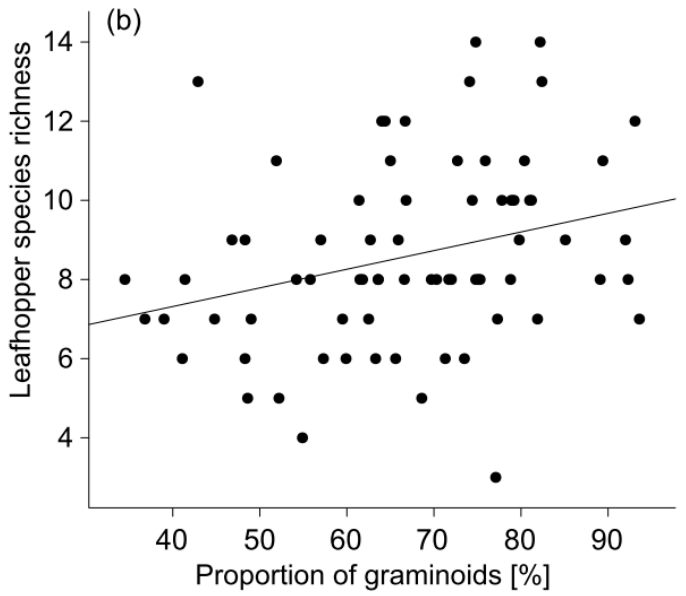

Fig. 4.5: a) Bar plot showing the effects of FG manipulation and cutting frequency on the numbers equivalent of Shannon diversity of leafhoppers $\left(\mathrm{e}^{\mathrm{H}^{\prime}}\right)$. The scatter-plot b) shows the positive relationship between leafhopper species richness [species per plot] and proportion of graminoids [\%] (Spearman's rho $=0.35 ; p=0.003$ ). The regression line represents a linear model $\left(\mathrm{Im} ; \mathrm{F}_{1,72}=6.56 ; \mathrm{P}=0.013\right)$.

Table 4.4: Effects of experimental treatments on leafhopper Shannon diversity, abundance and species richness (mean $\pm 1 \mathrm{SE}$ ).

\begin{tabular}{lcccrc}
\hline Herbicide & $\begin{array}{c}\text { Cutting } \\
\text { frequency }\end{array}$ & $\begin{array}{c}\text { Leafhopper } \\
\text { Shannon diversity }\end{array}$ & $\begin{array}{c}\text { Leafhopper } \\
\text { abundance }\end{array}$ & $\begin{array}{c}\text { Leafhopper } \\
\text { species richness }\end{array}$ & $\mathbf{N}$ \\
\hline Control & $1 \mathrm{x}$ & $4.02( \pm 0.38)$ & $72.58( \pm 7.33)$ & $9.58( \pm 0.83)$ & 12 \\
forb-rich & $1 \mathrm{x}$ & $3.19( \pm 0.15)$ & $60.75( \pm 8.69)$ & $7.08( \pm 0.34)$ & 12 \\
graminoid-rich & $1 \mathrm{x}$ & $3.69( \pm 0.27)$ & $87.00( \pm 10.67)$ & $9.67( \pm 0.38)$ & 12 \\
Control & $3 \mathrm{x}$ & $3.06( \pm 0.26)$ & $110.58( \pm 9.03)$ & $9.42( \pm 0.71)$ & 12 \\
forb-rich & $3 \mathrm{x}$ & $2.64( \pm 0.18)$ & $80.00( \pm 9.81)$ & $7.00( \pm 0.41)$ & 12 \\
graminoid-rich & $3 \mathrm{x}$ & $2.58( \pm 0.14)$ & $130.50( \pm 19.31)$ & $8.75( \pm 0.80)$ & 12 \\
\hline
\end{tabular}


Leafhopper Shannon diversity was highest in the most natural and least disturbed plots (one cut, no herbicide) with an average of $4.02( \pm 0.38)$ species per plot (Fig. 4.2a). A consistently negative effect of three cuts/year $\left(F_{1,72}=33.03 ; P<0.001\right)$ and of $F G$ manipulation $\left(F_{2,72}=5.76 ; P=0.005\right.$; Fig. 4.1, Table 4.2) was observed. Fertilizer application had no direct effect on leafhopper Shannon diversity. The proportion of graminoids [\%] had a positive overall effect on leafhopper species richness $\left(F_{1,72}=6.56 ; P=0.013 ;\right.$ Fig. 4.2b).

Table 4.5: Sequential F tests of terms in GLM models for the response variables exp Shannon plants, exp Shannon Leafhoppers and proportion of graminoids (\%).

\begin{tabular}{|c|c|c|c|c|c|c|c|}
\hline & \multirow[b]{2}{*}{ Df } & \multicolumn{2}{|c|}{$\begin{array}{l}\text { Plant Shannon } \\
\text { diversity }\left(\mathrm{e}^{\mathrm{H}^{\prime}}\right)\end{array}$} & \multicolumn{2}{|c|}{$\begin{array}{l}\text { Leafhopper Shannon } \\
\text { diversity }\left(\mathrm{e}^{\mathrm{H}^{\prime}}\right)\end{array}$} & \multicolumn{2}{|c|}{$\%$ graminoids } \\
\hline & & $\mathrm{F}$ & $\operatorname{Pr}(>\mathrm{F})$ & $\mathrm{F}$ & $\operatorname{Pr}(>\mathrm{F})$ & $\mathrm{F}$ & $\operatorname{Pr}(>\mathrm{F})$ \\
\hline Block & 5,71 & 4.70 & 0.001 & 4.47 & 0.002 & - & - \\
\hline FG manipulation & 2,71 & 16.34 & $<0.001$ & 5.76 & 0.005 & 40.87 & $<0.001$ \\
\hline cutting frequency & 1,71 & 23.06 & $<0.001$ & 33.03 & $<0.001$ & - & - \\
\hline fertilizer application & 1,71 & - & - & - & - & 24.53 & $<0.001$ \\
\hline block:column & 6,71 & - & - & 3.27 & 0.008 & - & - \\
\hline
\end{tabular}

Direct and indirect treatment effects on vegetation

The structural equation models (Fig. 4.3) show that an increasing proportion of graminoids, due to $F G$ manipulation, reduced plant diversity (standardized path coefficient $B=-0.61$ ). Plant diversity (latent variable) was mainly driven by forb diversity $(B=0.71)$. Fertilizer application and cutting frequency jointly influenced the latent variable "plant productivity": fertilization increased plant biomass and height, while cutting reduced both. Finally, higher plant productivity negatively influenced plant diversity $(B=-0.2)$. Notably, alternative pathways, e.g. arrows from plant diversity to plant productivity, were not supported by our data. 
Direct and indirect effects of treatments and vegetation on leafhoppers

Our structural equation models indicate that there were both direct and indirect effects of treatments on leafhopper abundance and species richness.

Plant functional group manipulation was the most important direct driver of leafhopper species richness $(B=0.53)$ : In forb-rich communities, leafhopper species richness was lowest, while it was highest in grass-rich communities. In contrast, a higher percentage of grasses affected plant diversity negatively, while the number of plant species (latent variable "plant diversity") had a positive effect on leafhopper species richness $(B=0.62$, see Fig. 4.3). Cutting frequency had a negative effect on leafhopper species richness $(B=-0.42$ ), whereas fertilizer application exhibited no effect on leafhopper species richness. Finally, leafhopper species richness was strongly related to leafhopper abundance $(B=0.66)$.

In addition to these direct effects, the treatments had indirect effects on leafhopper abundance and species richness. This was mediated by changes in plant productivity and plant diversity. An inspection of the standardized total effects (Table 4.4) shows that FG manipulation was the most important driver of leafhopper species richness (total effect $\varepsilon=0.379$ ). In addition, the latent variable "plant diversity" positively affected leafhopper species richness $(\varepsilon=0.249)$.

Table 4.6: Standardized total effects $(\varepsilon)$, combining indirect and direct effects.

${ }^{*}=\mathrm{P}<0.05 ;{ }^{* *}=\mathrm{P}<0.01 ;{ }^{* * *}=\mathrm{P}<0.001$

\begin{tabular}{|c|c|c|c|c|c|c|}
\hline & $\begin{array}{c}\text { fertilizer } \\
\text { application }\end{array}$ & $\begin{array}{c}\text { cutting } \\
\text { frequency }\end{array}$ & $\begin{array}{c}\mathrm{FG} \\
\text { manipulation }\end{array}$ & $\begin{array}{c}\text { plant } \\
\text { productivity }\end{array}$ & $\begin{array}{c}\text { plant } \\
\text { species } \\
\text { richness }\end{array}$ & $\begin{array}{l}\text { leafhopper } \\
\text { abundance }\end{array}$ \\
\hline plant productivity & $0.587^{* * *}$ & $-0.793^{* * *}$ & & & & \\
\hline plant species richness & -0.117 & 0.158 & $-0.613^{* * *}$ & -0.200 & & \\
\hline leafhopper abundance & 0.067 & $0.368 * \star \star$ & $0.348 * * *$ & 0.113 & $-0.568 * \star$ & \\
\hline leafhopper diversity & -0.029 & -0.080 * & 0.379 * & -0.050 & 0.249 & $0.659 * *$ \\
\hline
\end{tabular}






Fig. 4.6: Indirect and direct treatment effects on leafhoppers. The graph shows the minimal adequate structural equation model with $\mathrm{N}=72, \mathrm{X}^{2}=18.7, \mathrm{P}=0.664,22$ degrees of freedom and a root mean squared error of approximation of 0.00 (90\% confidence interval, [0, 0.081]). Rectangles represent observed variables (organism abundance and diversity = species richness), ellipses represent latent variables. Solid (dashed) arrows indicate positive (negative) relationships among variables. Numbers next to arrows and boxes are standardized path coefficients. Design variables were specified as numeric variables. Fertilizer application: no fertilizer $=0$; NPKfertilizer = 1; cutting frequency; one cut/year =0; three cuts/year = 1; and Graminoid enhancement: graminoidreduced $=-1$; control $=0$; forb-reduced $=1$. 


\section{Discussion}

The combination of management measures such as cutting and fertilizer application, with the manipulation of functional group composition and their interactions, led to contrasting sward types ranging from nutrient poor, forb-dominated plots harbouring a greater diversity of plants to highly productive, graminoid-dominated plots with lower plant diversity. This had both direct and indirect effects on leafhopper species richness and abundance. Leafhopper species richness profited directly from both a higher cover of graminoids (due to herbicide-induced reduction of forbs) and from a lower cutting frequency. However, an indirect (negative) effect on leafhopper species richness was caused by the higher proportion of graminoids due to forb reduction and management intensification, which both had a negative impact on plant diversity.

The finding that plant diversity had a negative effect on leafhopper abundance in our study can be explained by the preference for grasses of the most abundant leafhoppers such as Arthaldeus pascuellus (Nickel \& Remane 2002). Plant diversity was driven by forbs, whereas productivity was driven by graminoids, which benefit from fertilizer application. Therefore, fertilizer application led to lower plant diversity but higher amounts of harvestable aboveground biomass.

The grassland in the experimental field site has been used for cattle grazing and hay making for at least a century. We therefore also expect the leafhopper community to be adapted to the long-term managed the grass-dominated vegetation, which may have led to the selection of the dominant species in the pool associated with grasses (Nickel \& Remane 2002).

The increase in plant Shannon diversity $\left(\mathrm{e}^{\mathrm{H}^{\prime}}\right)$ with graminoid reduction, the decrease in plant Shannon diversity with forb reduction, as well as the strong decrease in plant Shannon diversity with increasing proportion of graminoids, highlights the impact of the functional group manipulation on plant diversity and composition and the strong contribution of forbs to plant species richness. Some graminoid species, such as Agrostis capillaris, Festuca rubra and Dactylis glomerata, play a dominant role in productivity in our study, resulting in a negative species richness-biomass relationship (Rose \& Leuschner 2012). 
The higher frequency of three cuts per year had a positive effect on plant diversity, confirming that cutting can increase plant species diversity due to removal of nutrients from the soil (Oomes \& Mooi 1981). But we expect that a moderate frequency of two cuts per year would improve plant species richness in our experimental field site even more, because the disturbance rate is lower but removal of nutrients is still high (Zechmeister et al. 2003). This nutrient limitation only occurs when no fertilizer is applied and the harvested AGB is removed. Such grasslands were shown to harbour a higher species number and proportion of forbs (Fischer \& Wipf 2002). This is in line with our finding of a higher number of plant species (mainly driven by forbs) under the regime of three cuts/year.

When fertilizer is applied, many herbs cannot efficiently use higher nitrogen inputs (Zechmeister et al. 2003) and are out-competed by more competitive species (Chapin 1980), which are mainly graminoids (Pearce \& van der Wal 2002). However, disturbance events such as mowing create niches for weaker competitors (MacDougall et al. 2013).

Similar to Morris (1981), we observed a negative direct effect of higher cutting frequency on leafhopper species richness, but a positive effect on leafhopper abundance. However, we did not observe any significant direct responses of leafhopper species richness, abundance or Shannon diversity $\left(\mathrm{e}^{\mathrm{H}^{\prime}}\right)$ to fertilizer application, which are often described in literature (e.g. Nickel \& Achtziger 1999).

As the path diagram indicates, fertilizer application had a weak indirect negative effect on leafhoppers, mediated by the strong increase in aboveground primary production and its negative association with plant species diversity.

NPK fertilizer application generally results in a strong increase in aboveground biomass production (Harpole \& Tilman 2007) along with an increase in the proportion of graminoids (MacDougall et al. 2013) and a decrease in plant species diversity (Pan et al. 2011). This is due to higher tolerance of the dominant graminoid species (Dactylis glomerata, Festuca rubra) to high cutting frequencies and their faster regrowth capacity after cutting, especially under fertilizer application (Leuschner, Gebel \& Rose 2013). 
Many generalist leafhoppers can benefit from the improved performance of some graminoids under more frequent cutting, as the opposing effect of cutting frequency on leafhopper abundance (positive) and leafhopper species richness (negative) in the path diagram shows. Some very abundant species (e.g. Arthaldeus pascuellus, Streptanus sordidus, Deltocephalus pulicaris), which are generalists on graminoids (Nickel \& Remane 2002), show a clear preference for areas cut three times per year.

The negative direct effect of higher cutting frequency on Shannon diversity $\left(\mathrm{e}^{\mathrm{H}^{\prime}}\right)$ and species richness of leafhoppers indicates that the majority of leafhopper species found within our study site showed a clear preference for plots cut only once a year, which is in line with findings of other studies (Morris \& Lakhani 1979; Nickel \& Achtziger 1999). This preference of leafhoppers for plots cut only once a year (Morris \& Lakhani 1979; Nickel \& Achtziger 1999) is also supported by our finding of a negative impact of higher cutting frequency on vegetation height and biomass.

This shows that reduced disturbance rate results in larger amounts of food resources and shelter due to higher vegetation and aboveground biomass. Higher vegetation and aboveground biomass were shown by Körösi et al. (2011) to have a positive effect on leafhopper abundance and species richness, we expect the same to apply here, since lower vegetation height and biomass on plots cut three times per year also implies a lower amount of available food resources and therefore directly results in lower leafhopper species richness.

The strong positive direct effect of the herbicide-induced increase of graminoids on leafhopper species richness can be explained by the preference for graminoids displayed by most leafhopper species found in our study (see Table 4.S4, Appendix) which is in accordance with other studies (Nickel \& Hildebrandt 2003).

Higher plant diversity also leads to more diverse leafhopper communities (Biedermann et al. 2005), which, in our study, is owed to less common but more specialized species (e.g. Acanthodelphax spinosa, Cicadula persimilis, Conomelus anceps).

The herbicide treatment was applied only once in 2008, nevertheless, this manipulation of plant functional group composition was efficient, since plant diversity 
and functional group composition were clearly affected even three years after the treatment.

Although most leafhopper species are mobile (Waloff 1973; Nickel 2003) and our plots were small, the differences in management and plant functional group composition caused species sorting even on a small scale, which has also been found to be the case for highly mobile bees and wasps (Ebeling et al. 2012).

Our experimental manipulation of established grassland shows very strong design effects on vegetation, therefore we expect the direct and indirect effects of management regime and vegetation parameters on leafhoppers to be even stronger in larger and unconnected areas. We also show the preferences of leafhoppers for certain microhabitats within a defined community.

To gain a deeper understanding of the interactions behind the design effects (cutting frequency, fertilizer application and FG manipulation), we included vegetation parameters, such as vegetation height, harvested peak biomass and plant species richness (for forbs and graminoids separately) in our path analysis.

The strong direct negative effect of higher cutting frequency and the positive direct effect of higher proportion of graminoids (due to FG manipulation) on leafhopper species richness (and also Shannon diversity $\left.\left(e^{\mathrm{H}^{\prime}}\right)\right)$ has several causes:

(i) Plant diversity was greater with herbicide-induced reduction of graminoids, higher cutting frequency and without application of NPK-fertilizer, since it was mainly driven by forbs. But species richness of graminoids, which are the preferred food source for the majority of the leafhopper species caught (Nickel \& Remane 2002) did not increase. Therefore a higher proportion of graminoids indirectly reduced leafhopper species richness via its negative effect on plant diversity, but also had a direct positive effect due to greater availability of the preferred food source.

(ii) Cutting is a disturbance event and reduces food resource heterogeneity. The higher its frequency, the higher the direct impact on leafhoppers, since many leafhoppers are killed and removed during the process of harvesting (Humbert et al. 
2010). This is comparable to the negative effects of cutting on slug abundance within the same experiment (Everwand, Scherber \& Tscharntke 2013).

(iii) The lower vegetation height and biomass on plots cut three times/year also implies a lower amount of available food resources and therefore results in lower leafhopper species richness.

The proportion of graminoids increased with fertilizer application and also with application of forb-specific herbicides. This increased proportion of graminoids explains the negative effect of vegetation biomass and height on plant diversity, indicated by the path diagram and demonstrates how a continuously managed agricultural system results in a high-yield but low-diversity system. This can go along with less resilience towards sudden perturbation, microclimatic change and invasions (MacDougall et al. (2013). 


\section{Overall Conclusion}

Due to direct and indirect interactions, the combination of the management regimes (cutting frequency and fertilizer application) with the manipulation of functional group composition leads to contrasting sward types.

Leafhopper species richness profited indirectly from nutrient-poor, forb-dominated plots, since these harbour a greater diversity of plants and therefore greater foodresource heterogeneity. On the other hand, leafhopper species richness profited directly from higher graminoid cover in highly productive plots with lower plant diversity, due to a greater availability of graminoids as a preferred food source for many leafhopper species.

With our novel approach of combining variation in cutting and fertilization with a manipulation of plant functional group composition (independent of management effects), we were able to disentangle the complexity of direct and indirect effects within this established, moderately species rich and continuously managed grassland based on the example of the easily accessible group of leafhoppers.

We gain a deep insight into the effects of grassland management on plant diversity, productivity and functional group composition and the trophic links and feedbacks on leafhopper species richness and abundance. Furthermore, we show that apart from food resource heterogeneity represented by plant diversity, the availability of preferred food sources and the frequency of disturbance are important drivers of leafhopper species richness, but interactions between them are highly complex.

\section{Acknowledgements}

We thank Tatiana From and Andreas Keuter for providing data on vegetation, biomass and soil properties, Lars Köhler and Johannes Isselstein for coordination of the Grassman project as well as David Perovic for proof reading. Furthermore we thank the Ministry of Science and Culture of Lower Saxony and the "Niedersächsisches Vorab" for financial support. 


\section{References}

Attwood, S., Maron, M., House, A. \& Zammit, C. (2008) Do arthropod assemblages display globally consistent responses to intensified agricultural land use and management? Global Ecology and Biogeography, 17, 585-599.

Bender, E.A., Case, T.J. \& Gilpin, M.E. (1984) Perturbation Experiments in Community Ecology: Theory and Practice. Ecology, 65, 1-13.

Biedermann, R., Achtziger, R., Nickel, H. \& Stewart, A. (2005) Conservation of Grassland Leafhoppers: A Brief Review. Journal of Insect Conservation, 9, 229-243.

Biedermann, R. \& Niedringhaus, R. (2004) Die Zikaden Deutschlands : Bestimmungstafeln für alle Arten. WABV Fründ, Scheeßel.

Bollen, K.A. (1989) Structural equations with latent variables.

Castle, M.E. (1976) Simple disk instrument for estimating herbage yield. Journal of the British Grassland Society, 31, 37-40.

Chapin, F.S. (1980) THE MINERAL-NUTRITION OF WILD PLANTS. Annual Review of Ecology and Systematics, 11, 233-260.

Clewer, A.G. \& Scarisbrick, D.H. (2001) Practical statistics and experimental design for plant and crop science. John Wiley \& Sons Ltd, Chichester.

Crawley, M.J. (2007) The R Book. John Wiley \& Sons Ltd., Southern Gate, Chichester, West Sussex.

Diaz, S., Symstad, A.J., Chapin, F.S., Wardle, D.A. \& Huenneke, L.F. (2003) Functional diversity revealed by removal experiments. Trends in Ecology \& Evolution, 18, 140-146.

Ebeling, A., Klein, A.-M., Weisser, W.W. \& Tscharntke, T. (2012) Multitrophic effects of experimental changes in plant diversity on cavity-nesting bees, wasps, and their parasitoids. Oecologia, 169, 453-465.

Everwand, G., Scherber, C. \& Tscharntke, T. (2013) Slug responses to grassland cutting and fertilizer application under plant functional group removal. Acta Oecologica, 48, 62-68.

FAOSTAT (2013) Food and Agricultural Organization Statistics Database. Food and Agricultural Organization of the United Nations., Rome, Italy. http://www.fao.org. 
Fischer, M. \& Wipf, S. (2002) Effect of low-intensity grazing on the species-rich vegetation of traditionally mown subalpine meadows. Biological Conservation, 104, 1-11.

Galloway, J., Dentener, F., Capone, D., Boyer, E., Howarth, R., Seitzinger, S., Asner, G., Cleveland, C., Green, P., Holland, E., Karl, D., Michaels, A., Porter, J., Townsend, A. \& Vöosmarty, C. (2004) Nitrogen Cycles: Past, Present, and Future. Biogeochemistry, 70, 153-226.

Grace, J.B. (2006) Structural Equation Modeling and Natural Systems. Cambridge University Press.

Graham, M.H. (2003) Confronting multicollinearity in ecological multiple regression. Ecology, 84, 2809-2815.

Harpole, W.S. \& Tilman, D. (2007) Grassland species loss resulting from reduced niche dimension. Nature, 446, 791-793.

Hollier, J., Maczey, N., Masters, G. \& Mortimer, S. (2005) Grassland leafhoppers (Hemiptera: Auchenorrhyncha) as indicators of habitat condition-a comparison of between-site and between-year differences in assemblage composition. Journal of Insect Conservation, 9, 299-307.

Humbert, J.-Y., Ghazoul, J. \& Walter, T. (2009) Meadow harvesting techniques and their impacts on field fauna. Agriculture, Ecosystems \&amp; Environment, 130, 1-8.

Humbert, J.Y., Ghazoul, J., Sauter, G.J. \& Walter, T. (2010) Impact of different meadow mowing techniques on field invertebrates. Journal of Applied Entomology, 134, 592-599.

Isselstein, J., Jeangros, B. \& Pavlu, V. (2005) Agronomic aspects of biodiversity targeted management of temperate grasslands in Europe-a review. Agronomy Research, 3, 139-151.

Jost, L. (2006) Entropy and diversity. Oikos, 113, 363-375.

Keuter, A., Hoeft, I., Veldkamp, E. \& Corre, M. (2012) Nitrogen response efficiency of a managed and phytodiverse temperate grassland. Plant and Soil, 1-14.

Klapp, E. \& Stählin, A. (1936) Standorte, Pflanzengesellschaften und Leistung des Grünlandes. Stuttgart: Ulmer. 
Koroesi, A., Batary, P., Orosz, A., Redei, D. \& Baldi, A. (2011) Effects of grazing, vegetation structure and landscape complexity on grassland leafhoppers (Hemiptera: Auchenorrhyncha) and true bugs (Hemiptera: Heteroptera) in Hungary. Insect Conservation and Diversity, 5, 57-66.

Kunz, G., Nickel, H. \& Niedringhaus, R. (2011) Fotoatlas der Zikaden Deutschlands Photographic Atlas of the Planthoppers and Leafhoppers of Germany. WABVFründ, Scheeßel.

Leuschner, C., Gebel, S. \& Rose, L. (2013) Root trait responses of six temperate grassland species to intensive mowing and NPK fertilisation: a field study in a temperate grassland. Plant and Soil, 1-12.

MacDougall, A.S., McCann, K.S., Gellner, G. \& Turkington, R. (2013) Diversity loss with persistent human disturbance increases vulnerability to ecosystem collapse. Nature, 494, 86-89.

Morris, M.G. (1981) Responses of Grassland Invertebrates to Management by Cutting. IV. Positive Responses of Auchenorhyncha. Journal of Applied Ecology, 18, 763-771.

Morris, M.G. \& Lakhani, K.H. (1979) Responses of grassland invertebrates to managementby cutting.1. Pecies-Diversity of Hemiptera. Journal of Applied Ecology, 16, 77-98.

Nickel, H. (2003) The leafhoppers and planthoppers of Germany (Hemiptera, Auchenorrhyncha): Patterns and strategies in a highly diverse group of phytophagous insects. Goecke \& Evers, Keltern.

Nickel, H. \& Achtziger, R. (1999) Wiesen bewohnende Zikaden (Auchenorrhynca) im Gradienten von Nutzungsintensität und Feuchte. Beiträge zur Zikadenkunde, 3, 65-80.

Nickel, H. \& Hildebrandt, J. (2003) Auchenorrhyncha communities as indicators of disturbance in grasslands ( Insecta, Hemiptera ) - a case study from the Elbe flood plains ( northern Germany ). Environment, 98, 183-199.

Nickel, H. \& Remane, R. (2002) Artenliste der Zikaden Deutschlands, mit Angabe von Nährpflanzen, Nahrungsbreite, Lebenszyklus , Areal und Gefährdung (Hemiptera, Fulgoromorpha et Cicadomorpha). Beiträge zur Zikadenkunde, 5, 27-64. 
Oomes, M. \& Mooi, H. (1981) The effect of cutting and fertilizing on the floristic composition and production of an Arrhenatherion elatioris grassland. Vegetatio, 46, 233-239.

Pan, Q., Bai, Y., Wu, J. \& Han, X. (2011) Hierarchical plant responses and diversity loss after nitrogen addition: testing three functionally-based hypotheses in the Inner Mongolia grassland. Plos One, 6, e20078.

Pearce, I.S. \& van der Wal, R. (2002) Effects of nitrogen deposition on growth and survival of montane Racomitrium lanuginosum heath. Biological Conservation, 104, 83-89.

Petersen, U., Wrage-Mönnig, N. \& Isselstein, J. (2013) Effects of herbicide application to control sward composition in different management variants. International Journal of Biodiversity Science, Ecosystem Services \& Management, 9, 1-11.

Petersen, U., Wrage, N., Köhler, L., Leuschner, C. \& Isselstein, J. (2012) Manipulating the species composition of permanent grasslands-A new approach to biodiversity experiments. Basic and Applied Ecology, 13, 1-9.

R-Development-Core-Team (2012) R: A language and environment for statistical computing. $\mathrm{R}$ foundation for statistical computing. Vienna, Austria,.

Rose, L., Coners, H. \& Leuschner, C. (2012) Effects of fertilization and cutting frequency on the water balance of a temperate grassland. Ecohydrology, $5,64-72$.

Rose, L. \& Leuschner, C. (2012) The diversity-productivity relationship in a permanent temperate grassland: negative diversity effect, dominant influence of management regime. Plant Ecology \& Diversity, 5, 265-274.

Rose, L., Rubarth, M.C., Hertel, D. \& Leuschner, C. (2012) Management alters interspecific leaf trait relationships and trait-based species rankings in permanent meadows. Journal of Vegetation Science, DOI:10.1111/j.16541103.2012.01455.x.

Sala, O.E., Chapin, F.S., Armesto, J.J., Berlow, E., Bloomfield, J., Dirzo, R., HuberSanwald, E., Huenneke, L.F., Jackson, R.B., Kinzig, A., Leemans, R., Lodge, D.M., Mooney, H.A., Oesterheld, M., Poff, N.L., Sykes, M.T., Walker, B.H., Walker, M. \& Wall, D.H. (2000) Biodiversity - Global biodiversity scenarios for the year 2100. Science, 287, 1770-1774. 
Scherber, C., Eisenhauer, N., Weisser, W.W., Schmid, B., Voigt, W., Fischer, M., Schulze, E.-D., Roscher, C., Weigelt, A., Allan, E., Beszler, H., Bonkowski, M., Buchmann, N., Buscot, F., Clement, L.W., Ebeling, A., Engels, C., Halle, S., Kertscher, I., Klein, A.-M., Koller, R., Konig, S., Kowalski, E., Kummer, V., Kuu, A., Lange, M., Lauterbach, D., Middelhoff, C., Migunova, V.D., Milcu, A., Muller, R., Partsch, S., Petermann, J.S., Renker, C., Rottstock, T., Sabais, A., Scheu, S., Schumacher, J., Temperton, V.M. \& Tscharntke, T. (2010a) Bottom-up effects of plant diversity on multitrophic interactions in a biodiversity experiment. Nature, 468, 553-556.

Scherber, C., Gladbach, D.J., Stevnbak, K., Karsten, R.J., Schmidt, I.K., Michelsen, A., Albert, K.R., Larsen, K.S., Mikkelsen, T.N., Beier, C. \& Christensen, S. (2013) Multi-factor climate change effects on insect herbivore performance. Ecology and Evolution, 3, 1449-1460.

Scherber, C., Mwangi, P.N., Schmitz, M., Scherer-Lorenzen, M., Bessler, H., Engels, C., Eisenhauer, N., Migunova, V.D., Scheu, S., Weisser, W.W., Schulze, E.D. \& Schmid, B. (2010b) Biodiversity and belowground interactions mediate community invasion resistance against a tall herb invader. Journal of Plant Ecology-Uk, 3, 99-108.

Scherber, C., Mwangi, P.N., Temperton, V.M., Roscher, C., Schumacher, J., Schmid, B. \& Weisser, W.W. (2006) Effects of plant diversity on invertebrate herbivory in experimental grassland. Oecologia, 147, 489-500.

Shipley, B. (2000) Cause and Correlation in Biology. Cambridge University Press.

Smart, S.M., Thompson, K., Marrs, R.H., Le Duc, M.G., Maskell, L.C. \& Firbank, L.G. (2006) Biotic homogenization and changes in species diversity across humanmodified ecosystems. Proceedings of the Royal Society B: Biological Sciences, 273, 2659-2665.

WallisDeVries, M.F., Poschlod, P. \& Willems, J.H. (2002) Challenges for the conservation of calcareous grasslands in northwestern Europe: integrating the requirements of flora and fauna. Biological Conservation, 104, 265-273.

Waloff, N. (1973) Dispersal by flight of leafhoppers (Auchenorrhyncha: Homoptera). Journal of Applied Ecology, 705-730.

Warton, D.I. \& Hui, F.K.C. (2010) The arcsine is asinine: the analysis of proportions in ecology. Ecology, 92, 3-10. 
Wesche, K., Krause, B., Culmsee, H. \& Leuschner, C. (2012) Fifty years of change in Central European grassland vegetation: Large losses in species richness and animal-pollinated plants. Biological Conservation, 150, 76-85.

Zechmeister, H.G., Schmitzberger, I., Steurer, B., Peterseil, J. \& Wrbka, T. (2003) The influence of land-use practices and economics on plant species richness in meadows. Biological Conservation, 114, 165-177. 


\section{Supplementary Material}

\section{Study design}

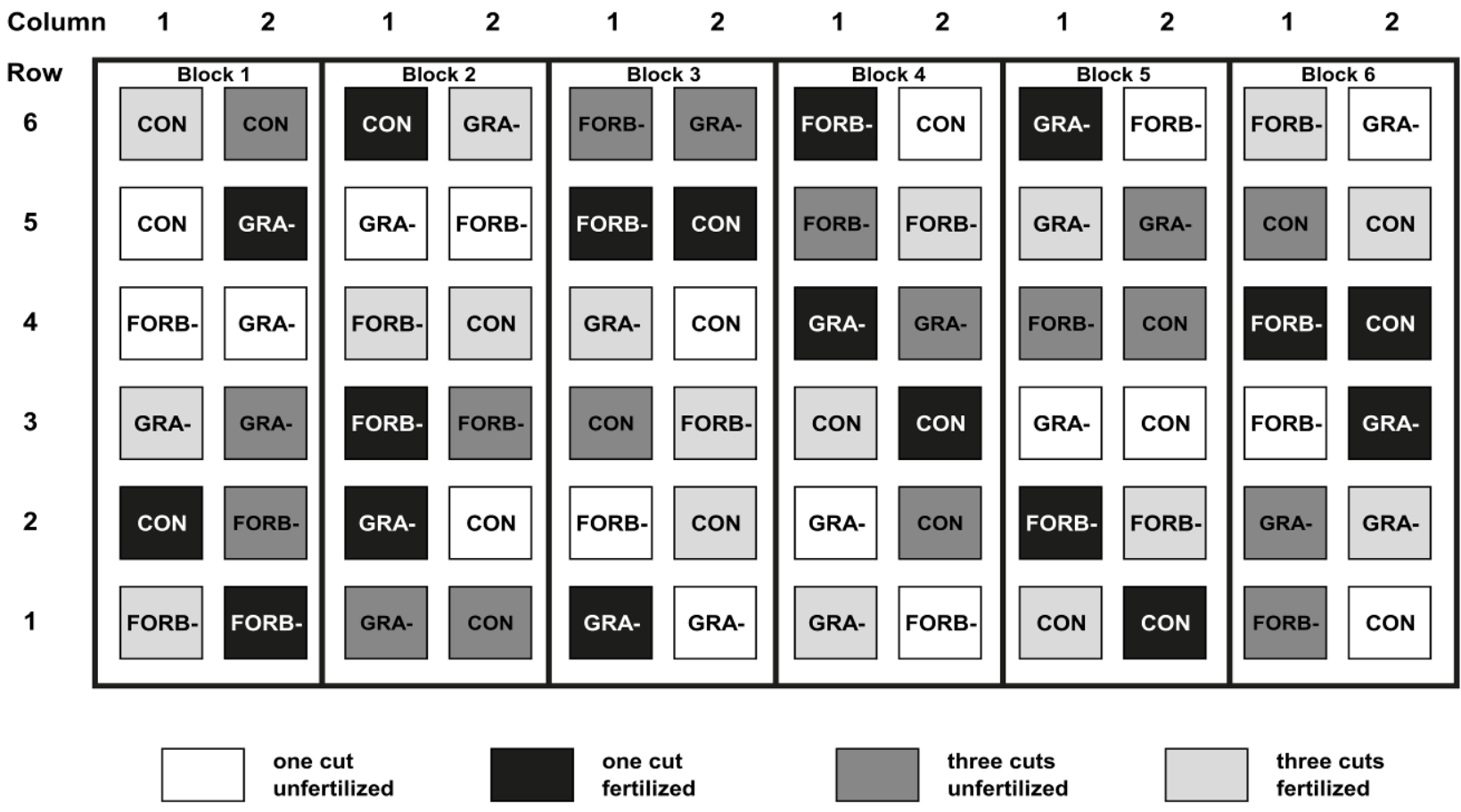

Fig. 4.S1: Experimental design of the Grassman Experiment, showing the Latin rectangle of 12 treatments in 6 replications. Gra- = graminoid reduced plots (=forb enhanced); Forb- =forb reduced (=graminoid enhanced); Con $=$ Control (no herbicide application). The grey area around and between the plots is mown monthly. Plot size $15 \mathrm{~m}$ x $15 \mathrm{~m}$, space between plots $3 \mathrm{~m}$, between blocks $5 \mathrm{~m}$. 


\section{Comparison of sampling methods}

Figure 4.S2 and Table 4.S1 show that sampling method had no interaction effect with the management variable (cutting frequency and fertilizer application).

a)

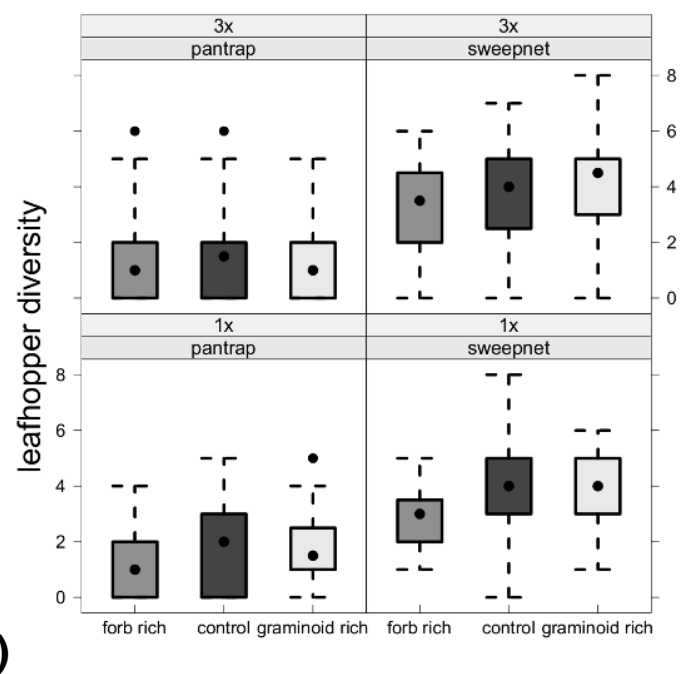

b)

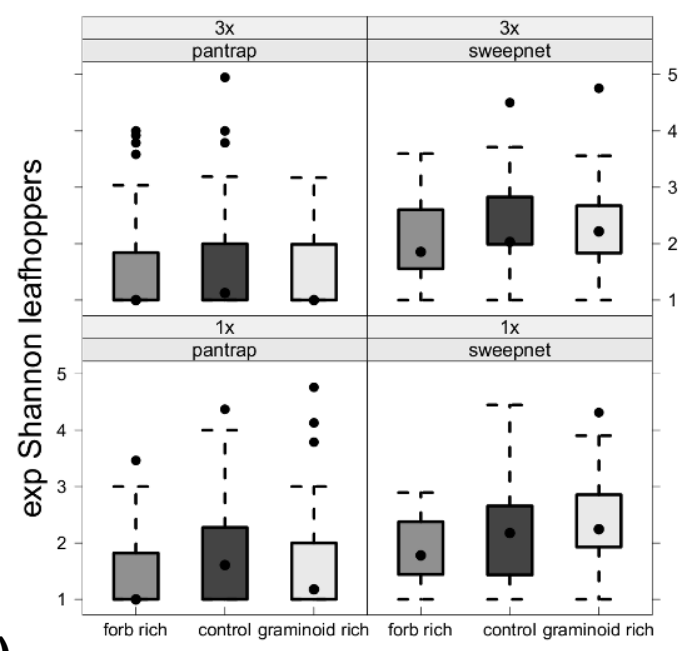

c)

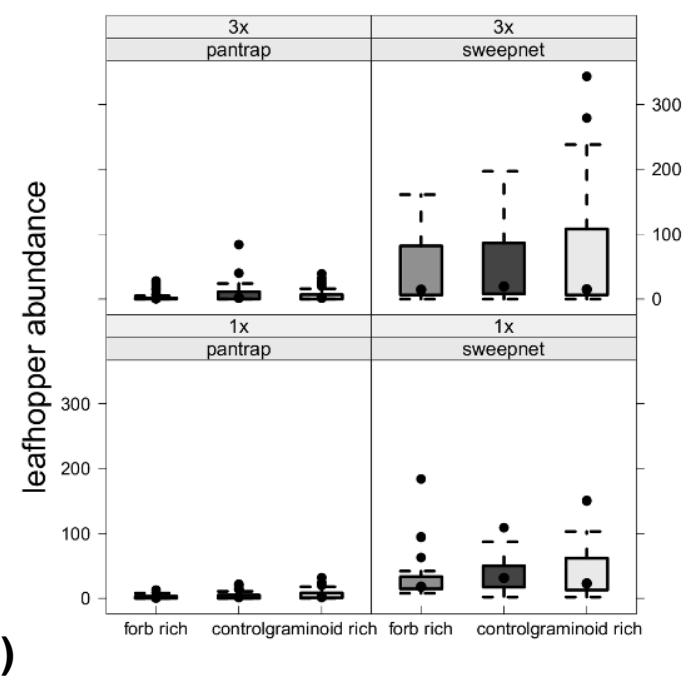

Figure 4.S2: Comparison of the two different sampling methods in combination with functional group manipulation and cutting frequency. (a) leafhopper species richness; (b) leafhopper Shannon diversity $\left(e^{\mathrm{H}^{\prime}}\right)$; (c) leafhopper abundance. 
Table 4.S1: $F$ and $p$-values of glm's testing for significant effects of sampling method in combination with design treatments.

\begin{tabular}{|c|c|c|c|c|c|c|c|c|}
\hline & \multicolumn{2}{|c|}{ Sampling } & \multicolumn{2}{|r|}{$\underline{\mathbf{F G}}$} & \multicolumn{2}{|c|}{ Cutting } & \multirow{2}{*}{\multicolumn{2}{|c|}{$\frac{\text { Sampling: }}{\underline{\text { FG }}}$}} \\
\hline & & & & & & & & \\
\hline & $\mathbf{F}$ & (p) & $\mathbf{F}$ & $(p)$ & $\mathbf{F}$ & (p) & $\mathbf{F}$ & $(p)$ \\
\hline Leafhopper species richness & 197.37 & $(<0.001)$ & 7.68 & $(<0.001)$ & \multicolumn{2}{|c|}{ n.s. } & \multicolumn{2}{|c|}{ n.s. } \\
\hline Leafhopper Shannon diversity & 55.43 & $(<0.001)$ & 6.95 & $(0.001)$ & \multicolumn{2}{|c|}{ n.s. } & \multicolumn{2}{|c|}{ n.s. } \\
\hline$\left(\mathrm{eH}^{\prime}\right)$ & & & & & & & & \\
\hline Leafhopper abundance & 342.06 & $(<0.001)$ & 2.08 & $(0.125)$ & 10.21 & $(0.001)$ & 6.38 & $(0.002)$ \\
\hline
\end{tabular}

Table 4.S2: ANOVA-table: Leafhopper species richness vs. Design

\begin{tabular}{lllllll}
\hline & Df & Deviance & Resid.Df & Resid.Dev & F & $\operatorname{Pr}(>\mathrm{F})$ \\
\hline NULL & 71.000 & 19.347 & & & & \\
as.factor(block) & 5.000 & 2.722 & 66.000 & 16.625 & 3.788 & 0.005 \\
FG manipulation & 2.000 & 1.505 & 64.000 & 15.120 & 5.237 & 0.008 \\
cutting frequency & 1.000 & 4.284 & 63.000 & 10.836 & 29.813 & $<0.001$ \\
as.factor(block):col & 6.000 & 2.571 & 57.000 & 8.265 & 2.982 & 0.013 \\
\hline
\end{tabular}

Table 4.S3: ANOVA-table: Leafhopper abundance vs. Design

\begin{tabular}{lllllll}
\hline & Df & Deviance & Resid.DF & Resid.Dev & $F$ & $\operatorname{Pr}(>\mathrm{F})$ \\
\hline NULL & 71 & 1542.32 & & & & \\
as.factor(row) & 5 & 202.67 & 66 & 1339.65 & 4.8742 & $<0.001$ \\
as.factor(block) & 5 & 419.38 & 61 & 920.28 & 10.0861 & $<0.001$ \\
FG manipulation & 2 & 194.39 & 59 & 725.89 & 11.6877 & $<0.001$ \\
cutting frequency & 1 & 236.7 & 58 & 489.19 & 28.4631 & $<0.001$ \\
\hline
\end{tabular}


Table 4.S4: Species list of the Auchenorrhyncha within the GrassMan experiment with food preferences according to Nickel \& Remane (2002) and their abundance.

\section{Species}

Acanthodelphax spinosa

Anoscopus flavostriata

Anoscopus serratulae

Anoscopus spec.

Aphrodes makarovi

Aphrophora alni

Arthaldeus pascuellus

Balclutha punctata

Cicadella viridis

Cicadula persimilis

Colobotettix morbillosus

Conomelus anceps

Cosmotetix costalis

Criomorphus albomarginatus

Deltocephalus pulicaris

Elymana sulphurella

Errastunus ocellaris

Eupteryx aurata

Eupteryx vittata

Evacanthus interruptus

Javesella dubia

Javesella pellucida

Kosswigianella exigua

Macrosteles viridigriseus

Macustus grisescens

Megadelphax sordidula

Megophtalamus scanicus

Mirabella albifrons

Neophilaenus lineatus

Philaenus spumarius

Psammotettix confinis

Stenocranus minutus

Stiroma bicarinata

Streptanus sordidus

Xanthodelphax stramineus

Zyginidia scutellaris

\begin{tabular}{cc} 
feeding preferences & Abundance \\
graminoids & 14 \\
graminoids & 11 \\
graminoids & 5 \\
graminoids & 10 \\
forbs & 8 \\
forbs & 4 \\
graminoids & 4414 \\
graminoids & 54 \\
graminoids & 8 \\
graminoids & 128 \\
forbs & 1 \\
graminoids & 83 \\
graminoids & 1 \\
graminoids & 1 \\
graminoids & 162 \\
graminoids & 6 \\
graminoids & 5 \\
forbs & 2 \\
forbs & 1 \\
forbs & 1 \\
graminoids & 58 \\
graminoids & 29 \\
graminoids & 1 \\
graminoids & 174 \\
graminoids & 1 \\
graminoids & 1 \\
forbs & 34 \\
graminoids & 1 \\
graminoids & 24 \\
forbs & 698 \\
graminoids & 49 \\
graminoids & 4 \\
graminoids & 1 \\
graminoids & 492 \\
graminoids & 5 \\
graminoids & 6 \\
gra & \\
\hline
\end{tabular}




\section{Leafhopper feeding preferences}

Most of the leafhopper species (28 out of 36) preferred grass as food source. The Shannon diversity of "grass specialists" leafhoppers was lower under three cuts/year $\left(T_{1,57}=-3.34 ; P=0,001\right)$ and with herbicide altered plant composition (forb rich: $T_{1,57=-}$ 3.25; $P=0.002$, graminoid rich: $T_{1,57}=2.33 ; P=0.023$ ). We found no design effects on forb preferring leafhoppers.

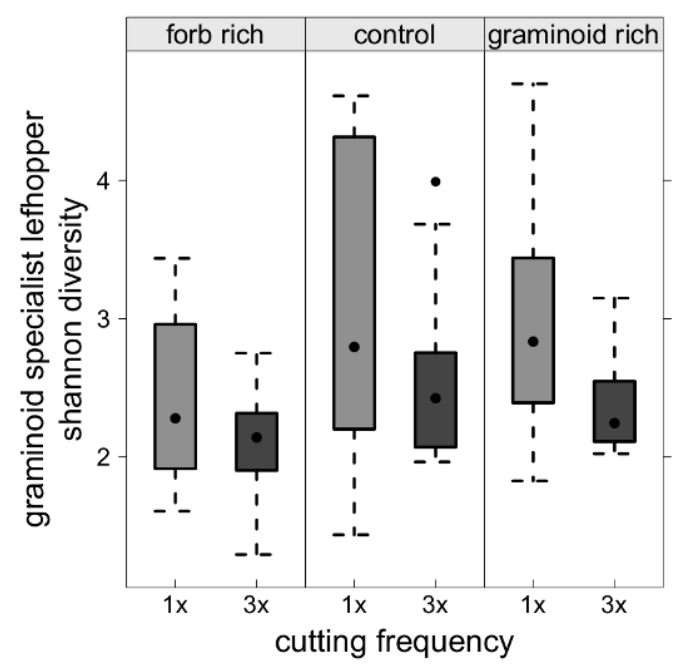

Fig. 4.S3: Box plot showing the effects of herbicide application and cutting frequency on Shannon diversity of grass specialist leafhopper. 
Table 4.S5: Mean and standard error of leafhopper responses to experimental design (treatments)

\begin{tabular}{lccccc}
\hline \multicolumn{1}{c}{ Sward } & Utilization & $\begin{array}{c}\text { Leafhopper } \\
\text { Shannon diversity } \\
\text { mean }( \pm \text { SE) }\end{array}$ & $\begin{array}{c}\text { Leafhopper } \\
\text { abundance } \\
\text { mean }( \pm S E)\end{array}$ & $\begin{array}{c}\text { Grass specialist } \\
\text { Shannon diversity } \\
\text { mean }( \pm S E)\end{array}$ & $\mathbf{N}$ \\
\hline Control & $1 \mathrm{x}$ & $4.02( \pm 0.38)$ & $72.58( \pm 7.33)$ & $3.1( \pm 0.33)$ & 12 \\
forb rich & $1 \mathrm{x}$ & $3.19( \pm 0.15)$ & $60.75( \pm 8.69)$ & $2.42( \pm 0.17)$ & 12 \\
graminoid rich & $1 \mathrm{x}$ & $3.69( \pm 0.27)$ & $87( \pm 10.67)$ & $2.98( \pm 0.22)$ & 12 \\
\hline Control & $3 \mathrm{x}$ & $3.06( \pm 0.26)$ & $110.58( \pm 9.03)$ & $2.58( \pm 0.19)$ & 12 \\
forb rich & $3 \mathrm{x}$ & $2.64( \pm 0.18)$ & $80( \pm 9.81)$ & $2.13( \pm 0.12)$ & 12 \\
graminoid rich & $3 \mathrm{x}$ & $2.58( \pm 0.14)$ & $130.5( \pm 19.31)$ & $2.38( \pm 0.1)$ & 12 \\
\hline
\end{tabular}




\section{ChAPTER 5}

INVERTEBRATE HERBIVORY-DRIVEN NUTRIENT

CYCLING IN A GRASSLAND MANAGEMENT

EXPERIMENT

Georg Everwand, Teja Tscharntke, Johannes Isselstein, Andreas Keuter, Tatiana From, Carola Feßel, Kathleen Lemanski, Annabelle Rohlfing, Hella Schlinkert, Edzo Veldkamp, Franziska Wemheuer \& Christoph Scherbe

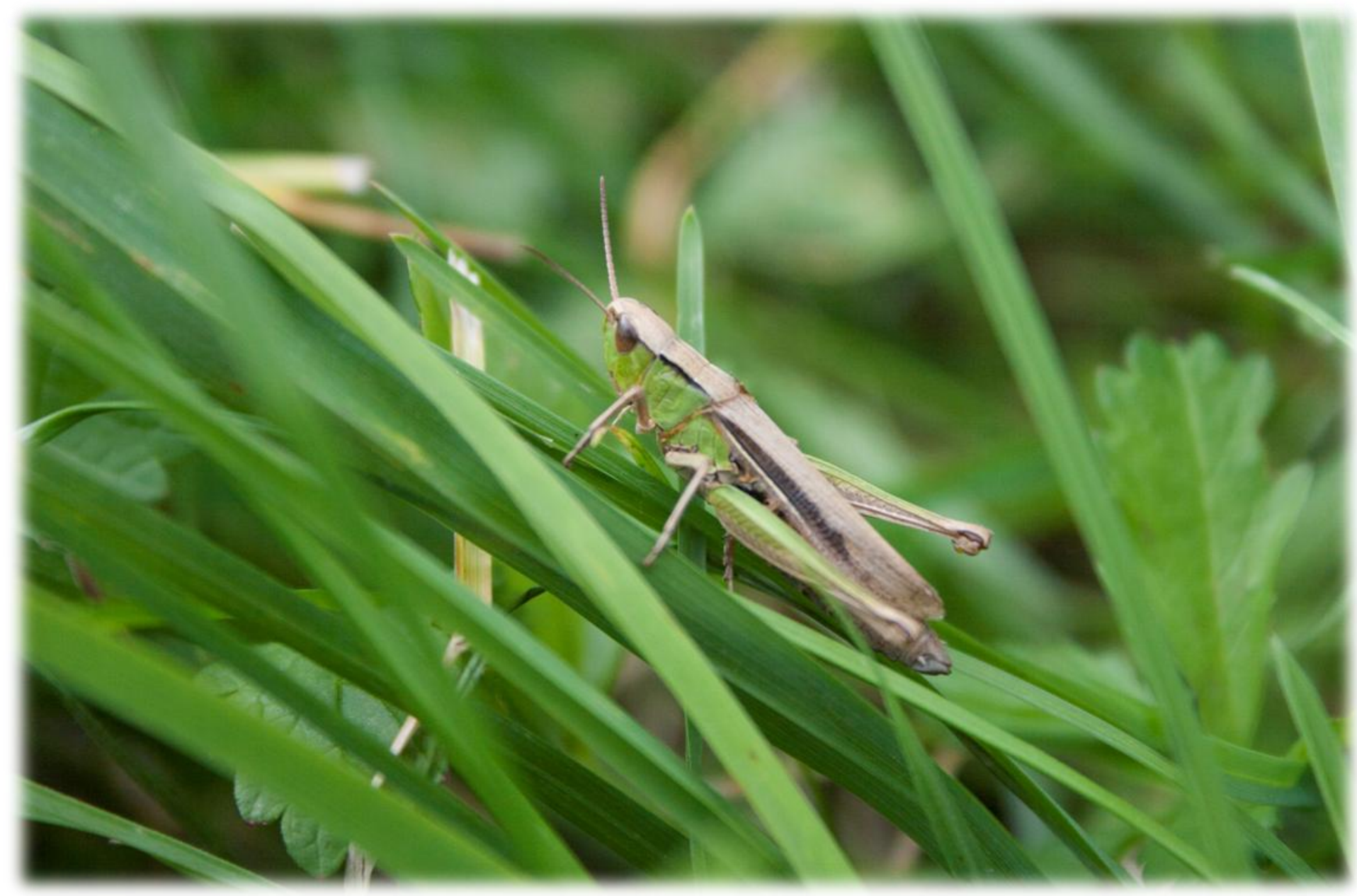




\section{Abstract}

Land-use change is one of the most important causes of biodiversity loss. In grassland ecosystems, management intensification such as higher cutting frequency and fertilizer application may considerably change plant species richness, plant functional-group composition, and associated ecosystem processes. How different practices of grassland intensification interact with each other in their effects on ecosystem processes, including invertebrate herbivory-driven nutrient cycling is not fully understood. We expect that fertilization and cutting affect herbivory-driven nutrient cycling, above- and belowground, in a complex way. We tested this with a functional-group manipulation experiment (using herbicides) the hypothesis that increasing grass cover (independent of grassland management) reduces plant species richness, increases biomass response to fertilization and enhances herbivory-driven nutrient cycling. On an approximately 100 years old grassland, we installed mesocosms in 2010 in the $\mathrm{N}=72$ plots of the Grassman Experiment, differing in fertilization, cutting frequency and plant functional group composition. About one year after the installation of the lysimeters, we induced a strong herbivory pulse over a two-week period using invertebrate herbivores.

We found that the experimental enhancement of grass shares reduced plant diversity, while herbivory and fertilization had opposing effects on grass cover. Furthermore, fertilization and cutting regime as well as herbivory affected plant productivity and nitrogen fluxes stronger than plant functional-group manipulation. A structural equation model suggested that litter production by herbivory increased with $\mathrm{C}: \mathrm{N}$ ratio (presumably due to compensatory feeding) and caused higher nitrate release, which was also higher in fertilized plots. Herbivore-induced nutrient acceleration differed from mineral nutrient applications in $\mathrm{N}_{2} \mathrm{O}$ emissions. In addition, soil nitrate content increased under invertebrate herbivory, especially on fertilized grassland plots.

By combining several management components, which are known from global change scenarios to become increasingly important in the future, we found multiple drivers to play a role in controlling the complex interactions driving nutrient cycling with invertebrate herbivory increasing the potential of nitrate and nitrous oxide release. 


\section{Introduction}

Declining biodiversity is a common effect of increasing agricultural management, especially in European grasslands (WallisDeVries et al. 2002). Permanent meadows and pastures cover about $37 \%$ of the agriculturally used area in Europe (FAOSTAT 2013) and harbor to a large extent the biodiversity of Europe. In order to increase productivity to meet increasing demands for food, fodder and bio-energy, grassland management has been intensified, e.g., by increased fertilizer use, higher cutting frequencies and the use of herbicides (Isselstein et al. 2005).

In temperate ecosystems, many plant and animal species are restricted to grassland habitats (Isselstein et al. 2005), but due to agricultural intensification and land-use change biodiversity in grasslands is under threat (Sala et al. 2000). For example, plant species that are adapted only to low nitrogen levels are replaced by more competitive, faster-growing species (Smart et al. 2006, Wesche et al. 2012). Frequent cutting, which acts like a selective kind of herbivory (Crawley 1989), is beneficial for small, vegetative spreading and early flowering plants. This results in an altered plant composition and vegetation structure, and in a direct removal of food resources for invertebrate herbivores (Isselstein et al. 2005, Everwand et al. 2013).

Invertebrates, such as grasshoppers and snails, are often the dominant invertebrate herbivores in temperate agricultural grassland ecosystems (Stein et al. 2010) and have been shown to affect several components within an ecosystem (Belovsky and Slade 2000).

Herbivores may enhance plant diversity due to feeding directly on competitively dominant plant species and therefore indirectly affect plant competition (Olff and Ritchie 1998). Differences in the feeding intensities and preferences of invertebrate herbivores may affect plant competition and therefore result in differences in plant species richness and composition (Allan and Crawley 2011).

Herbivores are expected to influence nitrogen cycling and plant species composition under diverse management regimes and plant functional group combinations (Belovsky and Slade 2000, Allan and Crawley 2011). 
Invertebrate herbivores may strongly affect nitrogen cycling in terrestrial systems and generally tend to accelerate it and may correlate with feeding intensity and abundance of herbivores (Seastedt and Crossley 1984, Lovett and Ruesink 1995).

This herbivore induced acceleration of nitrogen cycling can also increase productivity of plants, which are avoided by herbivores due to an release of competition and more available nutrients (Belovsky 2000).

Fast decomposing herbivore excrements may provide nutrients even on a rather short time scale of two weeks, if these nutrients are less available beforehand (Belovsky and Slade 2000).

Dominant but preferred food plants are better competitors when nutrients are more available, because food quality is better and herbivores feed less (Berner et al. 2005). However, combined with herbivory, fertilizer application may further accentuate nitrogen cycling, resulting in an increase of components of the nitrogen flux, such as nitrous oxide $\left(\mathrm{N}_{2} \mathrm{O}\right)$ emission.

Nitrogen cycling in the soil is related to many important ecosystem functions such as biodiversity, productivity (Oelmann et al. 2011) or water balance (Rose et al. 2012a).

Application of nitrogen fertilizer affects the nitrogen cycling in grasslands including the $\mathrm{N}$ mineralization and nitrification (Keuter et al. 2012). There are also studies, linking emissions of greenhouse gases such as $\mathrm{N}_{2} \mathrm{O}$, to grassland management ( $\mathrm{Li}$ et al. 2013) or animal production systems (Clough et al. 2013).

However, little is known about how nitrogen cycling and $\mathrm{N}_{2} \mathrm{O}$ emissions respond to invertebrate herbivores in combination with agricultural management and shifts in plant functional group composition as well as plant diversity.

Many studies on trophic interactions in biodiversity experiments have largely relied on artificially sown gradients of plant diversity (Roscher et al. 2004, Scherber et al. 2006, Scherber et al. 2010a, Tilman et al. 2012) or have only investigated the effects of fertilizer application and cutting frequency (Pavlů et al. 2011). Exclusion experiments (Curry 1994, Scherber et al. 2003, del-Val and Crawley 2004, Scheidel and Bruelheide 2005, Scherber et al. 2006) have shown invertebrates to strongly affect plant biomass production and species composition in grasslands. 
However, it is not yet well understood and not studied so far, within one experiment, how herbivory-driven nitrogen cycling interacts with grassland management when fertilization, cutting and functional-group composition are simultaneously manipulated.

We used a plant functional group manipulation experiment (Diaz et al. 2003) to better understand the effects of invertebrate herbivory on plant community composition and nutrient cycling. Using herbicides, we suppressed either dicots or monocots to test the idea that independently of grassland management practices, an increasing graminoid cover reduces plant species richness, increases biomass response to fertilization and enhances herbivory-driven nutrient cycling. A removal or manipulation experiment should better reflect the real-world effects of herbivory on nitrogen flux, caused by changes in grassland management than a functional-group composition treatment based on sown gradients (Diaz et al. 2003).

To disentangle the direct and indirect interactions within the system, we conducted our study using in-field lysimeter mesocosms, testing the following hypotheses:

1) Responses of plant community and nitrogen cycling become more complex with increasing number of interacting drivers (management, functional group manipulation, herbivory).

2) Herbicide induced reduction of graminoid cover enhances forb cover and thereby plant diversity and nitrogen cycling.

3) Fertilizer application and cutting frequency negatively affect plant diversity and nitrogen cycling due to changes in disturbance regimes and nutrient availability with increasing management intensity.

4) Invertebrate herbivory negatively affects graminoid cover and accelerates nitrogen cycling due to litter and excrement input. 


\section{Material and Methods}

Description of the study site

The study site of the "GrassMan"-Experiment (Petersen et al. 2012) is situated near Neuhaus (Solling) in the Solling Mountains of Northern Germany $\left(51^{\circ} 440 \mathrm{~N}, 9^{\circ} 320 \mathrm{E}\right.$, $490 \mathrm{~m}$ a.s.l.). Prior to the start of the experiment in 2008 the site was a nutrient poor, moderately wet Lolio-Cynosuretum grassland with high abundances of the grasses Agrostis capillaris (L.) and Festuca rubra (L.) and of the herbs Rumex acetosa (L.), Veronica chamaedrys (L.) and Ranunculus repens (L.) (Petersen et al. 2012). Mean annual precipitation is $1031 \mathrm{~mm}$ and mean annual temperature is $6.9^{\circ} \mathrm{C}$ (Deutscher Wetterdienst, 1961-1990, station Holzminden-Silberborn, $440 \mathrm{~m}$ a.s.I.). In the year of the study (2011), mean annual temperature was $8.9^{\circ} \mathrm{C}$ and annual precipitation was $725 \mathrm{~mm}$. The dominant soil type in the experimental area is a shallow $(40-60 \mathrm{~cm})$, stony Haplic Cambisol with a loamy silt texture, developed in loess sediments covering the Middle Buntsandstein formation (Triassic sandstone) (Keuter et al. 2012).

\section{Study design}

The experiment was established in 2008 on a permanent, formerly extensively cattlegrazed grassland and laid out as a three-factorial Latin rectangle (Clewer and Scarisbrick 2001) with the following factors: (i) plant functional group manipulation (3 levels) using herbicides, (ii) fertilizer application (2 levels) and (iii) cutting frequency (2 levels), resulting in twelve treatment combinations. To manipulate plant functional group presence, we applied (a) a combination of the forb-specific herbicides Fluroxypyr (Starane; Dow AgroSciences, Munich, Germany; $3 \mathrm{~L} \mathrm{ha}^{-1}$ ) and MecopropP (Duplosan; KV, Du Pont de Nemours, Neu-Isenburg, Germany; $3 L$ ha $^{-1}$ ) or (b) the graminoid-specific herbicide Select 240 EC (Stähler Int., Stade, Germany; 0.5 L ha ${ }^{-1}$ ), or finally (iii) no herbicide. These combinations resulted in three levels of plant diversity: i) forb reduced (=graminoid enhanced), ii) graminoid reduced (=forb enhanced) and iii) control. Herbicides were applied once at the beginning of the experiment in June 2008 ("pulse" experiment sensu Bender et al. (1984). 
This manipulation of the functional groups did not result in enlarging of bare ground patches. The unaffected plants occupied the space of the plants targeted with the herbicide very, maintaining a dense vegetation cover.

From 2009 onwards, plots were fertilized as follows: $\mathrm{N}$ fertilizer (Calcium ammonium nitrate $\mathrm{N} 27: 13.5 \% \mathrm{NH}_{4}-\mathrm{N}, 13.5 \% \mathrm{NO}_{3}-\mathrm{N}, 4 \% \mathrm{MgO}, 6 \% \mathrm{Ca}$ ) was applied at two equal doses $\left(2 \times 90 \mathrm{~kg} \mathrm{ha}^{-1}\right)$ in April and May/June. In addition, fertilized plots received $\mathrm{P}$ $\left(30 \mathrm{~kg} \mathrm{ha}^{-1}\right)$ and $\mathrm{K}\left(100 \mathrm{~kg} \mathrm{ha}^{-1}\right)$ in early June (Thomaskali $\Theta, 8 \% \mathrm{P}_{2} \mathrm{O}_{5}, 15 \% \mathrm{~K}_{2} \mathrm{O}$, $20 \% \mathrm{CaO}$ ). Control plots of the fertilizer treatment were not fertilized. Plots were cut at a height of $7 \mathrm{~cm}$ either once (in July) or three times a year (May, July, September) using a Haldrup $\circledast$ forage combine harvester (INOTEC Engineering $\mathrm{GmbH}$, Ilshofen, Germany). The resulting twelve treatment combinations (equalling one block of the Latin rectangle; Everwand et al. 2013) were arranged randomly and replicated six times, resulting in 72 quadratic plots with $15 \mathrm{~m}$ side length.

Plant functional groups were not entirely removed but strongly reduced in abundance, with slow recovery after herbicide application. However, even three years after functional group manipulation, all functional group manipulation treatments significantly affected several vegetation parameters, such as compressed vegetation height, biomass, functional group composition and plant species richness on the small lysimeter scale, but not on plot level (Keuter et al. under review).

More details on the experimental design, setup and treatment effects on vegetation can be found in Petersen et al. (Petersen et al. 2012, Petersen et al. 2013) and Rose et al. (Rose et al. 2012a, Rose et al. 2012b).

\section{Lysimeters}

The lysimeters were installed one year prior to the start of the herbivory experiment in August and September 2010 to give the soil core time to regenerate after the disturbance. Lysimeters were made from transparent Plexiglas cylinders (height 30 $\mathrm{cm}$, inside diameter $14.6 \mathrm{~cm}$, wall thickness $0.3 \mathrm{~cm}$ ). A transparent material was selected in order to control if the soil core was free from cracks, holes or large stones. To install lysimeters, a sharpened, tightly fitting metal ring was fixed on the bottom of the cylinder. 
A metal cap was fixed on the head end of the plastic cylinder to avoid damage of the Plexiglas whilst driving it into the soil using a hammer. After extracting the cylinder and the intact soil core, an exactly fitting baseplate with a culvert (diameter $1.6 \mathrm{~cm}$ ) was fixed to the bottom of the lysimeter using a light curing adhesive (Acrifix ${ }^{\circledR} 192$ ). To collect the drainage water, a Plexiglas tube (length $10 \mathrm{~cm}$ ) was connected to the culvert in the baseplate. To ensure an effective drainage of drainage water, the baseplate was covered with 70 fiberglass wicks (diameter $0.1 \mathrm{~cm}$ ), which channeled the water from the lysimeter through the culvert into a PE-bottle placed underneath.

The hole where the lysimeter was extracted from was stabilized using a PVC-cylinder (height $50 \mathrm{~cm}$, inside diameter $15.5 \mathrm{~cm}$ ) as permanent cladding, also to protect the lysimeter and allow frequent weighing and sampling of the drainage water.

\section{Cages}

Cages around the above-ground part of each lysimeter were made of gauze of $1.5 \mathrm{~mm}$ mesh size, which were sewed to fit tightly to the lysimeter and additionally fixed using a zip tie. The whole gauze cage was stabilized and protect from heavy wind using a bamboo stick with a length of $45 \mathrm{~cm}$, which was pushed into the ground for $15 \mathrm{~cm}$.

\section{Herbivores}

We selected a combination of mainly forb-feeding (Helix pomatia.) and mainly graminoid-feeding (Chorthippus albomarginatus) herbivores to ensure an equal level of herbivory, independent of plant community composition. Both species are common in central European grasslands, but $H$. pomatia doesn't inhabit the experimental area. Feeding preferences of these herbivores can be found in Pollard (1975) and Gardiner et al. (2002). All individuals of $H$. pomatia were of the same age, size and weight. They were delivered by a specialized snail breeder (Thüringer Weinbergschnecken-zucht, www.weinbergschnecken-thueringen.de) one week before start of the herbivory treatment to give the animals time to adapt to the new food composition. Individuals were starved for 24 hours prior to the start of the treatment. 
We used grasshopper females as these consume more than males (Franzke et al. 2010). One week before the start of the herbivory treatment, we caught grasshoppers of the species $C$. albomarginatus from another part of the experimental field site using sweep nets.

Between the two lysimeters per plot were randomly assigned the control and herbivory treatment and applied four grasshoppers and one snail per herbivory lysimeter. During the experiment, we replaced dead individuals to maintain a constant and consistent feeding pressure on the vegetation.

After two weeks, lysimeters were removed. At first, we performed all non-destructive measurements, e.g. vegetation surveys, plant height, weight of the lysimeter, gasand $\mathrm{H}_{2} \mathrm{O}$ fluxes as well as photographs for cover and vegetation structure analysis. Then we cut the above-ground vegetation and the soil core was removed from the inner plastic cylinder. The top $0-5 \mathrm{~cm}$ and the top $5-10 \mathrm{~cm}$ of the soil core were prepared for further analyses. One quarter of each depth was used to determine the root biomass. The remaining three quarters of each depth were homogenized and used for further soil analyses at.

Measurements taken

a. Plant composition and yield proportions

Vegetation surveys in each lysimeter were done before and after the herbivore treatment. In each survey, we recorded all plant species present, percentage cover and percentage litter (dead plant material). Furthermore, we determined the proportional yield of each species as well as for graminoids and forbs using the method of Klapp and Stählin (1936). From these visual estimates we assessed plant species richness (measured as number of plant species per lysimeter) and functional group composition (expressed as percentage of single plant species and functional groups).

b. Above-ground biomass (AGB)

At the end of the experiment, we cut the vegetation of each lysimeter at ground level. In order to determine fresh weight, dry weight and AGB water content, each sample 
was first weighed using special accuracy weighing machine and then oven-dried for $48 \mathrm{~h}$ at $60^{\circ} \mathrm{C}$ using a drying oven and then re-weighed. AGB water content was calculated as follows:

proportional $A G B$ water content $=1-\frac{d r y \text { weight }}{\text { wet weight }}$

c. N-cycle measurements

Oven-dried plant samples from the second cut (mid-July) of 2010 were milled and analyzed for carbon (C) and nitrogen ( $\mathrm{N}$ ) concentration using a CNS elemental analyser (Elementar Vario El, Hanau, Germany). Afterwards, the $\mathrm{C} / \mathrm{N}$ ratio was determined. Net $\mathrm{N}$ mineralization rates were measured using the buried bag method.

Directly after the herbivory treatment, two soil samples (of each lysimeter) were taken from the Ah soil horizon $(0-5 \mathrm{~cm})$. One sample was extracted directly in the field in


the laboratory, shaken for one hour and filtered through $\mathrm{K}_{2} \mathrm{SO}_{4}$-prewashed filter papers $(4 \mu \mathrm{m}$ nominal pore size). Filtered samples were stored in a freezer until analysis. $\mathrm{NH}_{4}{ }^{+}$and $\mathrm{NO}_{3}{ }^{-}$were measured using continuous flow injection colorimetry (Skalar, Cenco Instruments, Breda, The Netherlands). The second sample was transferred to an air-permeable plastic bag, incubated for ten days, and extracted as described above.

$\mathrm{NH}_{4}{ }^{+}$and $\mathrm{NO}_{3}{ }^{-}$was calculated using the Berthelot reaction method (Skalar Method 155-000) or the copper-cadmium reduction method (Method 461-000), respectively (Hart et al. 1994). For the determination of the gravimetric soil moisture content, each sample was weighed, dried at $105^{\circ} \mathrm{C}$ for 24 hours and weighed again. Net $\mathrm{N}$ mineralization rates $\left[\mathrm{mg} / \mathrm{m}^{2} / \mathrm{d}\right]$ were calculated from the difference between soil mineral $\mathrm{N}$ contents before and after incubation and with the incubation time for each sample. Net nitrification $\left[\mathrm{mg} / \mathrm{m}^{2} / \mathrm{d}\right]$ was determined as difference between $\mathrm{NO}_{3}{ }^{-}$ contents before and after the incubation for each sample (Hart et al. 1994, Keuter et al. 2012). 


\section{d. $\mathrm{N}_{2} \mathrm{O}$ gas fluxes}

$\mathrm{N}_{2} \mathrm{O}$ fluxes were determined using the closed chamber method. PVC chamber hoods fitted with an air sample port were installed on each lysimeter. Sampling was conducted three days before and one day after the herbivory treatment. Gas samples were taken in evacuated $100 \mathrm{ml}$ gas containers with teflon-coated stopcocks at 0,15, 30 and 45 minutes after chamber closure. $\mathrm{N}_{2} \mathrm{O}$ concentrations in gas samples were analyzed using a gas chromatograph (GC 6000, Carlo Erba Instruments/Thermo Fisher Scientific, Milan, Italy) equipped with an electron capture detector and an auto-sampler system (Loftfield et al. 1997).

Gas concentrations were calculated by comparing integrated peak areas of samples with three standard gases (353, 1005, and 1592 ppb $\mathrm{N}_{2} \mathrm{O}$; Deuste Steiniger $\mathrm{GmbH}$, Mühlhausen, Germany). $\mathrm{N}_{2} \mathrm{O}$ fluxes were calculated by the linear increase of $\mathrm{N}_{2} \mathrm{O}$ concentration versus time for each chamber with the ideal gas law, corrected with air temperature, chamber volume and air pressure (Ruser et al. 1998).

\section{e. Statistical Analysis}

Data were analysed using the statistical software package "R" (version 2.15.2) (RDevelopment-Core-Team 2012). Treatment effects on vegetation and ecosystem processes were assessed using linear mixed effect models (LMEs), using plot as a random effect to avoid pseudoreplication (one herbivory and one control lysimeter per plot) (Pinheiro and Bates 2000). Proportion data were logit-transformed prior to analysis. Models contained plant functional group composition (factor with three levels), herbivory, cutting frequency and fertilizer application (two levels each) with up to two-way-interactions. To account for heteroscedasticity, we tested the varPower variance structure and varldent variance structure (Zuur et al. 2009) for all design variables (herbivory, fertilizer application, functional group composition, cutting frequency, row, column and block) and compared the resulting models using AICC (Scherber et al. 2010b).

R-code:

model=Ime $\left(\right.$ response $\sim(\text { sward+utilization+nutrients+herbivory })^{\wedge} 2$,random $=\sim 1 \mid$ plot,data=data $)$ 
For each response variable in turn, the best maximal model containing the optimal combination of random-effects structure and variance functions was then automatically simplified (using maximum likelihood-based estimation) into models containing fewer explanatory variables. The models were subsequently compared using AICc, until a minimal adequate model containing only significant effects was obtained using REML estimation (Zuur et al. 2009). The significance of the effects was tested using ANOVA. Differences in degrees of freedom between some treatment combinations are due to broken lysimeters, resulting in a final sample size of 142 lysimeters.

To compare the effects of herbivory on the nitrogen cycle in lysimeters with and without herbivory, we employed path analyses in addition to traditional LME-based analyses, using a multi-group structural equation model. This structural equation model (SEM) allowed us to test more complex hypotheses of indirect effects of herbivory and fertilizer application on nitrogen cycling (Bollen 1989, Shipley 2000, Scherber et al. 2010b). SEMs are particularly well suited in experimental contexts, i.e. where some variables are manipulated experimentally (Grace 2006).

Further, SEMs "can be used to develop accurate and meaningful final multiple regression models when collinearities among explanatory variables are thought to be present" (Graham 2003). For example, this was clearly the case for Nitrogen-flux measures in a study of Scherber et al.(2010a). In the present study, structural equation models contained only fertilizer application as management treatment variable. Functional group manipulation had no significant effect on the measured nitrogen cycle components. Cutting frequency showed a negative impact only on $\mathrm{N}_{2} \mathrm{O}$ flux rate but had also no significant effects on other parts of the measured nitrogen cycle components. For this reason, we excluded these variables from the path analysis. Herbivory was used as a grouping variable in the multi-group analysis. Models were fitted using maximum likelihood, and model fit was assessed using $\mathrm{Chi}^{2}$ tests and the confidence interval of the residual mean square error of approximation (RMSEA). 


\section{Results}

a. Treatment effects on functional group composition on lysimeters Application of NPK-fertilizer in combination with functional group-manipulation (FGmanipulation) (Fertilizer:FG-manipulation interaction: $F_{2,65}=4.20 ; p=0.019$ ) led to the highest proportion of graminoids with up to $92.25 \pm 3.73 \%$ in forb-reduced plots (Fig. 5.1). Moreover, the much higher proportion of graminoids under herbivory in fertilized plots compared to unfertilized ones after herbivory visualized the interaction effect of herbivore pressure and NPK-fertilizer on proportion of graminoids (Fertilizer:Herbivory interaction: $\mathrm{F}_{1,69}=22.72 ; p<0.001$ ). The proportion of graminoids in unfertilized plots with herbivory was as low as to $8.83 \pm 5.01 \%$ of the AGB. But generally, herbivory reduced the proportion of graminoids (Herbivory main effect: $\left.F_{1,69}=21.55 ; p<0.001\right)$, as the lower proportion of graminoids under herbivory showed (Fig. 5.1).

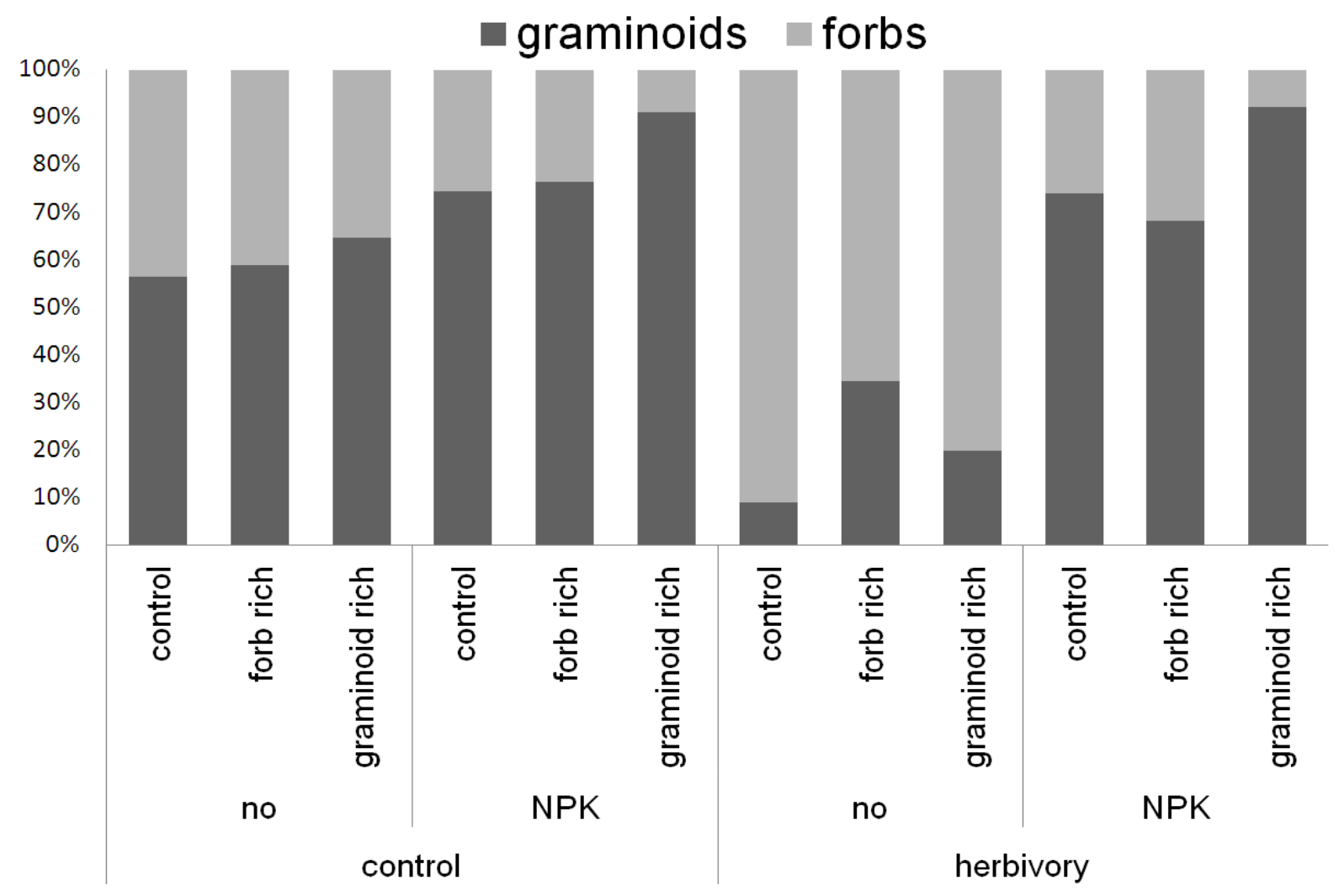

Fig. 5.7: Graminoid and forb proportions of the lysimeters in relation to functional group manipulation, fertilizer application and herbivory. Dark grey = graminoids; light grey = forbs (including legumes). 
The proportion of both graminoids and forbs was affected by functional group manipulation (Fig 5.1; FG main effect: $F_{2,65}=4.39 ; p=0.016$ ); with significantly fewer forbs in forb-reduced plots. Furthermore, NPK-fertilizer application had a positive effect on the proportion of graminoids (Fertilizer main effect: $F_{1,65}=64.30 ; p<0.001$ ).

b. Treatment effects on plant species diversity on lysimeters Plant species richness in lysimeters prior to the herbivore treatment was significantly affected by all three design treatments (fertilization, cutting, FG-manipulation). We found a higher plant species richness under three cuts per year (Fig. 5.2a; Cutting: $\left.F_{1,66}=11.18 ; p=0.001\right)$. In contrast to this, NPK-fertilizer application resulted in lower plant diversity (Fig. 5.2b; Fertilizer: $F_{1,66}=35.38 ; p<0.001$ ).

Functional group manipulation had a strong effect on plant diversity (FG main effect: $F_{2,66}=5.48 ; p=0.006$ ). For example, the plant diversity was low in graminoidsreduced plots (Fig. 5.2c). 
a)

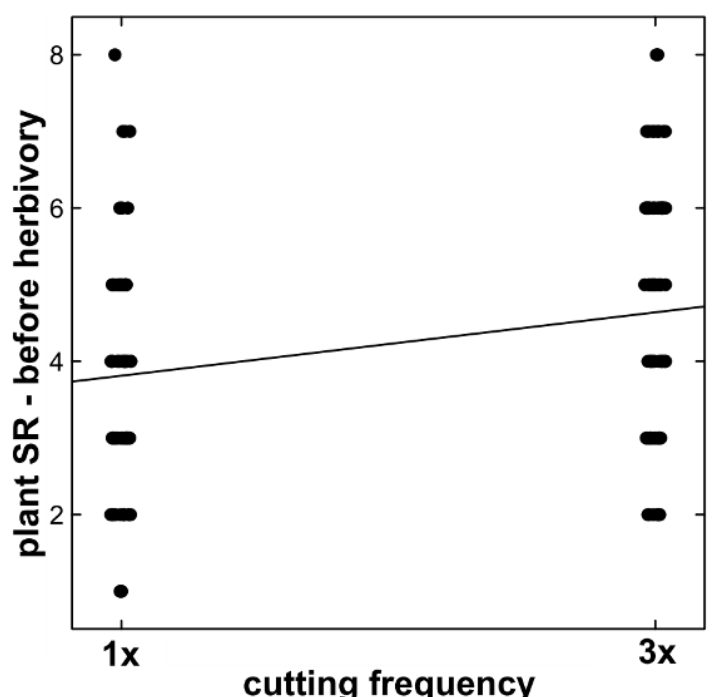

cutting frequency

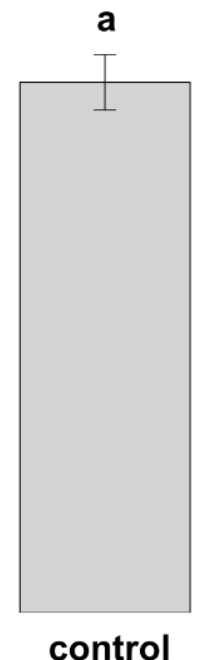

control

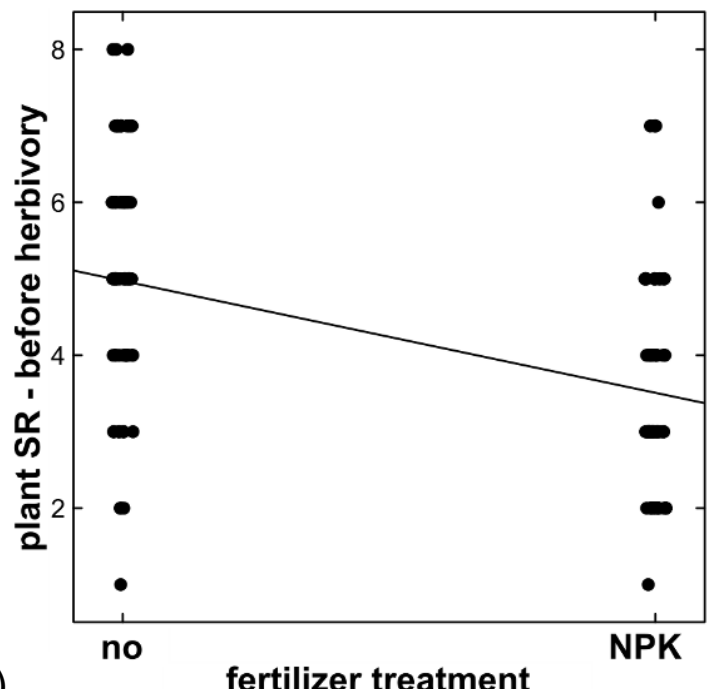

b)

fertilizer treatment b

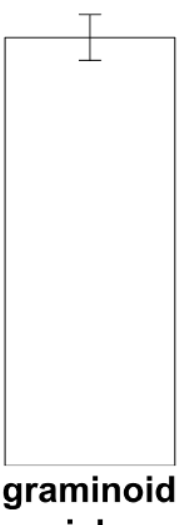

c)



rich

Fig. 5.8: Plant species richness on the lysimeters in combination with the management treatments cutting frequency (a) and fertilizer application (b) before herbivory. The bargraph (c) shows the effects of functional group (FG) manipulation on plant species richness. Forb rich (dark grey) = reduction of graminoids; control (light grey) = no FG manipulation; graminoid rich (white) = reduction of forbs. 

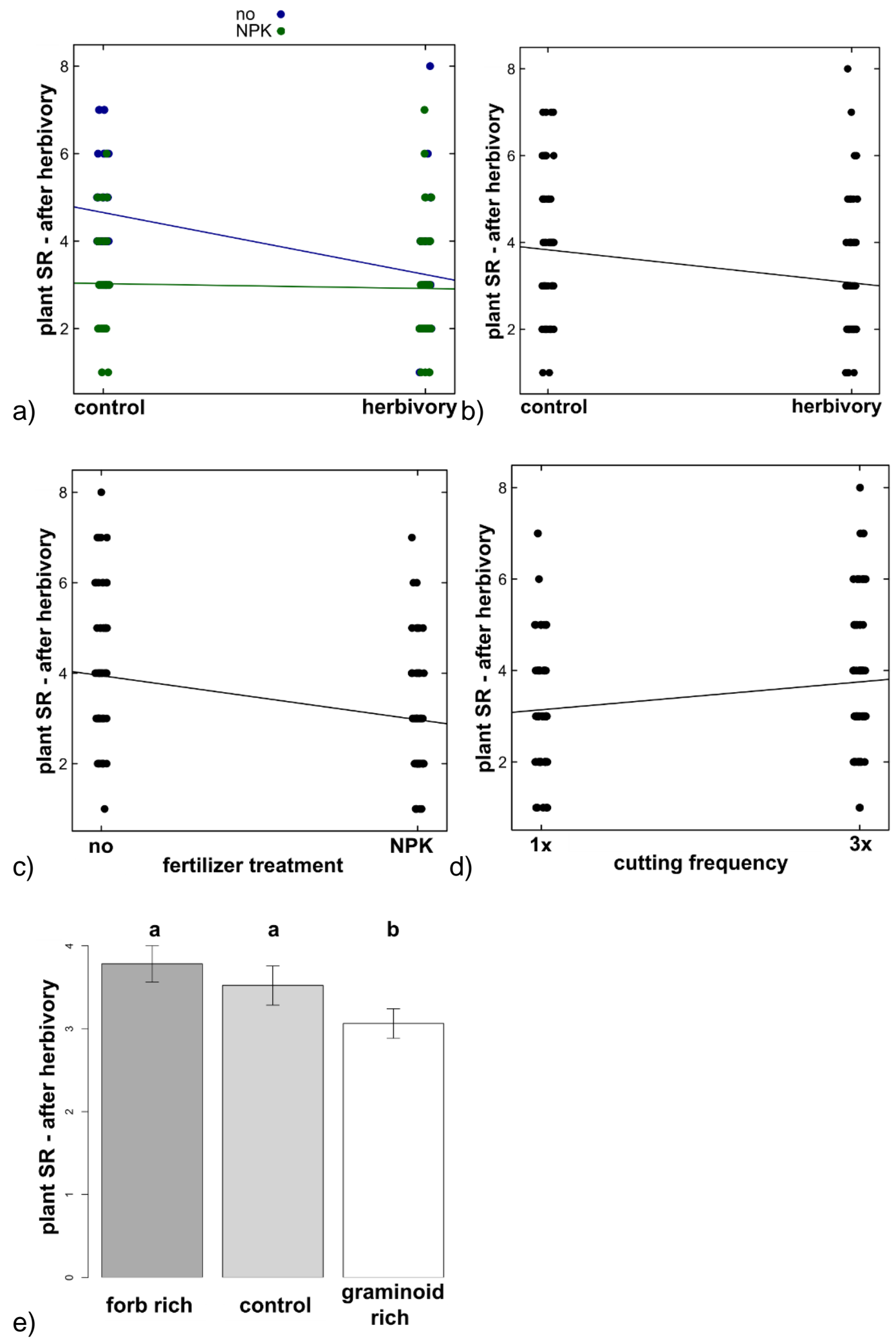

Fig. 5.9: Effects of experimental treatments on plant species richness after herbivory. a) Effects of herbivory in combination with fertilizer application: control (left) $=$ no herbivores; herbivory (right) $=$ high herbivore pressure; blue $=$ no fertilizer; green $=$ NPK fertilizer application. $b$ ) Effects of fertilizer application; c) Effects of herbivory; d) Cutting frequency e) Effects of functional group manipulation: forb-rich (= reduction of graminoids); control sward (= no FG manipulation); graminoid-rich (= reduction of forbs). 
After two weeks of herbivory, we found a significant two-way interaction between herbivory and NPK-fertilizer application (Herbivory:Fertilizer interaction: $F_{1,69}=10.42$; $p=0.002$ ). Plant species richness was slightly higher with fertilizer application and herbivory (Fig 5.3a).

When considered separately, both NPK-fertilizer application (Fig. 5.3b; Fertilizer main effect: $F_{1,66}=13.14 ; p<0.001$ ) and herbivory (Fig. 5.3c; Herbivory main effect: $F_{1,69}=11.45 ; p=0.001$ ) had a negative effect on plant species richness.

Three cuts per year (Fig. 5.3d) had a positive effect on plant species richness (Cutting main effect: $F_{1,66}=7.51 ; p=0.008$ ). The effect of functional group manipulation on plant species richness ( $F G$ main effect: $F_{2,66}=3.92 ; p=0.025$ ) was also still visible and significant after herbivory, with higher plant species richness in forb-rich plots and lower plant species richness in graminoid-rich plots (Fig. 5.3e).

c. Treatment effects on above-ground biomass (AGB)

Total AGB: After herbivory, the harvested dry weight of total $A G B$ in lysimeters (Fig. 5.4a) was significantly higher in fertilized plots (Fertilizer main effect: $F_{1,68}=9.30$; $p=0.003$ ). Both, increased cutting frequency (Cutting main effect: $F_{1,68}=5.73 ; p=0.019$ ) and herbivory (Herbivory main effect: $F_{1,70}=15.80 ; p<0.001$ ), resulted in lower $A G B$ in the lysimeters. When forb and graminoid biomass were considered separately, the impact of herbivores became apparent (Fig. 5.1 \& 5.4).

Graminoid AGB: There was a significant two-way interaction between NPKfertilizer and herbivory on harvested above-ground biomass of graminoids (Fertilizer:Herbivory interaction: $\mathrm{F}_{1,69}=5.66 ; p=0.020$ ), which resulted in a stronger impact of herbivory in unfertilized plots (Fig. 5.4b). AGB of graminoids increased under NPK-fertilizer application (Fertilizer main effect: $F_{1,68}=46.10 ; p<0.001$ ) and strongly decreased with herbivory (Herbivory main effect: $F_{1,69}=50.25 ; p<0.001$ ). In addition, AGB of graminoids was generally lower under three cuts/year than under one cut/year (Cutting main effect: $F_{1,68}=6.41 ; p=0.014$ ). 
Forb AGB: We also found a significant two-way interaction between NPK-fertilizer and herbivory on harvested above-ground biomass of forbs (Fertilizer:Herbivory interaction: $F_{1,69}=28.49 ; p<0.001$ ). Forb biomass (as well as proportion; see Fig. 5.1) was enhanced by herbivory, but only in unfertilized plots (Fig. 5.4c). Fertilizer application itself had a negative effect on forb biomass (Fertilizer main effect: $\left.F_{1,69}=26.71 ; p<0.001\right)$.

In contrast to graminoids, forb biomass (Fig. 5.4c) increased in response to herbivory (Herbivory main effect: $F_{1,69}=4.51 ; p=0.037$ ). Cutting frequency had no significant effect on forb biomass.


Fig. 5.10: Treatment effects (herbivory, fertilizer application, cutting frequency) on dry weight [g / lysimeter] of above-ground biomass (AGB) of a) total AGB, b) graminoid AGB and c) forb AGB. NPK (green) = NPK fertilizer application; no $($ blue $)=$ no fertilizer. 
The proportion of litter [\%] in the total AGB showed a significant interaction effect between herbivory and fertilizer application (Herbivory:Fertilizer interaction: $F_{1,69}=9.80 ; p=0.003$ ). This becomes apparent with the lower proportion of litter (due to herbivore activity) in fertilized plots (Fig. 5.5a).

a)

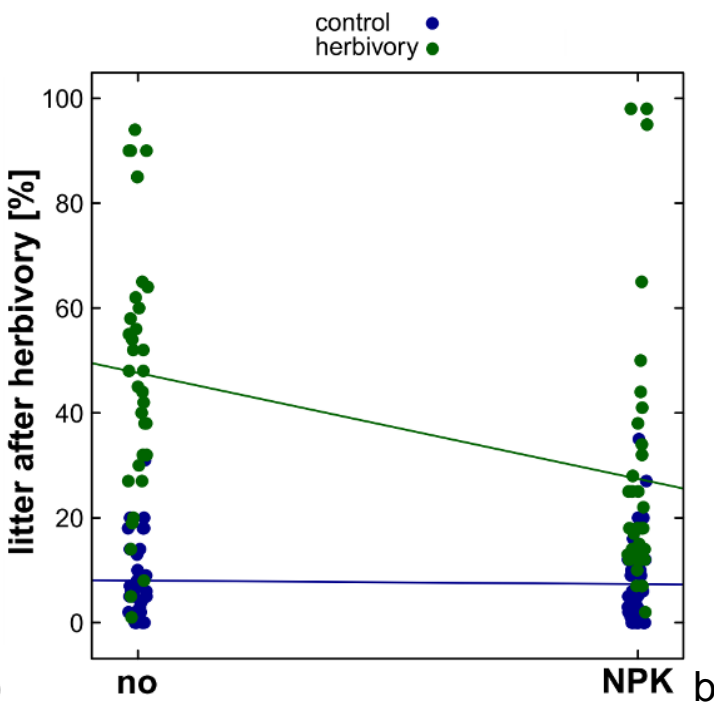

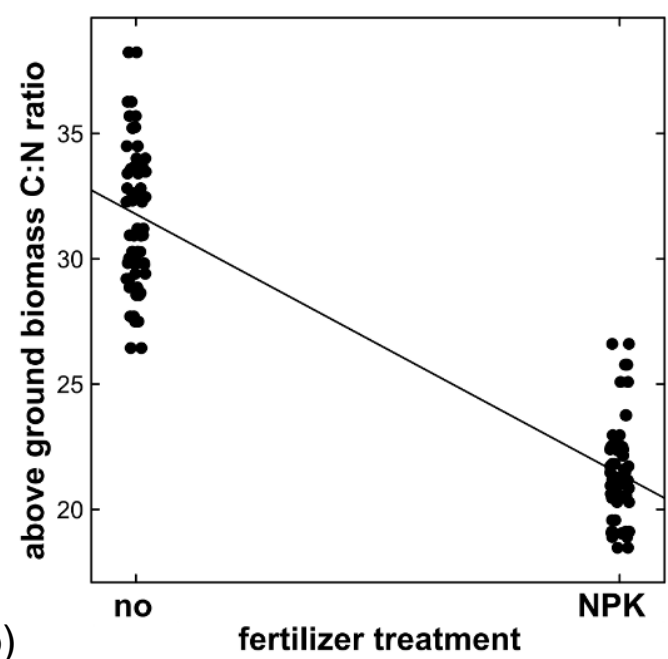

Fig. 5.11: a) Effects of fertilizer application and herbivory on proportion of litter on AGB [\%]. Green (control) = no herbivores; blue $=$ herbivory. $\mathrm{b}$ ) Effects of fertilizer application on above-ground biomass $\mathrm{C}: \mathrm{N}$ ratio.

As a main effect, herbivory led to a higher amount of litter (Herbivory main effect: $\mathrm{F}_{1,69=89.99 ;}<<0.001$ ), whereas NPK-fertilizer input resulted in a lower amount of litter (Fertilizer main effect: $F_{1,69}=11.43 ; p=0.001$ ).

The above-ground biomass C:N ratio (Fig. 5.5b) showed a strong decrease with NPK-fertilizer application (Fertilizer main effect: $F_{1,69}=353.16 ; p<0.001$ ).

Table 5.1 visualizes the different treatment effects on several vegetation parameters and measured components of the nitrogen cycle. 


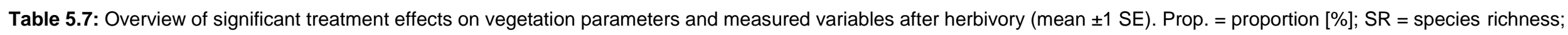
spec. $=$ species; lysi. = lysimeter; herb. $=$ herbivory; $\mathrm{AGB}=$ above-ground biomass dry weight $[\mathrm{g} /$ lysimeter]; Net $\mathrm{N}$ min. rate = Net $\mathrm{N}$ mineralisation rate .

\begin{tabular}{|c|c|c|c|c|c|c|c|c|c|c|}
\hline & \multirow[b]{2}{*}{ units } & \multicolumn{2}{|c|}{ Herbivory } & \multicolumn{3}{|c|}{ Functional group manipulation } & \multicolumn{2}{|c|}{ cutting frequency } & \multicolumn{2}{|c|}{ fertilizer application } \\
\hline & & control & herbivory & control & forb rich & gram. rich & once & thrice & no & NPK \\
\hline Prop. graminoids & $\%$ & $0.71 \pm 0.03$ & $0.49 \pm 0.05$ & $0.53 \pm 0.05$ & $0.60 \pm 0.05$ & $0.67 \pm 0.06$ & $0.64 \pm 0.04$ & $0.57 \pm 0.04$ & $0.40 \pm 0.04$ & $0.79 \pm 0.03$ \\
\hline Prop. forbs & $\%$ & $0.29 \pm 0.03$ & $0.50 \pm 0.05$ & $0.47 \pm 0.05$ & $0.40 \pm 0.05$ & $0.33 \pm 0.06$ & $0.36 \pm 0.04$ & $0.43 \pm 0.04$ & $0.59 \pm 0.04$ & $0.21 \pm 0.03$ \\
\hline Plant SR before herb. & spec./lysi. & $4.18 \pm 0.20$ & $4.28 \pm 0.18$ & $4.54 \pm 0.24$ & $4.50 \pm 0.24$ & $3.67 \pm 0.20$ & $3.81 \pm 0.18$ & $4.64 \pm 0.19$ & $4.97 \pm 0.18$ & $3.51 \pm 0.15$ \\
\hline Plant SR after herb. & spec./lysi. & $3.83 \pm 0.18$ & $3.07 \pm 0.16$ & $3.52 \pm 0.24$ & $3.78 \pm 0.22$ & $3.06 \pm 0.18$ & $3.14 \pm 0.16$ & $3.75 \pm 0.18$ & $3.94 \pm 0.18$ & $2.97 \pm 0.15$ \\
\hline AGB total after herb. & g/lysi. & $7.86 \pm 0.33$ & $6.57 \pm 0.26$ & $7.15 \pm 0.39$ & $7.34 \pm 0.36$ & $7.18 \pm 0.38$ & $7.77 \pm 0.32$ & $6.68 \pm 0.28$ & $6.51 \pm 0.26$ & $7.91 \pm 0.32$ \\
\hline AGB graminoids & g/lysi. & $5.86 \pm 0.42$ & $3.65 \pm 0.41$ & $4.27 \pm 0.51$ & $4.83 \pm 0.50$ & $5.16 \pm 0.57$ & $5.41 \pm 0.46$ & $4.12 \pm 0.38$ & $3.00 \pm 0.38$ & $6.46 \pm 0.38$ \\
\hline AGB forbs after herb. & g/lysi. & $1.89 \pm 0.21$ & $2.87 \pm 0.29$ & $2.76 \pm 0.31$ & $2.41 \pm 0.28$ & $1.99 \pm 0.34$ & $2.33 \pm 0.28$ & $2.44 \pm 0.23$ & $3.39 \pm 0.26$ & $1.40 \pm 0.20$ \\
\hline Prop. plant litter & $\%$ & $7.69 \pm 0.91$ & $37.38 \pm 3.21$ & $22.77 \pm 3.58$ & $17.39 \pm 2.84$ & $27.23 \pm 4.14$ & $24.03 \pm 3.05$ & $21.08 \pm 2.85$ & $27.90 \pm 3.25$ & $17.32 \pm 2.49$ \\
\hline AGB C:N ratio & ratio & $26.53 \pm 0.68$ & $26.53 \pm 0.68$ & $27.25 \pm 0.83$ & $25.89 \pm 0.74$ & $26.42 \pm 0.90$ & $26.29 \pm 0.68$ & $26.76 \pm 0.68$ & $31.79 \pm 0.32$ & $21.42 \pm 0.21$ \\
\hline Net nitrification rate & $\mathrm{mg} / \mathrm{m}^{2} / \mathrm{d}$ & $26.44 \pm 3.19$ & $34.95 \pm 2.93$ & $27.59 \pm 3.54$ & $28.78 \pm 2.42$ & $35.65 \pm 4.86$ & $31.15 \pm 3.18$ & $30.26 \pm 3.02$ & $20.29 \pm 2.52$ & $40.81 \pm 3.13$ \\
\hline Net $\mathrm{N}$ min. rate & $\mathrm{mg} / \mathrm{m}^{2} / \mathrm{d}$ & $29.53 \pm 4.04$ & $41.55 \pm 4.87$ & $31.77 \pm 6.35$ & $35.31 \pm 4.33$ & $39.54 \pm 5.69$ & $36.66 \pm 4.72$ & $34.46 \pm 4.35$ & $26.07 \pm 3.78$ & $44.76 \pm 4.91$ \\
\hline NO3 content & $\mathrm{mg} / \mathrm{kg}$ & $4.81 \pm 1.94$ & $4.44 \pm 2.10$ & $6.76 \pm 2.99$ & $1.54 \pm 0.89$ & $5.15 \pm 2.63$ & $5.99 \pm 2.49$ & $3.35 \pm 1.47$ & $0.04 \pm 0.02$ & $10.76 \pm 3.13$ \\
\hline N2O flux & $\mu \mathrm{g} / \mathrm{m}^{2} / \mathrm{h}$ & $24.95 \pm 8.69$ & $60.21 \pm 12.37$ & $40.04 \pm 16.65$ & $45.11 \pm 13.29$ & $42.70 \pm 9.14$ & $63.18 \pm 13.57$ & $22.56 \pm 6.75$ & $29.19 \pm 10.78$ & $55.60 \pm 10.78$ \\
\hline
\end{tabular}




\section{Treatment effects on components of the nitrogen cycle}

There was a significant two-way interaction between NPK-fertilizer and herbivory on Net nitrification rate $\left[\mathrm{mg} / \mathrm{m}^{2} / \mathrm{d}\right]$, with increasing nitrification rates in unfertilized plots as a result (Fig. 5.6a; Herbivory:Fertilizer interaction: $F_{1,69}=16.34 ; p<0.001$ ).

Under NPK fertilization, the nitrification rate was generally higher than on unfertilized plots (Fertilizer main effect: $F_{1,69=36.86 ;} p<0.001$ ) and not significantly affected by herbivory alone.

Net $\mathrm{N}$ mineralization $\left[\mathrm{mg} / \mathrm{m}^{2} / \mathrm{d}\right]$ showed a very similar pattern: an interaction effect of herbivory and NPK-fertilizer application (Herbivory:Fertilizer interaction: $\left.F_{1,69}=9.54 ; \quad p=0.003\right)$ and a significant effect of fertilizer application on mineralization rate (Fertilizer main effect: $\left.F_{1,69}=17.42 ; p<0.001\right)$ (Fig. 5.6b).


Fig. 5.12: Effects of herbivory and NPK-fertilizer application on a) Net - nitrification rate $\left[\mathrm{mg} / \mathrm{m}^{2} / \mathrm{d}\right]$; and b) Net N-mineralization rate $\left[\mathrm{mg} / \mathrm{m}^{2} / \mathrm{d}\right]$. NPK (green) = NPK fertilizer application; no (blue) = no fertilizer.

$\mathrm{N}_{2} \mathrm{O}$ flux rates $\left[\mu \mathrm{g} / \mathrm{m}^{2} / \mathrm{h}\right]$ after herbivory) increased under herbivory (Herbivory: $F_{1,70}=5.69 ; p=0.020$ ), but were slightly decreased by three cuts/year in comparison to one cut/year (Cutting: $F_{1,69}=7.56 ; p=0.008$ ) (Fig. 5.7a).

Extractable $\mathrm{NO}_{3}[\mathrm{mg} / \mathrm{kg}]$ in the soil increased with NPK fertilization (Fertilizer: $F_{1,69}=21.49 ; p<0.001$ ) (Fig. 5.7b). 

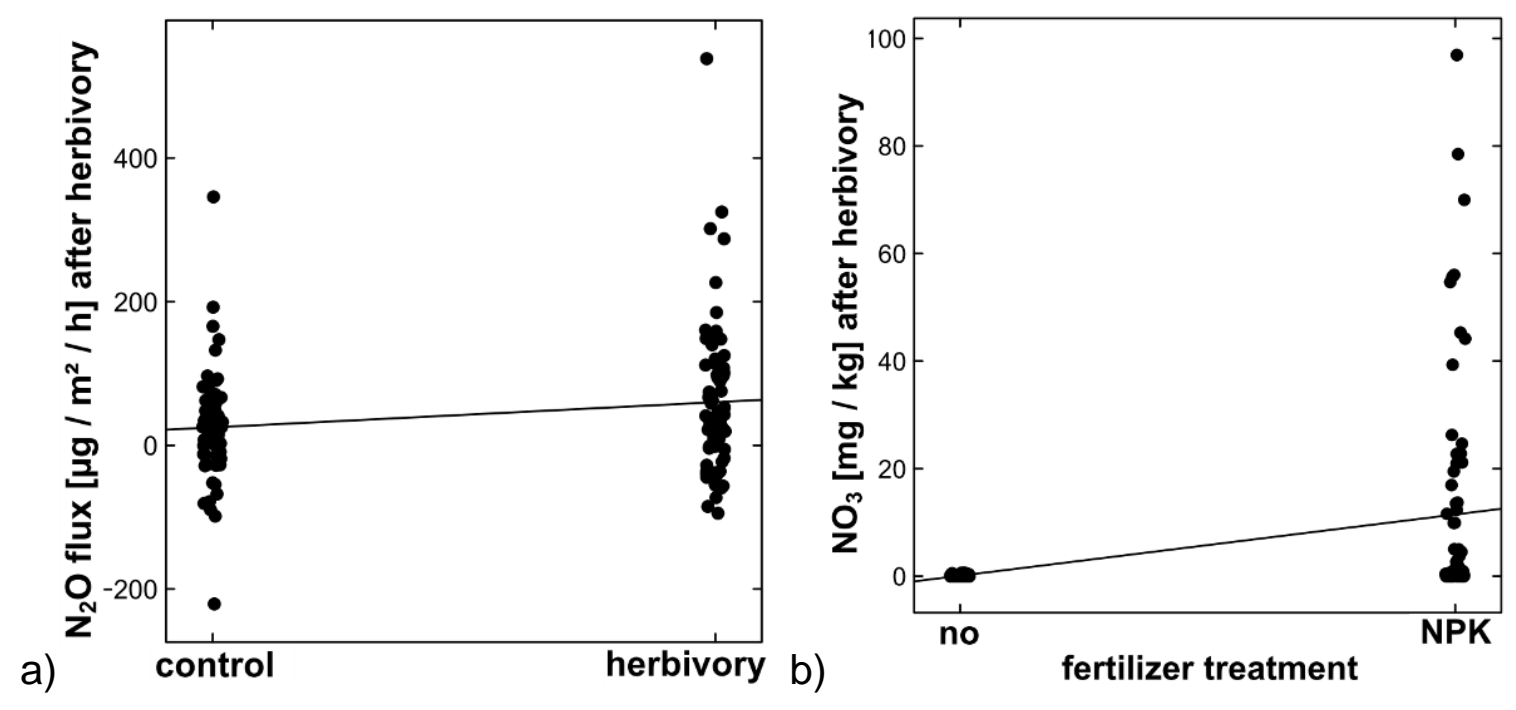

Fig. 5.13: a) Herbivory effects on nitrous oxide $\left(\mathrm{N}_{2} \mathrm{O}\right)=$ flux rate $\left(\mu \mathrm{g} / \mathrm{m}^{2} / \mathrm{h}\right)$; b) Fertilizer effect on the amount of nitrate $\left(\mathrm{NO}_{3} ; \mathrm{mg} / \mathrm{kg}\right)$ in the soil

d. Structural equation model (SEM) analysis of experimental treatments on components of the nitrogen cycle

Our minimal adequate structural equation model (SEM) of nitrogen cycle components was well supported by our data $\left(\mathrm{N}=71, \mathrm{X}^{2}=11.25, p=0.508,12 \mathrm{DF}\right.$, root mean squared error of approximation of 0.00 (90\% confidence interval, [0, 0.082]; Fig. 5.8). The model showed that both fertilizer application and herbivory positively affected the nitrogen flux, but through different pathways. The left pathway in Fig. 5.8 represents the nitrogen flux in control lysimeters without herbivory, the right pathway shows nitrogen flux in lysimeters with herbivores.

Fertilizer application, as a categorical exogenous variable, was the strongest and most important management treatment and a direct driver of nitrogen cycling. The above-ground biomass C:N ratio was strongly negatively influenced by fertilizer application (standardized path coefficient (coef.) $=-0.92$ ), due to the higher nitrogen content of the plant material.

Within herbivory treatments, plant litter input ([\%] of AGB) into the system was used as a measure for plant material eaten by herbivores. This value/ it was strongly positively correlated with the AGB C:N ratio $(+0.33)$. The corresponding path coefficient in the control lysimeters (left pathway) was not significant. 
Under herbivory, proportional litter input into the system was higher (Fig. 5.5a). Furthermore, it was a driver for the nitrate amount $\left(\mathrm{NO}_{3}, \mathrm{mg} / \mathrm{kg}\right)($ coef. $=+0.20)$. In contrast to this, $\mathrm{NH}_{4}(\mathrm{mg} / \mathrm{kg})$ was only weakly positive influenced $\left(\mathrm{NH}_{4}, \mathrm{mg} / \mathrm{kg}\right)$ (coef. $=+0.10)$. In unfertilized plots, litter had a greater impact on ammonium (coef. $=+0.19)$ compared to nitrate $($ coef. $=+0.09$ ), but litter input was very low (Fig. 5.5a).

In these plots, ammonium strongly drove nitrate content $(+0.28)$ and both nitrate and ammonium were driven by fertilizer application (coefs.: $\mathrm{NH}_{4}=+0.12$; $\mathrm{NO}_{3}=+0.35$ ). In addition, ammonium (coef. $=+0.15$ ) as well as nitrate content (coef. $=+0.16)$ positively affected nitrous oxide $\left(\mathrm{N}_{2} \mathrm{O}\right)$ flux rate $\left[\mu \mathrm{g} / \mathrm{m}^{2} / \mathrm{h}\right]$, showing strongest influence of fertilizer application on this part of the nitrogen cycle.

Within herbivory treatments, the effect of fertilizer application on ammonium (coef. $=-0.06$ ), the effect of ammonium on nitrate (coef. $=-0.02$ ) and the effect of ammonium on nitrous oxide (coef. $=+0.12$ ) were not significant and bypassed by the strong impact of herbivory induced litter input on nitrate (coef. $=+0.20)$.

Nitrate content under herbivory was also strongly influenced by fertilizer application $(+0.42)$ and a much stronger driver of the nitrous oxide flux $(+0.34)$ compared to control plots. 




Fig. 5.14: Multi-group structural equation model of the nitrogen cycle for comparison of the effects of lysimeters with and without herbivory, including fertilizer application as the most important driver of the nitrogen cycle. Filled arrows indicate the strong and significant correlations $(p \leq 0.1)$ within the nitrogen flux, while dashed arrows show quantitative weaker pathways $(p \geq 0.1$ ). Litter (org. $N)=$ proportion of dead above-ground plant material [\%]; Ammonium (NH4) = amount of $\mathrm{NH} 4$ (mg/kg) in the soil; Nitrate (NO3) = amount of $\mathrm{NO} 3(\mathrm{mg} / \mathrm{kg})$ in the soil; Nitrous oxide $(\mathrm{N} 2 \mathrm{O})=$ Flux rate $\left(\mu \mathrm{g} / \mathrm{m}^{2} / \mathrm{h}\right)$. Numbers next to arrows are standardized total effects. $\mathrm{N}=71, \mathrm{X}^{2}=11.25, \mathrm{p}=0.508,12$ degrees of freedom and a root mean squared error of approximation of 0.00 (90\% confidence interval, [0, 0.082]). 


\section{Discussion}

This study allowed us to disentangle complex above-ground and below-ground effects and interactions within a grassland ecosystem, using full factorial manipulations of agricultural management and functional groups as well as experimental herbivore pressure. Both above-ground vegetation and belowground measures of the nitrogen flux were significantly and interactively influenced by the factors manipulated.

\section{FG manipulation effects on plant community on lysimeters}

Contrary to our expectations (e.g., Tilman (2012)), plant FG manipulation had no effect on the measured response variables, except for changes in FG composition and reduced plant species richness in graminoid-rich plots. When dominant graminoids were reduced initially, the proportion of forbs increased. This supports the idea that an increase in the death rate of dominant and established plants (mainly graminoids) enhances the competitiveness of forbs, which drive the biodiversity especially in nutrient poor grasslands (Pearce and van der Wal 2002). This is especially true in an agriculturally managed system such as the GrassMan site (Everwand et al. 2013, Petersen et al. 2013).

\section{Management effects on plant community on lysimeters}

In this study, effects of agricultural management (fertilizer application, cutting) were among the strongest effects observed. Fertilizer application increased the total biomass as well as the proportion and biomass of graminoid AGB, but reduced forb biomass. Additionally, fertilizer application had a negative effect on plant species richness. We therefore found fertilizing to cause a competitive advantage for graminoids. A lower availability of nutrients has been shown to increase the proportion of forbs, whereas nitrogen application often results in increasing proportions of graminoids (Pearce and van der Wal 2002).

These patterns support similar findings of nutrient addition experiments in grasslands, e.g. the "Rengen-Grassland-Experiment" (Hejcman et al. 2007), the 
"Jena-Experiment" (Roscher et al. 2004) or Cedar Creek (Tilman et al. 1997) and others (Gough et al. 2000, Jacquemyn et al. 2003, Klimek et al. 2007).

Recent research has also shown that this can result in a loss of species in higher trophic guilds such as leafhoppers (Everwand et al., in prep.).

The positive effect of moderate cutting frequency on plant species richness (Hansson and Fogelfors 2000, Fischer and Wipf 2002) might be due to a removal of nutrients from the system due to frequent cutting. This can, especially without additional fertilizer inputs, improve plant species richness (Bakker et al. 2002, Fischer and Wipf 2002).

\section{Management effects on nitrogen cycling}

It is known that the rates of nutrient mineralization from organic matter are slow in low-nutrient ecosystems (Hobbie 1992, Keuter et al. 2012). Our study supports these findings by showing low net nitrification, net $\mathrm{N}$ mineralization, $\mathrm{N}_{2} \mathrm{O}$ flux rate and low amounts of $\mathrm{NO}_{3}$ in unfertilized plots. In addition, fertilizer application accelerated the nutrient cycling.

\section{Management effects on herbivores}

Fertilizer input resulted in better food quality for grasshoppers due to lower AGB $\mathrm{C}: \mathrm{N}$ ratio, indicating that better food quality may decrease the amount of biomass eaten by herbivores (Joern and Behmer 1998, Ebeling et al. 2013). Especially grasshoppers are known to counterbalance nitrogen shortage in the available food sources by compensatory feeding (Berner et al. 2005). Furthermore, they show preferences for fertilized vegetation in the field, even if cutting frequency is high (Hudewenz et al. 2012). Fertilizer application also increased the proportion and amount of graminoids as the preferred food source for the more active grasshoppers (Gardiner et al. 2002), which may also be a cause for lower litter input. 


\section{Herbivory effects on plant community}

Two weeks of herbivory reduced plant species richness, mainly due to a strong reduction of graminoids probably by grasshoppers (Gardiner et al. 2002). This led to the total disappearance of the above-ground parts of all graminoids in some lysimeters. It is a common effect of intense herbivore pressure, that preferred food sources are fully exploited by herbivores (Turley et al. 2013). The increase of higher forb biomass also showed the feeding preference of grasshoppers for graminoids.

In addition, this selective feeding of the herbivores was beneficial for the avoided forbs (Bernays and Chapman 1970), because damaged graminoid plants did not grow or survive as good as unconsumed forb plants (Belovsky 2000). We expected the low damage on forbs (and therefore a competitive advantage) due to the rather low observed activity of the snails caused by dry weather conditions during the herbivore treatment in August 2011. Helix pomatia is known to require warm and calcium rich, but moist soils (Pollard 1975).

Our approach covers the effects measured directly after a feeding period of two weeks. Many plants, especially graminoids, show a high regrowth capacity in response to herbivory (Turley et al. 2013), which is also enhanced by fertilizing effects of herbivore excrement and plant litter (Belovsky and Slade 2000). Therefore, we assume that this short term effect of herbivory on plant species richness and AGB might not be observed on a longer time scale.

\section{Herbivory effects on nitrogen cycling}

As expected, herbivory led to a higher amount of plant litter. This strongly correlates with the amount of herbivore excrements and herbivory mediated increases of root exudates (Bardgett et al. 1998). Due to the faster decomposition of herbivore faeces and the fast belowground plant responses (e.g., exudation) (Bardgett et al. 1998) in comparison to plant litter decomposition (McNaughton et al. 1988), we assume grasshopper faeces to account for strong effects of plant litter in our SEM. 
In addition, the reduced plant AGB because of herbivory will lead to a reduced nitrogen uptake by plants under herbivory and which in turn can affect the amount of available forms of nitrogen within the ecosystem (Vitousek et al. 2002). These effects of herbivores clearly accelerated nutrient cycling, presumably due to the increasing nitrogen input (e.g., litter, excrement and exudates) into the system (McNaughton et al. 1988, Bardgett et al. 1998, Belovsky and Slade 2000). Consequently, this may account for the increased amount of $\mathrm{N}_{2} \mathrm{O}$ emissions with herbivory.

As we did not measure the exact amount of faeces or root exudates, further investigation is required to identify the exact contribution of plant litter, herbivore faeces and root exudation on the herbivore induced acceleration of nutrient cycling.

\section{Interactions of FG manipulation and herbivory on plant community}

Responses of plant communities and nitrogen cycling become more complex with the increasing number of interacting drivers. The interactions of $F G$ manipulation and fertilization caused changes in FG composition may be an additive effect of increasing proportion of graminoids with fertilizing (e.g. Pearce and van der Wal 2002) and herbicide induced competitive advantages with reduction of the forbs.

\section{Interactions of management and herbivory on plant community}

The increase in proportion and biomass of forbs in lysimeters of unfertilized plots supports the idea that selective insect feeding is able to increase the death rate of established plants, which grow in dense stands and release forbs from interor intraspecific competition (Crawley 1989, Belovsky and Slade 2000, Gardiner et al. 2002). The simultaneous acceleration of nutrient cycling due to the input of faeces litter increase nitrogen availability for the avoided forbs (Bernays and Chapman 1970). 
In the present study, fertilizer application and invertebrate herbivory were the strongest drivers of plant community composition and nitrogen cycling. With our study we were able to disentangle these complex interactions. When there was no nutrient limitation for the primary producing plants due to NPK fertilizer input, resulting in higher AGB (Schmitz 1993), there was no shortage of available food for herbivores and the proportion of graminoids was consequently only slightly reduced compared to the unfertilized treatment. These results support the idea that grasshoppers can counterbalance nitrogen shortage in the available food sources by compensatory feeding and by the capability of selective feeding among graminoids of contrasting nutritional quality when given a choice (Raubenheimer and Simpson 2003, Berner et al. 2005). With higher availability of better quality AGB (Joern and Behmer 1998) due to fertilizer application, less AGB was consumed. This resulted in a lower risk for plants to be completely consumed by herbivores above-ground and explaining the lower proportion of litter due to herbivory on fertilized plots. This might also account for the stronger negative short term effect of herbivory on plant species richness and AGB of graminoids in unfertilized plots.

The acceleration of net nitrification and net $\mathrm{N}$ mineralization rates with herbivory in unfertilized plots may have several causes: (i) the excrements of the herbivores contribute to cycling of nitrogen in natural systems (Belovsky and Slade 2000); (ii) grasshopper herbivory increases rhizodeposition (Paterson 2003) and/or root exudates in particular (Holland et al. 1996); (iii) higher plant litter input also enhances nutrient cycling (Belovsky and Slade 2000). The already high net nitrification and net-N-mineralization rates under NPK fertilization support the herbivore induced acceleration of nutrient availability, since these were previously of low availability.

Summarizing, our SEM shows that both fertilizer application and herbivory positively affect components of the nitrogen cycle, but through different pathways. Fertilizer application accelerated the nitrogen fluxes due to greater availability of ammonium and nitrate, both main components of our $\mathrm{N}$-fertilizer.

Since grasshoppers can be of high abundance under natural conditions and cause more feeding damage on intensively managed grasslands (Hudewenz et 
al. 2012), we worry that emissions of $\mathrm{N}_{2} \mathrm{O}$, a very strong greenhouse gas (Lashof and Ahuja 1990), can further increase and therefore contribute to global warming due to an additive effect of fertilizer application and invertebrate herbivory. Therefore, long term studies of the combined effects of invertebrate herbivory in combination with an intensifying management of grasslands on greenhouse gasses, such as $\mathrm{N}_{2} \mathrm{O}$, are needed.

\section{Experimental Design}

Our study could be criticized for its short duration of the herbivory treatment, which lasted just about two weeks. However, we note that the lysimeters had been installed about one year prior to the start of the herbivory treatment. Every lysimeter was exposed to management for a period of more than one year. The herbivory treatment was applied for a shorter time period, as cages covered only a small area and consumption by herbivores was fast. But by conducting this mesocosm experiment in natural grassland, we take the inevitable trade-off between realism of field studies and precision of laboratory experiments into account (Morin 1998).

In addition, our plant functional group manipulation treatments were efficient, as plant diversity was still affected even three years after applying herbicides.

However, our study does not allow us to assess the longer term effects of herbivory on plant community structure or productivity. But since the herbivore load applied in this study was comparatively high, the resulting below-ground effects were strong, providing insights into multiple ecosystem responses to herbivory under different management regimes and differing plant functional group compositions.

\section{Comparison with other studies}

Many biodiversity experiments using sown gradients in plant diversity have yielded important insights on trophic interactions (Roscher et al. 2004, Scherber et al. 2006, Scherber et al. 2010a, Tilman et al. 2012), while others have only 
studied the effects of fertilizer application and cutting frequency (Pavlú et al. 2011). Exclusion experiments (Curry 1994, Scherber et al. 2003, del-Val and Crawley 2004, Scheidel and Bruelheide 2005, Scherber et al. 2006) have shown invertebrates to strongly affect plant biomass production and species composition in grasslands. Herbivore feeding activity changes with nutrient availability and above-ground plant biomass (Hudewenz et al. 2012) and also affects nutrient cycling via litter and excrement input into grasslands (Belovsky and Slade 2000). But studies relating herbivory, management and deterministic biodiversity loss to ecosystem processes such as nutrient cycling were lacking until now. We therefore expect our FG manipulation experiment (see e.g. Diaz et al. 2003 or Fry et al. 2013) in approximately 100-year old grassland and independently manipulated management intensity, plant functional group composition and herbivore presence may more directly resemble deterministic extinction scenarios and better reflect real world scenarios. 


\section{Overall Conclusions}

The effects of our experimental treatments (herbivore pressure, cutting frequency, NPK-fertilizer application and functional group manipulation) on several vegetation parameters and the measured components of the nitrogen cycle clearly show that management and herbivores affect productivity and nitrogen fluxes in highly complex ways; in general, management and herbivory had much stronger effects than the manipulation of plant functional group composition. Functional group manipulation had significant effects on the functional group composition and plant species richness before and after the herbivory treatment, but had no effect on further processes, such as AGB production or the components of the nitrogen cycle. Differences in plant species diversity and composition had only weak effects, probably masked by the strong effects of herbivores and grassland management.

Fertilizer application appeared to be the strongest driver of the nitrogen flux rates in our system and also led to lower herbivore- induced litter input.

Herbivory can short-cut the nitrogen cycling by increasing amounts of litter, excrement and root exudates, consequently positively affecting soil nitrogen contents $\left(\mathrm{NH}_{4}, \mathrm{NO}_{3}\right)$ and flux rates (mineralization, nitrification, $\mathrm{N}_{2} \mathrm{O}$ ). In addition to the strong effect of fertilizer application on the nitrogen cycle, $\mathrm{N}_{2} \mathrm{O}$ emissions may also increase under strong herbivory in fertilized grasslands, at least on a short timescale.

\section{Acknowledgements}

We are grateful to Lars Köhler for the coordination of the Grassman project and to Lena Everwand, Yann Clough, Björn K. Klatt, Laura Rose, Urs Kormann and Christine Venjakob for helpful comments during analysis, interpretation and writing. Further, we thank Lisa Denmead, Kristy Udy and Verena Rösch for helpful comments on the manuscript. Furthermore we thank the Ministry of Science and Culture of Lower Saxony and the "Niedersächsisches Vorab" for financial support. 


\section{References}

Allan, E., and M. J. Crawley. 2011. Contrasting effects of insect and molluscan herbivores on plant diversity in a long-term field experiment. Ecology Letters 14:1246.

Bakker, J., J. Elzinga, and Y. Vries. 2002. Effects of long-term cutting in a grassland system: perspectives for restoration of plant communities on nutrient-poor soils. Applied Vegetation Science 5:107-120.

Bardgett, R. D., D. A. Wardle, and G. W. Yeates. 1998. Linking above-ground and below-ground interactions: how plant responses to foliar herbivory influence soil organisms. Soil Biology and Biochemistry 30:1867-1878.

Belovsky, G. 2000. Do grasshoppers diminish grassland productivity? A new perspective for control based on conservation. Pages 7-29 Grasshoppers and Grassland Health. Springer.

Belovsky, G. E., and J. B. Slade. 2000. Insect herbivory accelerates nutrient cycling and increases plant production. PNAS 97:14412-14417.

Bender, E. A., T. J. Case, and M. E. Gilpin. 1984. Perturbation Experiments in Community Ecology: Theory and Practice. Ecology 65:1-13.

Bernays, E. A., and R. F. Chapman. 1970. Experiments to Determine the Basis of Food Selection by Chorthippus parallelus (Zetterstedt) (Orthoptera: Acrididae) in the Field. Journal of Animal Ecology 39:761-776.

Berner, D., W. U. Blanckenhorn, and C. Körner. 2005. Grasshoppers cope with low host plant quality by compensatory feeding and food selection: $N$ limitation challenged. Oikos 111:525-533.

Bollen, K. A. 1989. Structural equations with latent variables.

Clewer, A. G., and D. H. Scarisbrick. 2001. Practical statistics and experimental design for plant and crop science. John Wiley \& Sons Ltd, Chichester.

Clough, T. J., C. Müller, and R. J. Laughlin. 2013. Using stable isotopes to follow excreta $\mathrm{N}$ dynamics and $\mathrm{N} 2 \mathrm{O}$ emissions in animal production systems. animal 7:418-426.

Crawley, M. J. 1989. Insect herbivores and plant population dynamics. Annual Review of Entomology 34:531-562.

Curry, J. P. 1994. Grassland Invertebrates. Chapman \& Hall, London. 
del-Val, E., and M. J. Crawley. 2004. Importance of tolerance to herbivory for plant survival in a British grassland. Journal of Vegetation Science 15:357364.

Diaz, S., A. J. Symstad, F. S. Chapin, D. A. Wardle, and L. F. Huenneke. 2003. Functional diversity revealed by removal experiments. Trends in Ecology \& Evolution 18:140-146.

Ebeling, A., E. Allan, J. Heimann, G. Köhler, M. Scherer-Lorenzen, A. Vogel, A. Weigelt, and W. W. Weisser. 2013. The impact of plant diversity and fertilization on fitness of a generalist grasshopper. Basic and Applied Ecology 14:246-254.

Everwand, G., C. Scherber, and T. Tscharntke. 2013. Slug responses to grassland cutting and fertilizer application under plant functional group removal. Acta Oecologica 48:62-68.

FAOSTAT. 2013. Food and Agricultural Organization Statistics Database. Food and Agricultural Organization of the United Nations., Rome, Italy. http://www.fao.org.

Fischer, M., and S. Wipf. 2002. Effect of low-intensity grazing on the species-rich vegetation of traditionally mown subalpine meadows. Biological Conservation 104:1-11.

Franzke, A., S. B. Unsicker, J. Specht, G. Koehler, and W. W. Weisser. 2010. Being a generalist herbivore in a diverse world: how do diets from different grasslands influence food plant selection and fitness of the grasshopper Chorthippus parallelus? Ecological Entomology 35:126-138.

Fry, E. L., P. Manning, D. G. P. Allen, A. Hurst, G. Everwand, M. Rimmler, and S. A. Power. 2013. Plant Functional Group Composition Modifies the Effects of Precipitation Change on Grassland Ecosystem Function. Plos One 8:e57027.

Gardiner, T., M. Pye, R. Field, and J. Hill. 2002. The influence of sward height and vegetation composition in determining the habitat preferences of three Chorthippus species (Orthoptera: Acrididae) in Chelmsford, Essex, UK. Journal of Orthoptera Research 11:207-213.

Gough, L., C. W. Osenberg, K. L. Gross, and S. L. Collins. 2000. Fertilization effects on species density and primary productivity in herbaceous plant communities. Oikos 89:428-439. 
Grace, J. B. 2006. Structural Equation Modeling and Natural Systems. Cambridge University Press.

Graham, M. H. 2003. Confronting multicollinearity in ecological multiple regression. Ecology 84:2809-2815.

Hansson, M., and H. Fogelfors. 2000. Management of a semi-natural grassland; results from a 15-year-old experiment in southern Sweden. Journal of Vegetation Science 11:31-38.

Hart, S. C., J. M. Stark, E. A. Davidson, and M. K. Firestone. 1994. Nitrogen mineralization, immobilization, and nitrification. Methods of Soil Analysis: Part 2-Microbiological and Biochemical Properties:985-1018.

Hejcman, M., M. Klaudisová, J. Schellberg, and D. Honsová. 2007. The Rengen Grassland Experiment: Plant species composition after 64 years of fertilizer application. Agriculture, Ecosystems \&amp; Environment 122:259-266.

Hobbie, S. E. 1992. Effects of plant species on nutrient cycling. Trends in Ecology \& Evolution 7:336-339.

Holland, J. N., W. Cheng, and D. A. Crossley, Jr. 1996. Herbivore-induced changes in plant carbon allocation: assessment of below-ground $C$ fluxes using carbon-14. Oecologia 107:87-94.

Hudewenz, A., A.-M. Klein, C. Scherber, L. Stanke, T. Tscharntke, A. Vogel, A. Weigelt, W. W. Weisser, and A. Ebeling. 2012. Herbivore and pollinator responses to grassland management intensity along experimental changes in plant species richness. Biological Conservation 150:42-52.

Isselstein, J., B. Jeangros, and V. Pavlu. 2005. Agronomic aspects of biodiversity targeted management of temperate grasslands in Europe-a review. Agronomy Research 3:139-151.

Jacquemyn, H., R. Brys, and M. Hermy. 2003. Short-term effects of different management regimes on the response of calcareous grassland vegetation to increased nitrogen. Biological Conservation 111:137-147.

Joern, A., and S. T. Behmer. 1998. Impact of diet quality on demographic attributes in adult grasshoppers and the nitrogen limitation hypothesis. Ecological Entomology 23:174-184. 
Keuter, A., I. Hoeft, E. Veldkamp, and M. Corre. 2012. Nitrogen response efficiency of a managed and phytodiverse temperate grassland. Plant and Soil 364:193-206.

Klapp, E., and A. Stählin. 1936. Standorte, Pflanzengesellschaften und Leistung des Grünlandes. Stuttgart: Ulmer.

Klimek, S., A. Richter gen. Kemmermann, M. Hofmann, and J. Isselstein. 2007. Plant species richness and composition in managed grasslands: The relative importance of field management and environmental factors. Biological Conservation 134:559-570.

Lashof, D. A., and D. R. Ahuja. 1990. Relative contributions of greenhouse gas emissions to global warming.

Li, D., C. J. Watson, M. J. Yan, S. Lalor, R. Rafique, B. Hyde, G. Lanigan, K. G. Richards, N. M. Holden, and J. Humphreys. 2013. A review of nitrous oxide mitigation by farm nitrogen management in temperate grasslandbased agriculture. Journal of Environmental Management 128:893-903.

Loftfield, N., H. Flessa, J. Augustin, and F. Beese. 1997. Automated Gas Chromatographic System For Rapid Analysis Of The Atmospheric Trace Gases Methane, Carbon Dioxide, And Nitrous Oxide. J. Environ. Qual. 26:560-564.

Lovett, G. M., and A. E. Ruesink. 1995. Carbon and nitrogen mineralization from decomposing gypsy-moth frass. Oecologia 104:133-138.

McNaughton, S. J., R. W. Ruess, and S. W. Seagle. 1988. Large mammals and process dynamics in african ecosystems. Bioscience 38:794-800.

Morin, P. J. 1998. Realism, precision, and generality in experimental ecology. Experimental ecology: issues and perspectives. Oxford University Press, New York, New York, USA:50-70.

Oelmann, Y., N. Buchmann, G. Gleixner, M. Habekost, C. Roscher, S. Rosenkranz, E.-D. Schulze, S. Steinbeiss, V. M. Temperton, A. Weigelt, W. W. Weisser, and W. Wilcke. 2011. Plant diversity effects on aboveground and belowground $\mathrm{N}$ pools in temperate grassland ecosystems: Development in the first 5 years after establishment. Global Biogeochemical Cycles 25:GB2014.

Olff, H., and M. E. Ritchie. 1998. Effects of herbivores on grassland plant diversity. Trends in Ecology \& Evolution 13:261-265. 
Paterson, E. 2003. Importance of rhizodeposition in the coupling of plant and microbial productivity. European Journal of Soil Science 54:741-750.

Pavlů, V., J. Schellberg, and M. Hejcman. 2011. Cutting frequency vs. N application: effect of a 20-year management in Lolio-Cynosuretum grassland. Grass and Forage Science 66:501-515.

Pearce, I. S., and R. van der Wal. 2002. Effects of nitrogen deposition on growth and survival of montane Racomitrium lanuginosum heath. Biological Conservation 104:83-89.

Petersen, U., N. Wrage-Mönnig, and J. Isselstein. 2013. Effects of herbicide application to control sward composition in different management variants. International Journal of Biodiversity Science, Ecosystem Services \& Management 9:1-11.

Petersen, U., N. Wrage, L. Köhler, C. Leuschner, and J. Isselstein. 2012. Manipulating the species composition of permanent grasslands-A new approach to biodiversity experiments. Basic and Applied Ecology 13:1-9.

Pinheiro, J. C., and D. M. Bates. 2000. Mixed-Effects Models in S and S-PLUS. Springer Verlag, New York.

Pollard, E. 1975. Aspects of the ecology of Helix pomatia (L.). Journal of Animal Ecology:305-329.

R-Development-Core-Team. 2012. R: A language and environment for statistical computing. $R$ foundation for statistical computing. Vienna, Austria,.

Raubenheimer, D., and S. J. Simpson. 2003. Nutrient balancing in grasshoppers: behavioural and physiological correlates of dietary breadth. Journal of Experimental Biology 206:1669-1681.

Roscher, C., J. Schumacher, J. Baade, W. Wilcke, G. Gleixner, W. W. Weisser, B. Schmid, and E. D. Schulze. 2004. The role of biodiversity for element cycling and trophic interactions: an experimental approach in a grassland community. Basic and Applied Ecology 5:107-121.

Rose, L., H. Coners, and C. Leuschner. 2012a. Effects of fertilization and cutting frequency on the water balance of a temperate grassland. Ecohydrology 5:64-72. 
Rose, L., M. C. Rubarth, D. Hertel, and C. Leuschner. 2012b. Management alters interspecific leaf trait relationships and trait-based species rankings in permanent meadows. Journal of Vegetation Science:DOI:10.1111/j.16541103.2012.01455.x.

Ruser, R., R. Schilling, H. Steindl, H. Flessa, and F. Beese. 1998. Soil compaction and fertilization effects on nitrous oxide and methane fluxes in potato fields. Soil Science Society of America Journal 62:1587-1595.

Sala, O. E., F. S. Chapin, J. J. Armesto, E. Berlow, J. Bloomfield, R. Dirzo, E. Huber-Sanwald, L. F. Huenneke, R. B. Jackson, A. Kinzig, R. Leemans, D. M. Lodge, H. A. Mooney, M. Oesterheld, N. L. Poff, M. T. Sykes, B. H. Walker, M. Walker, and D. H. Wall. 2000. Biodiversity - Global biodiversity scenarios for the year 2100. Science 287:1770-1774.

Scheidel, U., and H. Bruelheide. 2005. Effects of slug herbivory on the seedling establishment of two montane Asteraceae species. Flora 200:309-320.

Scherber, C., M. J. Crawley, and S. Porembski. 2003. The effects of herbivory and competition on the invasive alien plant Senecio inaequidens (Asteraceae). Diversity and Distributions 9:415-426.

Scherber, C., N. Eisenhauer, W. W. Weisser, B. Schmid, W. Voigt, M. Fischer, E.-D. Schulze, C. Roscher, A. Weigelt, E. Allan, H. Beszler, M. Bonkowski, N. Buchmann, F. Buscot, L. W. Clement, A. Ebeling, C. Engels, S. Halle, I. Kertscher, A.-M. Klein, R. Koller, S. Konig, E. Kowalski, V. Kummer, A. Kuu, M. Lange, D. Lauterbach, C. Middelhoff, V. D. Migunova, A. Milcu, R. Muller, S. Partsch, J. S. Petermann, C. Renker, T. Rottstock, A. Sabais, S. Scheu, J. Schumacher, V. M. Temperton, and T. Tscharntke. 2010a. Bottom-up effects of plant diversity on multitrophic interactions in a biodiversity experiment. Nature 468:553-556.

Scherber, C., P. N. Mwangi, M. Schmitz, M. Scherer-Lorenzen, H. Bessler, C. Engels, N. Eisenhauer, V. D. Migunova, S. Scheu, W. W. Weisser, E. D. Schulze, and B. Schmid. 2010b. Biodiversity and belowground interactions mediate community invasion resistance against a tall herb invader. Journal of Plant Ecology-Uk 3:99-108.

Scherber, C., P. N. Mwangi, V. M. Temperton, C. Roscher, J. Schumacher, B. Schmid, and W. W. Weisser. 2006. Effects of plant diversity on invertebrate herbivory in experimental grassland. Oecologia 147:489-500. 
Schmitz, O. J. 1993. Trophic exploitation in grassland food-chains - simplemodels and a field experiment. Oecologia 93:327-335.

Seastedt, T. R., and D. A. Crossley. 1984. The influence of arthropods on ecosystems. Bioscience 34:157-161.

Shipley, B. 2000. Cause and Correlation in Biology. Cambridge University Press.

Smart, S. M., K. Thompson, R. H. Marrs, M. G. Le Duc, L. C. Maskell, and L. G. Firbank. 2006. Biotic homogenization and changes in species diversity across human-modified ecosystems. Proceedings of the Royal Society B: Biological Sciences 273:2659-2665.

Stein, C., S. B. Unsicker, A. Kahmen, M. Wagner, V. Audorff, H. Auge, D. Prati, and W. W. Weisser. 2010. Impact of invertebrate herbivory in grasslands depends on plant species diversity. Ecology 91:1639-1650.

Tilman, D., J. Knops, D. Wedin, P. Reich, M. Ritchie, and E. Siemann. 1997. The influence of functional diversity and composition on ecosystem processes. Science 277:1300-1302.

Tilman, D., P. B. Reich, and F. Isbell. 2012. Biodiversity impacts ecosystem productivity as much as resources, disturbance, or herbivory. Proceedings of the National Academy of Sciences 109:10394-10397.

Turley, N. E., W. C. Odell, H. Schaefer, G. Everwand, M. J. Crawley, and M. T. J. Johnson. 2013. Contemporary evolution of plant growth rate following experimental removal of herbivores. Am Nat 181 Suppl 1:S21-S34.

Vitousek, P. M., S. Hättenschwiler, L. Olander, and S. Allison. 2002. Nitrogen and nature. AMBIO: A Journal of the Human Environment 31:97-101.

WallisDeVries, M. F., P. Poschlod, and J. H. Willems. 2002. Challenges for the conservation of calcareous grasslands in northwestern Europe: integrating the requirements of flora and fauna. Biological Conservation 104:265-273.

Wesche, K., B. Krause, H. Culmsee, and C. Leuschner. 2012. Fifty years of change in Central European grassland vegetation: Large losses in species richness and animal-pollinated plants. Biological Conservation 150:76-85.

Zuur, A. F., E. N. Ieno, N. J. Walker, A. A. Saveliev, and G. M. Smith. 2009. Mixed effects models and extensions in ecology with R. Springer. 


\section{Supplementary material}

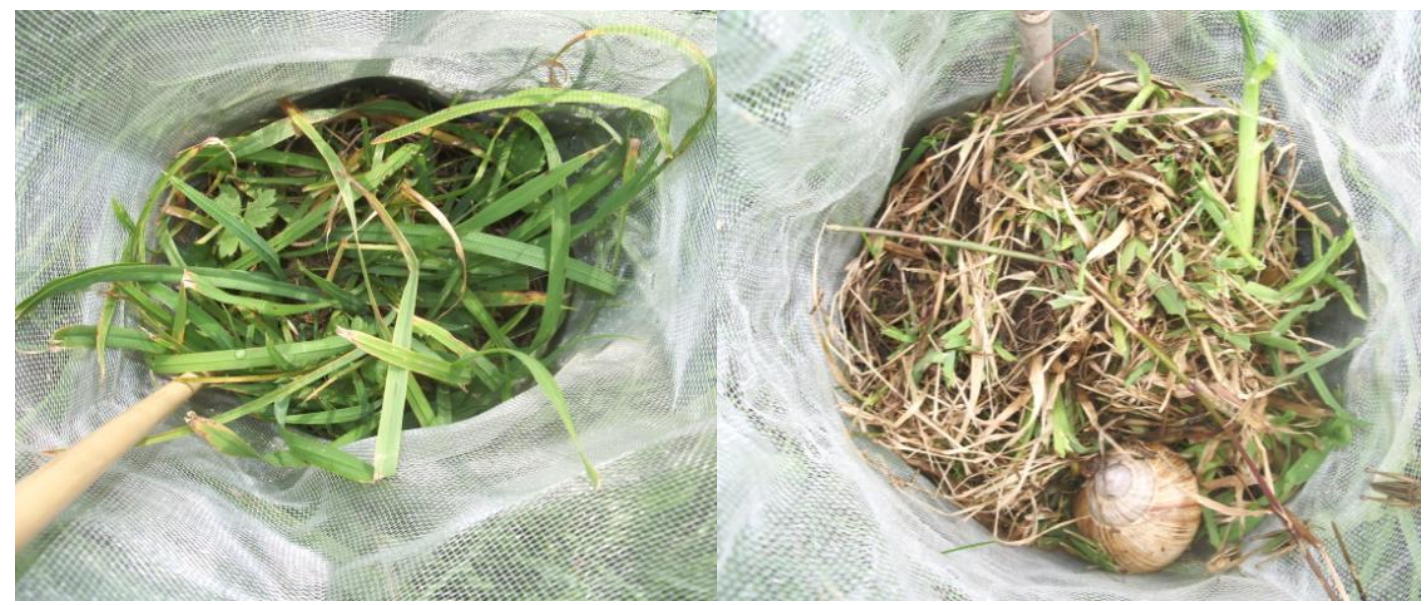

Figure S15: Gauze covered lysimeter without herbivores (left) in comparison to lysimeter with herbivores (right) after two weeks of herbivory. On the right picture Helix pomatia and Chorthippus albomarginatus are visible.

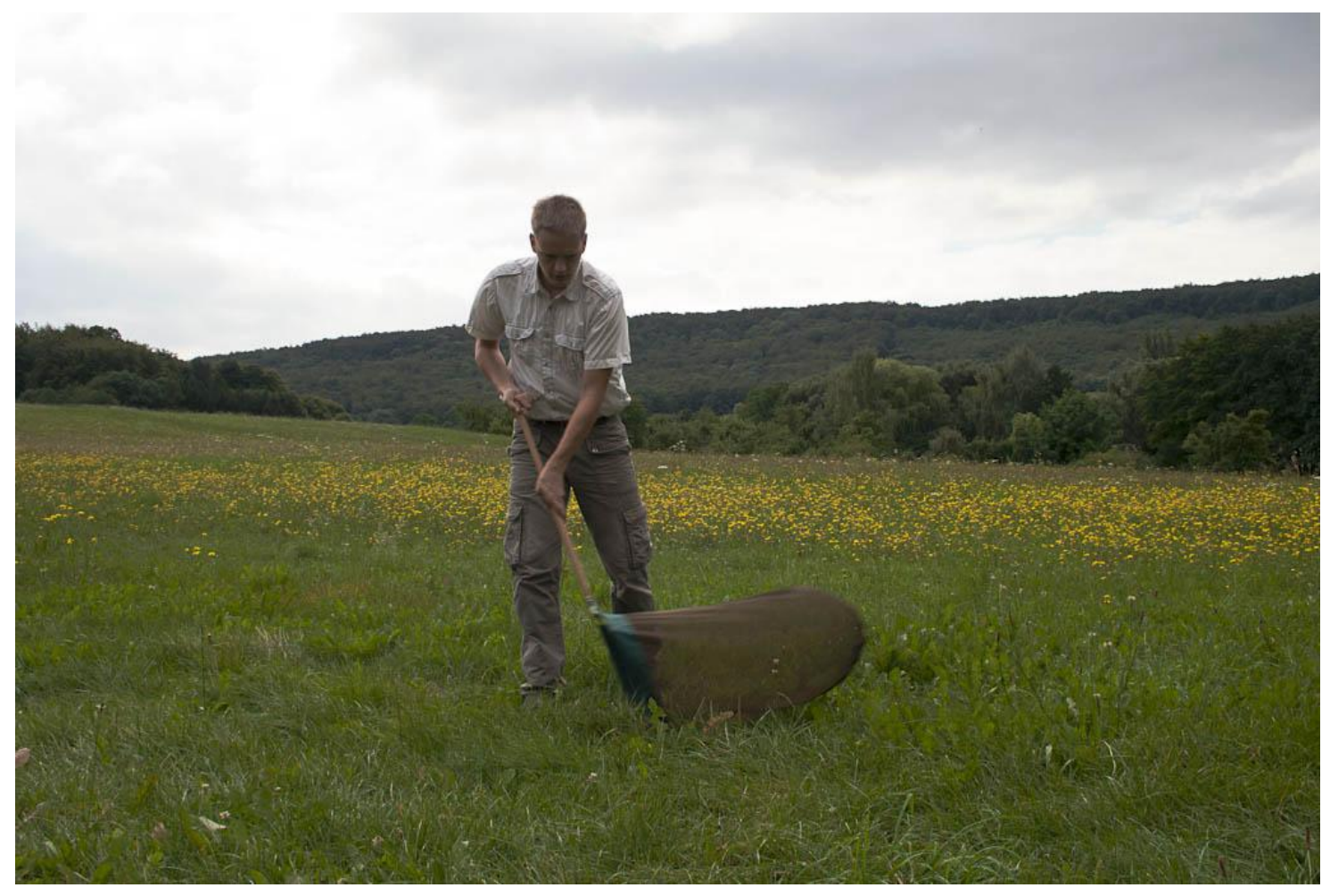

Figure S16: Sweep netting to catch grasshoppers for the lysimeters. 


\section{Chapter 6}

\section{SYNTHESIS}

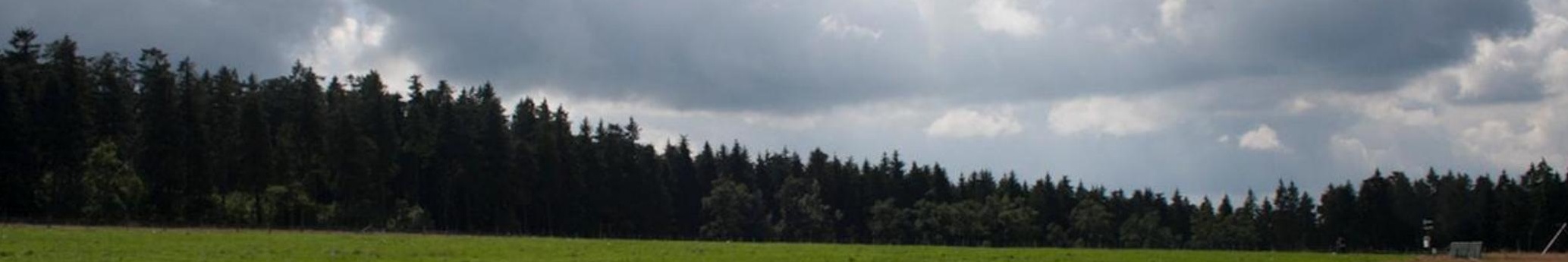




\section{General Discussion}

With the results presented in this thesis, I show that intensified agricultural management of grassland as well as experimental shifts in plant functional group composition directly and indirectly affect plants, invertebrates and ecosystem processes in a highly complex manner (Fig. 6.1).

The studies included in this thesis allowed us to disentangle these complex aboveand belowground effects and interactions within a grassland ecosystem, using full factorial manipulations of agricultural management, functional group manipulation (reduction of either graminoids or forbs) and experimental herbivore pressure. Herbivores (Fig. 6.1; arrows 3, 5, 7, 9), as well as above-ground vegetation (Fig. 6.1; arrows 1, 4, 6, 8) and below-ground measures of the nitrogen flux (Fig. 6.1; arrows 2, $11,12)$ were significantly, and interactively, influenced by the factors manipulated.

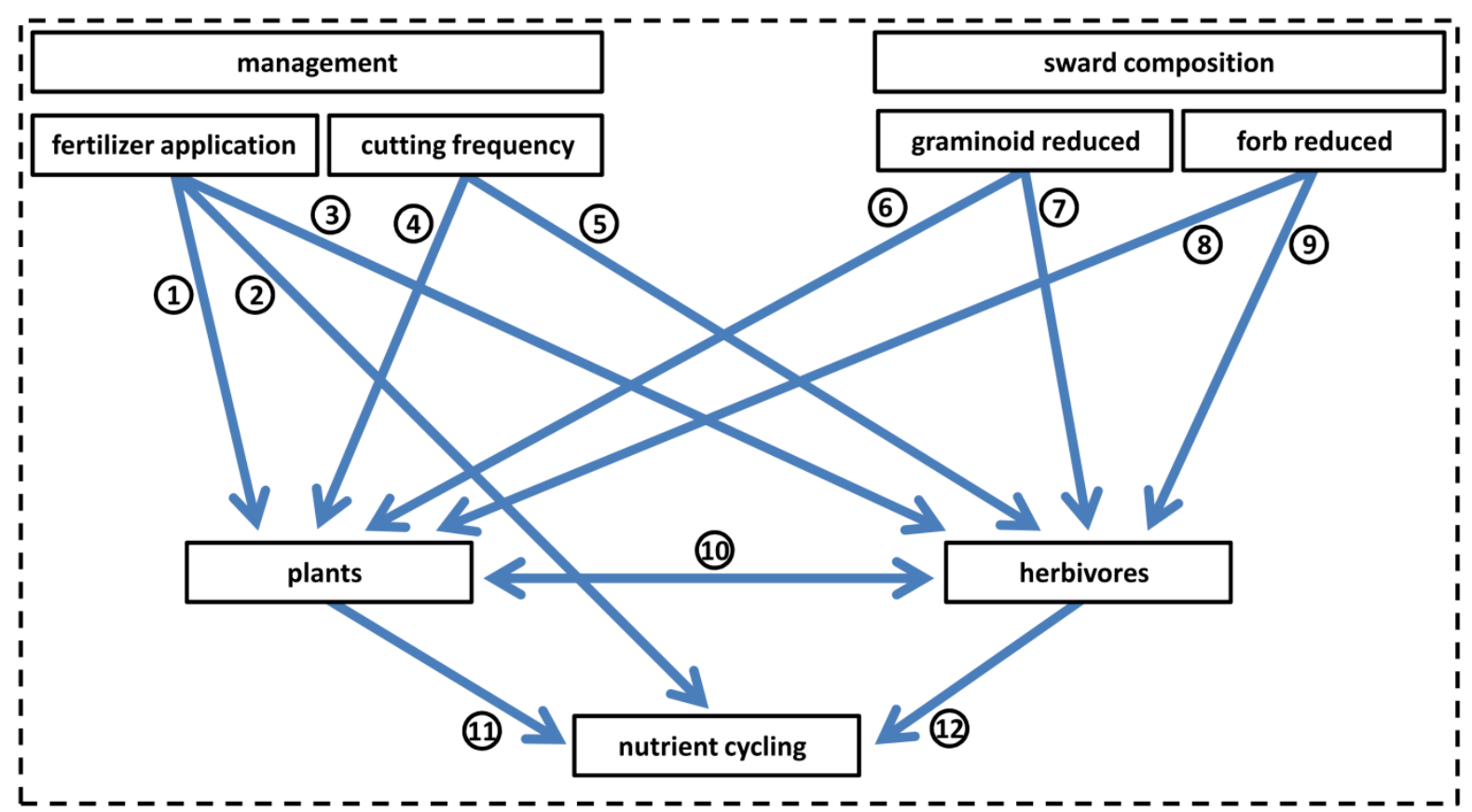

Figure 6.17: Simplified illustration of the interactions and effects investigated in this thesis.

The combination of management measures, such as cutting and fertilizer application, with the manipulation of functional group composition, and the interactions between them, led to contrasting sward types. 
These ranged from nutrient-poor, forb-dominated plots harbouring a greater diversity of plants, to highly productive, graminoid-dominated plots with lower plant diversity. Moreover, invertebrate herbivores were influenced by the resulting contrasting sward types, and intense herbivore pressure in turn influenced the vegetation (Fig. 6.1; arrow 10) and nutrient cycling (Fig. 6.1; arrow 12).

In the following, the main results and research objectives addressed in this thesis are discussed:

I. Reduction of grasses due to functional group manipulation enhances plant species richness, whereas reduction of forbs will decrease plant diversity (chapter 2 - 5).

We found that changes in sward composition associated with functional group manipulation lasted for three years and affected the proportions of grasses, herbs and legumes, as well as species evenness, while dynamics of species richness varied across the sward types and years. Plant species richness was significantly reduced in graminoid rich plots. Therefore the higher plant diversity in graminoid reduced plots supports the idea that an increase in the death rate of dominant and established plants (mainly grasses) increases competitiveness of forbs, which in turn drives biodiversity especially in nutrient poor grasslands (Pearce and van der Wal 2002).

II. Plant species diversity is correlated with productivity (chapter 2).

Prior to the start of the experiment in 2008 the site was a nutrient-poor, moderately wet Lolio-Cynosuretum grassland with high abundances of the grasses Agrostis capillaris (L.) and Festuca rubra (L.) and the herbs Rumex acetosa (L.), Veronica chamaedrys (L.) and Ranunculus repens (L.) (Petersen et al. 2012). We did not find any consistent effects of diversity on productivity across the experimental years and our results suggest that the absence of a direct effect of species richness on aboveground biomass production over the whole investigation time-period is the result of multiple direct and indirect effects of fertilization, sward composition and cutting frequency. We assume the short plant-species-richness-gradient may have prevented us from detecting significant biodiversity effects, since there were neither very species poor plots ("monocultures") nor very species rich ones, such as the 60species mix in the Jena Experiment (Roscher et al. 2004). 
Laird et al. (2003) considered that the absence of a relationship between diversity and productivity in an old field might have been due to competitive dominance causing deterministic structuring of the vegetation composition.

While dominant species are the most important factors in determining ecosystem processes and properties (Grime 1998, Mokany et al. 2008), it seems that their contribution to the above-ground biomass production did not cause a reduction in the numbers of less-dominant species in this grassland and the effects of species richness on productivity were therefore not significant.

In short-term synthetic communities biomass production may be affected by initial species abundances (Jiang et al. 2009), but it seems that in real-world grasslands the natural variation of species dynamics is also important for above-ground biomass production. For future studies where plant composition and diversity are manipulated using herbicides, it might be an interesting approach to include a treatment with repeated herbicide applications to achieve a stronger and long-term gradient in plant diversity to further investigate the diversity-productivity relationship.

III. Productivity will increase with higher cutting frequency and fertilizer application, whereas plant diversity will decrease with fertilizer application (chapter $2-5)$.

The primary determinants of an increase in biomass production were fertilization and cutting frequency, with the highest dry matter yields characteristic for intensively managed plots. Fertilizer application increased the total biomass production as well as the proportion and biomass of graminoid AGB, but reduced forb biomass. Additionally fertilizer application had a negative effect on plant species richness. We therefore found fertilizing to cause a competitive advantage for graminoids. A lower availability of nutrients has been shown to increase the proportion of forbs, whereas nitrogen application often results in increasing proportions of graminoids (Pearce and van der Wal 2002). Depending on the state of the plant community and levels of nutrient input, it has been found, by some authors, that fertilization can reduce the species number (Lepš 2004), but it may also have no significant effect on the species number and composition (Pavlů et al. 2012).

It was also observed within the "Park Grass Experiment" that the dominance shifts between different species under different levels of nutrient limitation under long term 
nutrient addition (Tilman 1982) and that productivity has a negative effect upon species richness (Silvertown et al. 2006).

These patterns support similar findings from nutrient addition experiments in grasslands, e.g. the "Rengen-Grassland-Experiment" (Hejcman et al. 2007), the "Jena-Experiment" (Roscher et al. 2004) or Cedar Creek (Tilman et al. 1997) and several others (Gough et al. 2000, Jacquemyn et al. 2003, Klimek et al. 2007). The positive effect of moderate cutting frequency on plant species richness (Hansson and Fogelfors 2000, Fischer and Wipf 2002) might be due to a removal of nutrients from the system due to frequent cutting. This can, especially without additional fertilizer inputs, improve plant species richness (Bakker et al. 2002, Fischer and Wipf 2002).

IV. Feeding damage on leaves of Rumex acetosa is affected by abundance of invertebrate herbivores and management regime (chapter 3 ).

We found no effects of slug abundance on herbivory of $R$. acetosa (L.), despite strong differences in slug abundance between the plots. Therefore we assume that other herbivores, other than slugs, may have been responsible for most of the herbivory on this plant species. Slugs generally play a minor role as a pest in managed grasslands, which is in line with the finding of Frank (1998), who found the same for slugs in winter wheat fields adjacent to wild flower strips. Thus, the higher rate of herbivory damage on $R$. acetosa on nutrient-enriched plots may be due to an increase in plant palatability (Tscharntke and Greiler 1995) and/or a higher abundance and activity of other herbivores not accounted for in this study.

V. Diversity and abundance of herbivorous invertebrates are positively affected by plant species diversity (chapter $3 \& 4$ ).

Higher plant diversity - as found in the forb-rich plots of our experiment (see also Petersen (2012)) - provides a more attractive habitat for slugs, possibly via the higher variety of food sources or a more complex vegetation structure (Dedov et al. 2006). Compared to the lower slug abundance in less plant species rich plots, it gives evidence that decreasing plant biodiversity not only threatens the persistence of generalist insect herbivores (Unsicker et al. 2010), but also of slugs. 
Similar to Biedermann et al. (2005), we found that higher plant diversity also leads to more diverse leafhopper communities, which in our study was owed to less common, but more specialized, species. Plant diversity was higher with herbicide-induced reduction of graminoids, higher cutting frequency and without application of NPK-fertilizer, since it was mainly driven by forbs. But diversity of graminoids, which are the preferred food source for the majority of the leafhopper species collected (Nickel and Remane 2002) did not increase. Therefore a higher proportion of graminoids indirectly reduced leafhopper diversity via its negative effect on plant diversity. The finding that plant diversity negatively affected leafhopper abundance in our study supports this idea and can be explained with the preference for grasses of the most abundant leafhoppers like Arthaldeus pascuellus (Nickel and Remane 2002), whereas plant diversity was mainly driven by forbs. Overall, invertebrates showed an obvious response to changes in plant functional group composition, but we assume the effect to be stronger with a stronger gradient in plant diversity, which could be achieved for future experiments e.g., due to repeated herbicide application in an additional treatment.

VI. Due to feeding preferences, diversity and abundance of herbivorous invertebrates, such as slugs or leafhoppers, are affected by changes in plant functional group composition (chapter 3 \& 4).

We used leafhoppers and slugs as model organisms, since these are a major part of the invertebrate herbivore community, with some species being common pests in agriculture and grasslands and many respond rapidly to changes in plant composition, diversity and management. We found slug abundance, as well as leafhopper diversity, to be significantly affected by plant functional group composition. It is likely that slugs were more abundant in forb-dominated plots because of the higher nutritional quality of forb-rich grasslands and the preferential consumption of forbs when the choice was available (Pallant 1969, 1972, Rathcke 1985, Briner and Frank 1998, Peters et al. 2000).

The intermediate forb to graminoid ratio in the control plots, after cutting, may be more suitable for slugs as it could still provide enough shelter due to the higher regrowth capability of graminoids (Tscharntke and Greiler 1995) whilst also containing high quality and quantity of forbs and annual plants, which are a preferred food 
source, e.g. for A. lusitanicus (Briner and Frank 1998). In addition, the negative effect of cutting on slug abundance was lowest in control plots with their naturally developed graminoid-forb communities. In this, more-natural plant composition, slug abundance showed either a higher tolerance to disturbance or a higher capacity to re-organize after disturbance. Unfortunately our sampling design did not allow detailed investigation of the mechanisms behind this effect.

But this finding supports the idea that slug communities in manipulated ecosystems (e.g. with a disturbed or altered plant community structure) are less tolerant of disturbance (e.g. grazing or mowing) than those in more natural habitats. This is similar to the results of Dedov et al. (2006), who also found slug abundance to be highest in diverse, naturally assembled plant communities. The finding that there are higher numbers of slugs in less manipulated, or more-natural plots, raises the question of whether this is also true for other invertebrates, which could indeed have potential implications for pest management practice. We also found a strong positive direct effect of herbicide-induced increase of graminoids on leafhopper diversity, which can also be explained by their feeding preference.

Most of the leafhopper species we found were shown to have a preference for graminoids (Nickel and Remane 2002). This increase of leafhopper diversity with higher availability of the preferred food source is in accordance with other studies (Nickel and Hildebrandt 2003). Overall, invertebrates showed a strong response to changes in plant functional group composition.

VII. Higher cutting frequency has negative effects on diversity and abundance of herbivorous invertebrates (chapter $3 \& 4$ ).

Three cuts had a consistently negative effect on slug abundance in comparison to the one-cut management. This lower abundance has several potential causes: (i) many slugs are likely to have been killed and removed directly during the process of cutting or due to soil compaction by a heavy machine, which has also been shown to decrease invertebrate populations (Ferguson et al. 1988, Hitchmough 2003, Humbert et al. 2010). (ii) Sward height is positively correlated with soil moisture (Gross et al. 2008) and due to the obvious effect of cutting on vegetation height and standing biomass, it leads to a lack of food and shelter availability as well as a drier soil surface and altered temperature pattern. 
For leafhoppers we observed a negative direct effect of higher cutting frequency on species richness (similar to Morris (1981)), but a positive effect on abundance. The negative direct effect of higher cutting frequency on species diversity of leafhoppers indicates that the majority of leafhopper species found within our study site showed a clear preference for plots cut only once a year, which is in line with findings of other studies (Morris and Lakhani 1979, Nickel and Achtziger 1999). This preference of leafhoppers for plots cut only once a year (Morris and Lakhani 1979, Nickel and Achtziger 1999) is also supported by the negative impact of higher cutting frequency on vegetation height and biomass. This shows that lower disturbance results in larger amounts of food resources and shelter due to higher vegetation and aboveground biomass. Cutting is a disturbance and reduces food resource heterogeneity, and the higher the frequency, the higher the direct impact on leafhoppers, since many leafhoppers may be killed and removed during the process of harvesting (Humbert et al. 2010). This is comparable to the negative effects of cutting on slug abundance within the same experiment (Everwand et al. 2013). Many generalist leafhoppers can benefit from the better performance of some graminoids under more frequent cutting, as the opposing effect of cutting frequency on leafhopper abundance (positive) and leafhopper diversity (negative) in the path diagram shows. Some very abundant species (e.g. Arthaldeus pascuellus, Streptanus sordidus, Deltocephalus pulicaris), which are generalists on graminoids (Nickel and Remane 2002), show a clear preference for areas cut three times per year.

VIII. Fertilizer application has positive effects on abundance of herbivorous invertebrates but negative effects on their diversity (chapter $3 \& 4$ ).

In contrast to our expectations, and findings of other studies (Davidson and Potter 1995, Nickel and Achtziger 1999), we did not observe any significant direct responses of fertilizer application on leafhoppers or slugs in this temperate grassland. But we assume that indirect effects of fertilizer application may still occur, e.g. due to the effect of fertilizer application on food quality (Ebeling et al. 2013), vegetation density, height and soil moisture (Rose et al. 2012). 
IX. Feeding intensities and preferences of different herbivore species may affect plant competition and therefore result in differences in plant species richness and composition (chapter 5)

In chapter 5 we show that two weeks of herbivory reduced plant species richness, mainly due to a strong reduction of graminoids, probably by grasshoppers (Gardiner et al. 2002), which led to the total disappearance of the above-ground parts of all graminoids in some lysimeters. It is a common effect of intense herbivore pressure, that preferred food sources are fully exploited by herbivores (Turley et al. 2013). The observed increase of forb biomass also shows the feeding preference of grasshoppers for graminoids. This selective feeding of the herbivores was also beneficial for the avoided forbs (Bernays and Chapman 1970), because damaged graminoid plants did not grow or survive as well as unconsumed forb plants (Belovsky 2000). We expect the low damage on forbs (and therefore a competitive advantage) to be due to the rather low observed activity of the snails due to dry weather conditions during the herbivore treatment in August 2011. H. pomatia is known to require warm and calcium rich, but moist soils (Pollard 1975).

Our approach covers the effects measured directly after a feeding period of two weeks. Many plants, especially graminoids, show a high regrowth capacity in response to herbivory (Turley et al. 2013), also enhanced due to fertilizing effects of herbivore excrement and plant litter (Belovsky and Slade 2000). Therefore, we assume that this short term effect of herbivory on plant species richness and AGB might not be observed on a longer time scale.

X. Herbivory and fertilizer application accelerate nutrient cycling (chapter 5).

As expected, we found that herbivory increased the amount of plant litter, which has been shown to strongly correlate with the amount of herbivore excrements and herbivory-mediated increases of root exudates (Bardgett et al. 1998). Due to the faster decomposition of herbivore faeces and the fast belowground plant responses (e.g. exudation) (Bardgett et al. 1998) in comparison to plant litter decomposition (McNaughton et al. 1988), therefore we assume herbivore faeces to account for a strong effect of plant litter in lysimeter study. In addition, the reduced plant AGB due to herbivory, may lead to a reduced nitrogen uptake by plants under herbivory, which 
in turn can affect the amount of available forms of nitrogen within the ecosystem (Vitousek et al. 2002). Consequently, this may account for the increased amount of $\mathrm{N}_{2} \mathrm{O}$ emissions with herbivory. Responses of plant communities and nitrogen cycling become more complex with increasing number of interacting drivers, but fertilizer application and invertebrate herbivory were the strongest drivers of plant community composition and nitrogen cycling. With our study we were able to disentangle these complex interactions. When there was no nutrient limitation for the primary producing plants, due to NPK fertilizer input - resulting in higher AGB (Schmitz 1993) - there was no shortage of available food for herbivores and the proportion of graminoids was consequently only slightly reduced compared to the unfertilized treatment.

Our results support that grasshoppers can counterbalance nitrogen shortages in the available food sources by compensatory feeding and the capability of selective feeding among graminoids of contrasting nutritional quality when a choice is available (Raubenheimer and Simpson 2003, Berner et al. 2005).

Also, with higher availability of better quality AGB (Joern and Behmer 1998), due to fertilizer application, less AGB was consumed, resulting in a lower risk for plant species to be completely consumed by herbivores aboveground and explaining the lower proportion of litter due to herbivory on fertilized plots. This might also account for the stronger negative short-term effect of herbivory on plant species richness and AGB of graminoids in unfertilized plots.

The acceleration of net nitrification and net-N-mineralization rates with herbivory in unfertilized plots may be have several causes: (i) the excrement of the herbivores contribute to cycling of nitrogen in natural systems (Belovsky and Slade 2000); (ii) grasshopper herbivory increases rhizodeposition (Paterson 2003) and/or root exudates in particular (Holland et al. 1996); (iii) higher plant litter input also enhances nutrient cycling (Belovsky and Slade 2000). The already high net nitrification and net$\mathrm{N}$-mineralization rates under NPK fertilization underpin the herbivore-induced acceleration of nutrient availability, since these were previously of low availability.

Summarizing, we have shown that both fertilizer application and herbivory positively affect components of the nitrogen cycle, but through different pathways. Fertilizer application accelerated the nitrogen fluxes due to greater availability of ammonium and nitrate, both main components of our $\mathrm{N}$-fertilizer. 
Since grasshoppers are more abundant under normal conditions and cause more feeding damage on intensively managed grasslands (Hudewenz et al. 2012), we worry that emissions of $\mathrm{N}_{2} \mathrm{O}$, a very strong greenhouse gas (Lashof and Ahuja 1990), can further increase and therefore contribute to global warming due to an additive effect of fertilizer application and invertebrate herbivory. Therefore long term studies of the combined effects of invertebrate herbivory in combination with an intensifying management of grasslands on greenhouse gasses, such as $\mathrm{N}_{2} \mathrm{O}$, are needed. 


\section{General conclusions}

Overall, grassland management, plant functional-group composition and invertebrate herbivory directly and indirectly drive plant productivity, diversity, composition and nutrient cycling. The responses of plants and invertebrates, as well as nitrogen cycling, become more complex with increasing number of interacting drivers.

Our results suggest that with elaborate management strategies, providing sufficient resources for the least-productive species, it is possible to maintain high productivity without losing plant species.

We revealed positive effects of forb richness on plant diversity and slug density and indicate that populations of invertebrates will increase in abundance not only where there is greater plant species richness but also in more-natural plant communities.

Leafhopper diversity profited indirectly from nutrient-poor, forb-dominated plots, since these harbour a greater diversity of plants and therefore greater food-resource heterogeneity. On the other hand, leafhopper diversity profited directly from higher graminoid cover in highly productive plots with lower plant diversity, due to a greater availability of graminoids as a preferred food source for many leafhopper species.

We clearly show that management and herbivory had much stronger effects than the manipulation of plant functional-group composition and show fertilizer application to be the strongest driver of the nitrogen flux rates in our system. Herbivory can shortcut the nitrogen cycling by increasing amounts of litter, excrement and root exudates, consequently, positively affecting soil nitrogen contents $\left(\mathrm{NH}_{4}, \mathrm{NO}_{3}\right)$ and flux rates (mineralization, nitrification, $\mathrm{N}_{2} \mathrm{O}$ ). In addition to the strong effect of fertilizer application on the nitrogen cycle, emissions of $\mathrm{N}_{2} \mathrm{O}-$ a very potent greenhouse gas can also increase under intense herbivory in fertilized grasslands, at least on a short timescale. This leads us to concerns, that these $\mathrm{N}_{2} \mathrm{O}$ emissions can further increase and therefore contribute to global warming due to an additive effect of fertilizer application and invertebrate herbivory. 


\section{References}

Bakker, J., J. Elzinga, and Y. Vries. 2002. Effects of long-term cutting in a grassland system: perspectives for restoration of plant communities on nutrient-poor soils. Applied Vegetation Science 5:107-120.

Bardgett, R. D., D. A. Wardle, and G. W. Yeates. 1998. Linking above-ground and below-ground interactions: how plant responses to foliar herbivory influence soil organisms. Soil Biology and Biochemistry 30:1867-1878.

Belovsky, G. 2000. Do grasshoppers diminish grassland productivity? A new perspective for control based on conservation. Pages 7-29 Grasshoppers and Grassland Health. Springer.

Belovsky, G. E., and J. B. Slade. 2000. Insect herbivory accelerates nutrient cycling and increases plant production. PNAS 97:14412-14417.

Bernays, E. A., and R. F. Chapman. 1970. Experiments to Determine the Basis of Food Selection by Chorthippus parallelus (Zetterstedt) (Orthoptera: Acrididae) in the Field. Journal of Animal Ecology 39:761-776.

Berner, D., W. U. Blanckenhorn, and C. Körner. 2005. Grasshoppers cope with low host plant quality by compensatory feeding and food selection: $\mathrm{N}$ limitation challenged. Oikos 111:525-533.

Biedermann, R., R. Achtziger, H. Nickel, and A. Stewart. 2005. Conservation of Grassland Leafhoppers: A Brief Review. J. Insect Conservation 9:229-243.

Briner, T., and T. Frank. 1998. The palatability of 78 wildflower strip plants to the slug Arion lusitanicus. Annals of Applied Biology 133:123-133.

Davidson, A. W., and D. A. Potter. 1995. Response of plant-feeding, predatory, and soil-inhabiting invertebrates to Acremonium endophyte and nitrogen fertilization in tall fescue turf. Journal of Economic Entomology 88:367-379.

Dedov, I., I. L. Stoyanov, L. Penev, J. A. Harvey, W. H. Van der Putten, and T. M. Bezemer. 2006. Long-term effects of sowing high or low diverse seed mixtures on plant and gastropod diversity. Acta Oecologica 30:173-181.

Ebeling, A., E. Allan, J. Heimann, G. Köhler, M. Scherer-Lorenzen, A. Vogel, A. Weigelt, and W. W. Weisser. 2013. The impact of plant diversity and fertilization on fitness of a generalist grasshopper. B.\& Appl. Ecol. 14:246-254. 
Everwand, G., C. Scherber, and T. Tscharntke. 2013. Slug responses to grassland cutting and fertilizer application under plant functional group removal. Acta Oecologica 48:62-68.

Ferguson, C. M., B. I. P. Barratt, and P. A. Jones. 1988. Control of the grey field slug (Deroceras-reticulatum (Muller)) by stock management prior to direct-drilled pasture establishment. Journal of Agricultural Science 111:443-449.

Fischer, M., and S. Wipf. 2002. Effect of low-intensity grazing on the species-rich vegetation of traditionally mown subalpine meadows. Biol. Cons. 104:1-11.

Frank, T. 1998. Slug damage and number of slugs (Gastropoda:Pulmonata) in winter wheat in fields with sown wildflower strips. J. Molluscan Studies 64:319-328.

Gardiner, T., M. Pye, R. Field, and J. Hill. 2002. The influence of sward height and vegetation composition in determining the habitat preferences of three Chorthippus species (Orthoptera: Acrididae) in Chelmsford, Essex, UK. Journal of Orthoptera Research 11:207-213.

Gough, L., C. W. Osenberg, K. L. Gross, and S. L. Collins. 2000. Fertilization effects on species density and primary productivity in herbaceous plant communities. Oikos 89:428-439.

Grime, J. P. 1998. Benefits of plant diversity to ecosystems: immediate, filter and founder effects. Journal of Ecology 86:902-910.

Gross, N., T. M. Robson, S. Lavorel, C. Albert, Y. Le Bagousse-Pinguet, and R. Guillemin. 2008. Plant response traits mediate the effects of subalpine grasslands on soil moisture. New Phytologist 180:652-662.

Hansson, M., and H. Fogelfors. 2000. Management of a semi-natural grassland; results from a 15-year-old experiment in southern Sweden. Journal of Vegetation Science 11:31-38.

Hejcman, M., M. Klaudisová, J. Schellberg, and D. Honsová. 2007. The Rengen Grassland Experiment: Plant species composition after 64 years of fertilizer application. Agriculture, Ecosystems \&amp; Environment 122:259-266.

Hitchmough, J. D. 2003. Effects of sward height, gap size, and slug grazing on emergence and establishment of Trollius europaeus (Globeflower). Restoration Ecology 11:20-28.

Holland, J. N., W. Cheng, and D. A. Crossley, Jr. 1996. Herbivore-induced changes in plant carbon allocation: assessment of below-ground $C$ fluxes using carbon14. Oecologia 107:87-94. 
Hudewenz, A., A.-M. Klein, C. Scherber, L. Stanke, T. Tscharntke, A. Vogel, A. Weigelt, W. W. Weisser, and A. Ebeling. 2012. Herbivore and pollinator responses to grassland management intensity along experimental changes in plant species richness. Biological Conservation 150:42-52.

Humbert, J. Y., J. Ghazoul, G. J. Sauter, and T. Walter. 2010. Impact of different meadow mowing techniques on field invertebrates. Journal of Applied Entomology 134:592-599.

Jacquemyn, H., R. Brys, and M. Hermy. 2003. Short-term effects of different management regimes on the response of calcareous grassland vegetation to increased nitrogen. Biological Conservation 111:137-147.

Jiang, L., S. Q. Wan, and L. H. Li. 2009. Species diversity and productivity: why do results of diversity-manipulation experiments differ from natural patterns? Journal of Ecology 97:603-608.

Joern, A., and S. T. Behmer. 1998. Impact of diet quality on demographic attributes in adult grasshoppers and the nitrogen limitation hypothesis. Ecological Entomology 23:174-184.

Klimek, S., A. Richter gen. Kemmermann, M. Hofmann, and J. Isselstein. 2007. Plant species richness and composition in managed grasslands: The relative importance of field management and environmental factors. Biological Conservation 134:559-570.

Laird, R., J. Pither, and L. Aarssen. 2003. Species evenness, not richness, has a consistent relationship with productivity in old-field vegetation. Community Ecology 4:21-28.

Lashof, D. A., and D. R. Ahuja. 1990. Relative contributions of greenhouse gas emissions to global warming.

Lepš, J. 2004. What do the biodiversity experiments tell us about consequences of plant species loss in the real world? Basic and Applied Ecology 5:529-534.

McNaughton, S. J., R. W. Ruess, and S. W. Seagle. 1988. Large mammals and process dynamics in african ecosystems. Bioscience 38:794-800.

Mokany, K., J. Ash, and S. Roxburgh. 2008. Functional identity is more important than diversity in influencing ecosystem processes in a temperate native grassland. Journal of Ecology 96:884-893. 
Morris, M. G. 1981. Responses of Grassland Invertebrates to Management by Cutting. IV. Positive Responses of Auchenorhyncha. Journal of Applied Ecology 18:763-771.

Morris, M. G., and K. H. Lakhani. 1979. Responses of grassland invertebrates to managementby cutting.1. Pecies-Diversity of Hemiptera. Journal of Applied Ecology 16:77-98.

Nickel, H., and R. Achtziger. 1999. Wiesen bewohnende Zikaden (Auchenorrhynca) im Gradienten von Nutzungsintensität und Feuchte. Beiträge zur Zikadenkunde 3:65-80.

Nickel, H., and J. Hildebrandt. 2003. Auchenorrhyncha communities as indicators of disturbance in grasslands ( Insecta, Hemiptera ) - a case study from the Elbe flood plains ( northern Germany ). Environment 98:183-199.

Nickel, H., and R. Remane. 2002. Artenliste der Zikaden Deutschlands, mit Angabe von Nährpflanzen, Nahrungsbreite, Lebenszyklus , Areal und Gefährdung (Hemiptera, Fulgoromorpha et Cicadomorpha). Beiträge zur Zikadenkunde 5:27-64.

Pallant, D. 1969. Food of the grey field slug (Agriolimax reticulatus (MÜLLER)) in woodlands. Journal of Animal Ecology 38:391-397.

Pallant, D. 1972. Food of the grey field slug (Agriolimax reticulatus (MÜLLER)) on grassland. Journal of Animal Ecology 41:761-769.

Paterson, E. 2003. Importance of rhizodeposition in the coupling of plant and microbial productivity. European Journal of Soil Science 54:741-750.

Pavlů, V., J. Gaisler, L. Pavlů, M. Hejcman, and V. Ludvíková. 2012. Effect of fertiliser application and abandonment on plant species composition of Festuca rubra grassland. Acta Oecologica 45:42-49.

Pearce, I. S., and R. van der Wal. 2002. Effects of nitrogen deposition on growth and survival of montane Racomitrium lanuginosum heath. Biol. Cons.104:83-89.

Peters, H. A., B. Baur, F. Bazzaz, and C. Korner. 2000. Consumption rates and food preferences of slugs in a calcareous grassland under current and future $\mathrm{CO} 2$ conditions. Oecologia 125:72-81.

Petersen, U., N. Wrage, L. Köhler, C. Leuschner, and J. Isselstein. 2012. Manipulating the species composition of permanent grasslands- $A$ new approach to biodiversity experiments. Basic and Applied Ecology 13:1-9.

Pollard, E. 1975. Aspects of the ecology of Helix pomatia (L.). J. Ani. Ecol.:305-329. 
Rathcke, B. 1985. Slugs as generalist herbivores - Tests of 3 Hypotheses on plant choices. Ecology 66:828-836.

Raubenheimer, D., and S. J. Simpson. 2003. Nutrient balancing in grasshoppers: behavioural and physiological correlates of dietary breadth. Journal of Experimental Biology 206:1669-1681.

Roscher, C., J. Schumacher, J. Baade, W. Wilcke, G. Gleixner, W. W. Weisser, B. Schmid, and E. D. Schulze. 2004. The role of biodiversity for element cycling and trophic interactions: an experimental approach in a grassland community. Basic and Applied Ecology 5:107-121.

Rose, L., H. Coners, and C. Leuschner. 2012. Effects of fertilization and cutting frequency on the water balance of a temperate grassland. Ecohydrology 5:64-72.

Schmitz, O. J. 1993. Trophic exploitation in grassland food-chains - simple-models and a field experiment. Oecologia 93:327-335.

Silvertown, J., P. Poulton, E. Johnston, G. Edwards, M. Heard, and P. M. Biss. 2006. The Park Grass Experiment 1856-2006: Its contribution to ecology. Journal of Ecology 94:801-814.

Tilman, D. 1982. Resource Competition and Community Structure. Princeton University Press.

Tilman, D., J. Knops, D. Wedin, P. Reich, M. Ritchie, and E. Siemann. 1997. The influence of functional diversity and composition on ecosystem processes. Science 277:1300-1302.

Tscharntke, T., and H. J. Greiler. 1995. Insect communities, grasses, and grasslands. Annual Review of Entomology 40:535-558.

Turley, N. E., W. C. Odell, H. Schaefer, G. Everwand, M. J. Crawley, and M. T. J. Johnson. 2013. Contemporary evolution of plant growth rate following experimental removal of herbivores. Am Nat 181 Suppl 1:S21-S34.

Unsicker, S. B., A. Franzke, J. Specht, G. Koehler, J. Linz, C. Renker, C. Stein, and W. W. Weisser. 2010. Plant species richness in montane grasslands affects the fitness of a generalist grasshopper species. Ecology 91:1083-1091.

Vitousek, P. M., S. Hättenschwiler, L. Olander, and S. Allison. 2002. Nitrogen and nature. AMBIO: A Journal of the Human Environment 31:97-101. 


\section{Summary}

Within the last few centuries the rapid growth of the human population, along with increasing economic development, has caused increasing demands for agricultural products such as food and fuel. This has led to an extension of agricultural areas, and the intensification of existing agricultural areas to maximize crop production, therewith increasing pressures on ecosystems around the world. Agricultural intensification, with high inputs of fertilizer and increasing cutting regimes, leads to a decline in plant species richness, lower stability to climatic extremes, such as drought or high rainfalls, resulting in a threat to biodiversity on higher trophic levels and important ecosystem processes.

In this thesis we analyse the direct and indirect effects of different levels of agricultural management intensity and functional group composition within the Grassland Management Experiment (GrassMan) near the towns of Neuhaus (Solling) and Silberborn in the Solling Mountains, which are situated in Northern Germany. We created twelve treatment combinations by independently combining two cutting frequencies, two levels of fertilizer application and three different sward types via manipulation of functional groups. We further investigate the effects of plant diversity, cutting, and fertilizer application on grassland productivity, herbivorous invertebrates and nutrient cycling, as well as the impact of herbivory on the overall system. The main focus of this thesis lies in exploring the impact of these agricultural management practices and declines in species diversity as well as shifts in functional group composition on plant-insect interactions, such as invertebrate herbivore pressure on plant-performance and its feedbacks on nutrient cycling.

In chapter two, we show that overall species-richness had no significant effect on the above-ground biomass production across the five study years. In addition, swardtype diversity had significant effects on the above-ground biomass production only in the experimental year with extremely dry weather conditions for the summer months before the peak standing crop, when control plots had higher yields than the forband graminoid-reduced treatments. While management intensification caused an increase in above-ground biomass production, changes in species numbers were not dramatic over the whole investigation period, with increasing cutting frequency promoting the establishment of more species. 
In our study, existing species composition of the semi-natural grassland was highly resilient. Four years after the manipulation of functional groups, we recorded a composition of grasses, herbs and legumes showing almost no differences between the sward types, with larger shares of grasses being typical of fertilized plots and larger shares of herbs typical of frequent cutting. Shares of legumes were suppressed by fertilization, but were found in almost all plots by the end of the experimental period.

In chapter three we show the strong effects of grassland management, plant diversity and composition on slug abundance, which was highest in plots with a low cutting frequency and high food resource availability (increased forb cover and taller vegetation). Higher cutting frequency decreased slug abundance, but with lower impact in control plots, with their naturally developed graminoid-forb communities, giving evidence that more-natural plant species compositions can reduce the impact of disturbances (e.g. through cutting or grazing) on invertebrates.

In chapter four, our results show that plant diversity, functional group composition and management regime affect leafhopper species richness and abundance. Higher cutting frequencies directly led to decreased leafhopper diversity, whereas fertilizer application only had a small indirect negative effect via its opposing trends on aboveground plant biomass, diversity and composition. Leafhopper diversity profited from graminoid-rich swards as well as from higher plant diversity, which itself was mediated by functional group manipulation and agricultural management.

In chapter five we show that additional herbivore pressure interacts with our initial experimental treatments (cutting frequency, NPK-fertilizer application and functional group manipulation) and affects several vegetation parameters as well as the nitrogen cycle. We found that management and herbivores affect productivity and nitrogen fluxes and show stronger effects than the manipulation of plant functional group composition.

In general, we show that grassland management, plant functional group composition and invertebrate herbivory directly and indirectly drive plant productivity, diversity, composition and nutrient cycling. The responses of plant and invertebrate communities, as well as nitrogen cycling, become more complex with increasing number of interacting drivers. 
Our results suggest that with proper management strategies, providing sufficient resources for the least-productive species, it is possible to maintain high productivity while maintaining high diversity. We revealed positive effects of forb richness on plant diversity and slug density, indicating that populations of invertebrates will increase in abundance not only where there is greater plant species richness but also in more-natural plant communities. Leafhopper diversity profited indirectly in nutrient-poor, forb-dominated plots, since these harbour a greater diversity of plants and therefore greater food-resource heterogeneity. On the other hand, leafhopper diversity profited directly from higher graminoid cover in highly productive plots with lower plant diversity, due to a greater availability of graminoids as a preferred food source for many leafhopper species. We show that management and herbivory had much stronger effects than the manipulation of plant functional group composition. Fertilizer application was the strongest driver of the nitrogen flux rates in our system. Herbivory, however, can short-cut the nitrogen cycling by increasing amounts of litter, excrement and root exudates, consequently positively affecting soil nitrogen contents $\left(\mathrm{NH}_{4}, \mathrm{NO}_{3}\right)$ and flux rates (mineralization, nitrification, $\mathrm{N}_{2} \mathrm{O}$ ). In addition to the strong effect of fertilizer application on the nitrogen cycle, emissions of $\mathrm{N}_{2} \mathrm{O}$, a very important greenhouse gas, can also increase under intense herbivory in fertilized grasslands, at least on a short timescale. This leads us to concerns that these $\mathrm{N}_{2} \mathrm{O}$ emissions can further increase, and therefore contribute to global warming, due to an additive effect of fertilizer application and invertebrate herbivory. 


\section{Zusammenfassung}

Die Nachfrage nach Agrarprodukten ist im Laufe der letzten Jahrhunderte durch die wachsende Weltbevölkerung in Kombination mit einem zunehmenden Pro-KopfBedarf stark gestiegen. Weltweit steigt der Druck auf Ökosysteme durch Ausweitung und Nutzungsintensivierung landwirtschaftlich genutzter Flächen Auf intensiv genutzten Grasflächen führt der hohe Einsatz von Düngemitteln und häufiger Mahd zu einem Verlust der Pflanzendiversität. Dies bedingt eine geringere Stabilität des Ökosystems gegenüber Wetterextremen wie Trockenheit oder massiven Regenfällen, was wiederum eine Gefahr für die biologische Vielfalt auf höheren trophischen Ebenen (u.a. invertebrate Herbivore) und wichtige Ökosystem-Prozesse darstellt.

In dieser Arbeit werden die direkten und indirekten Auswirkungen verschiedenen Bewirtschaftungsintensitäten in Kombination mit manipulierter Vegetationszusammensetzung innerhalb eines Grasland Management Experimentes (GrassMan) in der Nähe der Norddeutschen Städte Neuhaus und Silberborn im Solling untersucht. Zwei Mahdfrequenzen (1x; 3x), zwei Düngungsintensitäten (keine Düngung; NPK Düngung) und drei unterschiedlich manipulierte Grasnarben (Gräser reduziert, Kräuter reduziert \& nicht manipuliert) ergaben zwölf verschiedene Behandlungskombinationen, welche jeweils sechs Mal repliziert wurden. Auf den daraus resultierenden 72 Parzellen (jeweils $15 \mathrm{~m}$ mal $15 \mathrm{~m}$ ) wurden die Auswirkungen von Pflanzendiversität, Mahdhäufigkeit und Düngung auf die Produktivität, den Stickstoffhaushalt, trophische Interaktionen und deren Wechselwirkungen im Grasland untersucht. Der Schwerpunkt dieser Arbeit liegt darauf, die Auswirkungen landwirtschaftlicher Intensivierung, reduzierter Artenvielfalt sowie Verschiebungen in der Zusammensetzung der Grasnarbe auf Pflanze-InsektInteraktionen zu untersuchen.

Im zweiten Kapitel wird gezeigt, dass über den Versuchszeitraum die Pflanzenbiodiversität keinen signifikanten Einfluss auf die oberirdische BiomasseProduktion hatte. Die Grasnarbenzusammensetzung hatte lediglich große Auswirkungen auf die oberirdische Biomasse-Produktion, wenn in einem Jahr noch vor dem Erreichen der maximalen oberirdischen Biomasse extrem trockene Witterung auftrat. In solchen Jahren produzierten Parzellen mit natürlicher 
Artenzusammensetzung größere Erträge als manipulierte Flächen. Während eine höhere Bewirtschaftungsintensität zu einem Anstieg der oberirdischen Biomasse führte, war keine signifikante Veränderung der Pflanzenartenzahl über den Untersuchungszeitraum zu verzeichnen. Höhere Mahdfrequenz führte dagegen zu einer erhöhten Pflanzenartenanzahl im Vergleich zu der am Beginn der Experimente. Die bestehende Artenzusammensetzung in dem naturnahen Grünland (ohne Manipulation), war sehr robust und vier Jahre nach dem Manipulieren zeigten die verschiedenen Grasnarben fast keine Unterschiede mehr in der Zusammensetzung von Gräsern, Kräutern und Leguminosen. Ein größerer Anteil von Gräsern war typisch für gedüngte Parzellen und größere Anteile von Kräutern waren eine typische Folge von häufigerem Mähen. Durch Düngung wurde der Anteil von Leguminosen reduziert, allerdings wurden auch zum Ende des Experimentes noch in fast allen Parzellen Leguminosen gefunden.

In Kapitel drei werden die starken Auswirkungen der landwirtschaftlichen Intensivierung sowie Pflanzendiversität und Artenzusammensetzung auf die Abundanz von Nacktschnecken gezeigt. Die Schneckenabundanz war höher auf den Parzellen mit einer niedrigen Mahdhäufigkeit und hoher Verfügbarkeit von bevorzugten Nahrungsressourcen. Die Abnahme der Schneckenabundanz durch eine höhere Mahdfrequenz war in den Parzellen mit natürlicher Vegetation am geringsten. Dies könnte ein Beleg dafür sein, dass sich Störungen auf Invertebrate (z. B. durch Mahd oder Beweidung) in natürlicherer Vegetation weniger stark auswirken. In Kapitel vier werden die Einflüsse von Pflanzenbiodiversität, Zusammensetzung der funktionellen Gruppen und der Nutzungsintensität auf Zikaden untersucht. Eine häufigere Mahd bedingte eine niedrigere Artenzahl an Zikaden. Düngung hatte nur indirekt - aufgrund von gegenläufigen Effekten auf die oberirdische Biomasse, Diversität und Zusammensetzung der Vegetation - einen marginal negativen Effekt auf die Zikadendiversität. Zikadendiversität profitierte von einer von Gras dominierten Vegetation, sowie von einer höheren Pflanzendiversität, welche ihrerseits durch Manipulation der Grasnarbe und das Grasland-Management beeinflusst wurde. In Kapitel fünf wird gezeigt, dass erhöhter Herbivoriedruck mit den anderen experimentellen Behandlungen (Mahdhäufigkeit, Düngung und Manipulation der funktionellen Gruppen) interagiert und mehrere Vegetationsparameter und einige Komponenten des Stickstoffkreislaufs beeinflusst. Es stellte sich heraus, dass sowohl 
Grasland-Management als auch invertebrate Herbivoren die Produktivität und den Stickstoffhaushalt beeinflussen und einen stärkeren Einfluss haben als die Vegetationszusammensetzung.

Insgesamt wird mit dieser Versuchsreihe deutlich gemacht, dass GraslandManagement, Manipulation der Vegetationszusammensetzung und experimentell erhöhte Herbivorie einen direkten und indirekten Einfluss auf Produktivität, Zusammensetzung und Biodiversität der Vegetation sowie den Stickstoffhaushalt haben. Die Interaktionen zwischen Vegetation, Herbivoren und dem Stickstoffkreislauf werden mit zunehmender Anzahl wechselwirkender Faktoren zunehmend komplexer. Die Ergebnisse deuten darauf hin, dass eine Erhöhung der Produktivität ohne Pflanzenartenverlust durch eine ausgereifte ManagementStrategie ermöglicht wird.

\section{Schlussfolgerung}

Zusammenfassend wird in dieser Arbeit gezeigt, dass die Manipulation zu Gunsten krautiger Pflanzen einen positiven Effekt auf die gesamte Pflanzendiversität sowie auf die Abundanz von Schnecken hat. Außerdem kann nicht nur eine höhere Pflanzendiversität, sondern auch natürlichere Pflanzengesellschaften zu höheren Populationen von Invertebraten führen. Zikadendiversität profitiert von verschiedenen Faktoren - zum Einen indirekt von einer höheren Pflanzendiversität auf nährstoffarmen, krautdominierten Flächen, da diese eine größere Vielfalt and Nahrungsressourcen für spezialisierte Arten bieten. Ebenso war die Zikadendiversität positiv von einem höheren Grasanteil an der Vegetation auf gedüngten Flächen mit niedrigerer Pflanzenbiodiversität beeinflusst, da Gräser die bevorzugte Nahrungsquelle für viele der gefundenen Zikadenarten mit einem eher generalistischen Nahrungsspektrum waren. Grasland-Management und Herbivorie haben insgesamt einen wesentlich stärkeren Einfluss auf den Stickstoffhaushalt als die Manipulation der Vegetationszusammensetzung, wobei Düngung der stärkste Faktor ist. Herbivore können den Stickstoffkreislauf durch einen höheren Eintrag von totem Pflanzenmaterial, Wurzelexsudaten und durch Ausscheidungen beschleunigen. Dieser Eintrag von Nährstoffen hat folglich positiven Einfluss auf den Bodenstickstoffgehalt $\left(\mathrm{NH}_{4}, \mathrm{NO}_{3}\right)$ und auf Stickstofflussraten (Mineralisierung, Nitrifikation, $\mathrm{N}_{2} \mathrm{O}$ ). 
Neben dem starken Einfluss von Düngung auf den Stickstoffkreislauf können die Emissionen von $\mathrm{N}_{2} \mathrm{O}$, einem wichtigen Treibhausgas, auch innerhalb eines kurzen Zeitraums durch starke Herbivorie zunehmen. Somit könnte ein steigender Nährstoffeintrag durch Düngung in Kombination mit erhöhter Herbivorie zu einer Erhöhung von $\mathrm{N}_{2} \mathrm{O}$-Emissionen im Grasland führen. Dieser additive Effekt könnte dann zur globalen Erwärmung beitragen. 


\section{Acknowledgements}

I owe deep thanks to Prof. Dr. Teja Tscharntke for providing the possibility to conduct this thesis and for the interesting scientific discussions, his general continuous support, critical advice, encouragement and new ideas. Funding was kindly granted by the Ministry of Science and Culture of Lower Saxony and the 'Niedersächsisches Vorab' within the framework of the Cluster of Excellence 'Functional Biodiversity Research' at the University of Göttingen.

Furthermore I thank Prof, Dr. Johannes Isselstein, Pd Dr. Dirk Gansert, PD Dr. Klaus Hövemeyer, Prof. Dr. Ulrich Brose and Prof. Dr. Stefan Vidal for being part of my thesis committee.

For his great support and for providing priceless theoretical and practical expertise, I want to thank my personal friend and supervisor Christoph "The Scherbinator" Scherber. Without his supportive lections and exceptional encouragement to finding new ways and approaches to analyze data in R and AMOS to get to the core of the results this research would not have been possible. I admire his inspiring enthusiasm and his love for details.

The Agroecology group provided a great community and environment for my $\mathrm{PhD}$ time. I want to express a special "thank you" especially to the Glasgow Conference travellers Urs Kormann, Iris Motzke, Verena Rösch and Claudia Normann not only for making this conference remarkable but for their great support and friendship throughout my PhD. To my office mates Björn Christian Klatt, Max von Fragstein, William Marthy and Christine Venjakob: "thank you", for those great discussions and humorous hours we had in the office with coffee, tea and chocolate.

For their help in the field and a good time in the GrassMan Experiment I thank my fellow project companions: Tatiana From, Andreas Keuter, Kathleen Lemanski, Hella Schlinkert, Till Benner, Annabelle Rohlfing, Carola Fessel and Lars Köhler who was the coordinator of the GrassMan Project.

To Jutta Gilles, Susanne Jahn, Brigitte Jünemann, Suse Schiele and Ulrike Kierbaum I want to express my thankfulness for their technical assistance and help whilst 
leading me through the jungle of the Agroecology Group and the university bureaucracy.

Thanks also to the DNPW IT-team Thomas Österreich, Jan Tönjes and Siggi Opolka for responding to my needs and queries. For proofreading and expert comments to some chapters of this thesis, I am very grateful to Pete Manning, Laura Sutcliffe, David Perovic and Lisa Denmead.

From the bottom of my heart I thank my beloved wife Lena, my parents, my brothers, my sister and my friends. I am very grateful for their continuous encouragement and persistent support of my work and want to thank them for their understanding of my continuous absence, especially during the last months. 


\section{Publications}

N. Turley, W. Odell, H. Schaefer, G. Everwand, M. Crawley and M. Johnson (2013). Rapid evolution of plant growth rate following experimental removal of herbivores. American Naturalist 181: 21-34; (http://dx.doi.org/10.5061/dryad.cp00b).

E. Fry, P. Manning, D. Allen, A. Hurst, G. Everwand, M. Rimmler and S. Power (2013). Plant functional group identity modifies precipitation change impacts on grassland ecosystem function. PLoS ONE 8(2): e57027. doi:10.1371/journal.pone.0057027.

G. Everwand, C. Scherber and T. Tscharntke (2013). Slug response to grassland management is mediated by experimental removal of plant functional groups. Acta Oecologica, 10.1016/j.actao.2013.01.015.

T. Didiano, N. Turley, G. Everwand, H. Schaefer, M. Crawley, M. Johnson (submitted July 2013, Journal of Ecology). Long-term herbivore exclusion drives plant defense evolution in multiple species.

G. Everwand, E. Fry, T. Eggers and P. Manning (submitted August 2013, Functional Ecology). Seasonal variation in the relationship between plant traits and grassland carbon and water fluxes.

G. Everwand, V. Rösch, T. Tscharntke and C. Scherber (submitted September 2013, Peerage of Science). Disentangling the direct and indirect effects of expermental grassland management and plant functional-group manipulation on plant and insect biodiversity.

G. Everwand, A. Keuter, T. From, T. Tscharntke, J. Isselstein and C. Scherber (in prep.). The Nutrient Acceleration Hypothesis Revisited: Effects of Grassland Management, Herbivory and Plant Composition on Nutrient Cycling.

T. From, G. Everwand, N. Wrage, C. Scherber, C. Leuschner, T. Tscharntke and J. Isselstein (in prep.). Bringing biodiversity experiments to the real world: Diversity versus management in a semi-natural grass land. 


\section{Conference contributions}

$08 / 30 / 2008-09 / 03 / 2010$

40th Meeting of the Ecological Society of Germany, Austria and Switzerland (Gießen, Germany) G. Everwand, C. Scherber and T. Tscharntke

Trophic Interactions in a Grassland Management Experiment.

06/20/2011 - 06/22/2011 Functions and Services of Biodiversity Conference (Göttingen, Germany)

G. Everwand, C. Scherber and T. Tscharntke

Molluscs respond to biodiversity and grassland management in a functional group removal experiment.

96th Annual Meeting of the Ecological Society of America (ESA) (Austin, Texas, USA)

N. Turley, W. Odell, H. Schaefer, G. Everwand, M. Crawley and M. Johnson

Rapid evolution in plants following experimental removal of herbivores.

Talk. (No. COS 94-7)

08/28/2012-09/01/2012

European Conference on Conservation Biology (ECCB)

(Glasgow, UK)

G. Everwand, C. Scherber and T. Tscharntke

Leafhopper diversity can profit from moderate mowing and fertilization in a grassland biodiversity experiment. 


\section{Declaration of originality and certificate of ownership}

Thesis declaration

The chapters 2 to 5 are a series of manuscripts that have or will be submitted to peer-reviewed journals. I am the main author of all manuscripts (except chapter 2 - co-author) presented in this thesis. I have personally collected and analysed the data for all manuscripts, developed the main ideas presented in the manuscripts, written all manuscripts, made the tables, figures, and appendices, and contributed significantly to the maintenance of the experimental design. My supervisors laid out the study design and helped with analysis, discussions and writing. The other co-authors contributed to the discussions of results.

\section{Declaration plagiarism}

I, Georg Everwand, hereby confirm that I have written this doctoral thesis independently that I have not used other sources or facilities others than the ones mentioned in the chapters, that I have not used unauthorised assistance and that I have not submitted this thesis previously in any form for another degree at any university or institution.

Göttingen, December 2013 